Portland State University

PDXScholar

$1-1-1982$

\title{
Laser induced hydroxyl radical fluoresence at atmospheric pressure
}

Cornelius Yuk-kwan Chan

Portland State University

Follow this and additional works at: https://pdxscholar.library.pdx.edu/open_access_etds Let us know how access to this document benefits you.

\section{Recommended Citation}

Chan, Cornelius Yuk-kwan, "Laser induced hydroxyl radical fluoresence at atmospheric pressure" (1982). Dissertations and Theses. Paper 69.

https://doi.org/10.15760/etd.69

This Dissertation is brought to you for free and open access. It has been accepted for inclusion in Dissertations and Theses by an authorized administrator of PDXScholar. Please contact us if we can make this document more accessible: pdxscholar@pdx.edu. 
LASER INDUCED HYDROXYL RADICAL FLUORESCENCE

AT ATMOSPHERIC PRESSURE

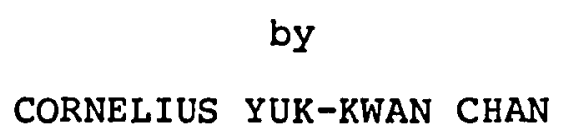

A dissertation submitted in partial fulfillment of the requirements for the degree of

DOCTOR OF PHILOSOPHY
ENVIRONMENTAL SCIENCES AND RESOURCES-CHEMISTRY

Portland State University

1982 
AN ABSTRACT OF THE DISSERTATION OF Cornelius Yuk-kwan Chan for the Doctor of Philosophy in Environmental Sciences and Resources presented November 9, 1982.

Title: Laser Induced Hydroxyl Radical Fluorescence at Atmospheric Pressure

APPROVED BY MEMBERS OF THE DISSERTATION COMMITTEE:

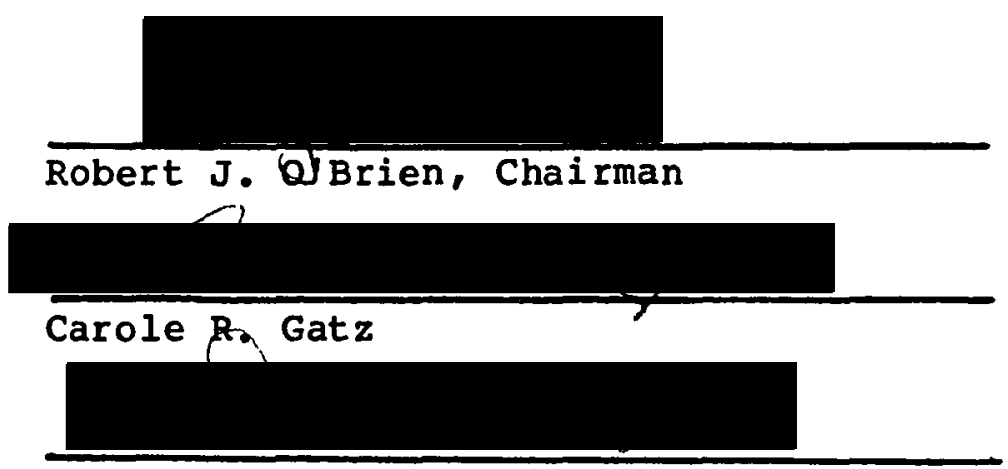

David K. Roe

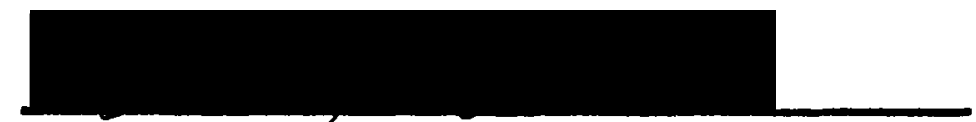

Stanley s. Hili lman

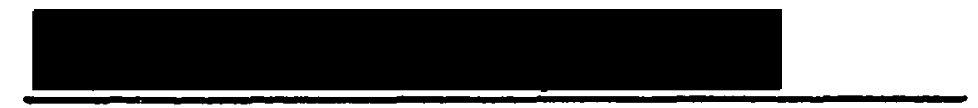

Raymond W. Sommerfeldt

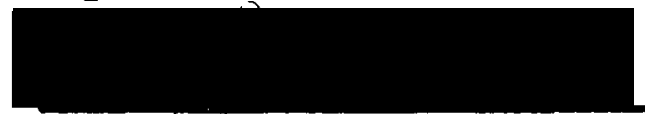

William W. Paudler

Laser Induced Fluorescence (LIF) is one of the chief methods for detecting ambient hydroxyl radicals. To measure the absolute concentration of this important atmospheric chemical species, accurately known quenching 
rate constants due to the dominant gases in the air are of paramount importance. Unfortunately, these rate constants have only been measured under conditions remote from those of ambient air. This dissertation reports the measurement of the rate constants of water, argon, nitrogen and oxygen under ambient conditions.

As the LIF is carried out at atmospheric pressure, the $\mathrm{OH}$ fluorescence life-time becomes extremely short (about $1 \mathrm{~ns}$ ). Time correlated Photon Counting was used to study this short fluorescence phenomenon. The unique feature of this study was that the deactivation processes of the excited $\mathrm{OH}$ could be described completely by a kinetic model. Detailed theoretical treatments of the LIF processes are presented. The data obtained are consistent with the accepted model, thereby demonstrating the usefulness and validity of the experimental approach.

The rate constants (cc molecule-1 $\mathrm{sec}^{-1}$ ) for quenching by water and argon were accurately measured. The vibrational relaxation rate constant by water $\left(3.4 \pm 0.6 \times 10^{-10}\right.$ ) is the first value ever reported, while the electronic quenching rate constants for water $\left(k_{Q O}=7.9 \pm 0.47 \times 10^{-10}, k_{Q 1}=1.48 \pm 0.74 \times 10^{-10}\right)$ are the first measured at atmospheric pressure. The electronic quenching rate constants of the ${ }^{2} \sum\left(v^{\prime}=1\right)$ state $\left(k_{Q_{1}}\right)$ and the ${ }^{2} \Sigma\left(v^{\prime}=0\right)$ state $\left(k_{Q O}\right)$ by argon are $k_{Q O}=0.48 \pm 0.14 \times 10^{-12}$ and $k_{Q 1}=0.24 \pm 0.06 \times 10^{-11}$. The vibrational relaxation rate 
constant by argon is $k_{10}=0.34 \pm 0.06 \times 10^{-11}$. The rate constants for oxygen $\left(k_{Q 1}+k_{10}=1.83 \pm 0.43 \times 10^{-9}\right.$ and $k_{Q 0}=2.6 \pm 0.6 \times 10^{-10}$ ) are significantly higher than the limited measurements available at low pressure. The rate constants for nitrogen are $k_{Q 0}=0.71 \pm 0.08 \times 10^{-11}$ and $k_{10}=8.07 \pm 0.65 \times 10^{-11}$. All these values are the first obtained at atmospheric pressure and although shown to be consistent with the widely scattered low pressure values, they allow more reliable analysis of ambient $\mathrm{OH}$ measurements, and result in a 31.28 increase in the published values. 
TO THE OFFICE OF GRADUATE STUDIES AND RESEARCH:

The members of the committee approve the dissertation of Cornelius Yuk-kwan Chan presented November 9, 1982.

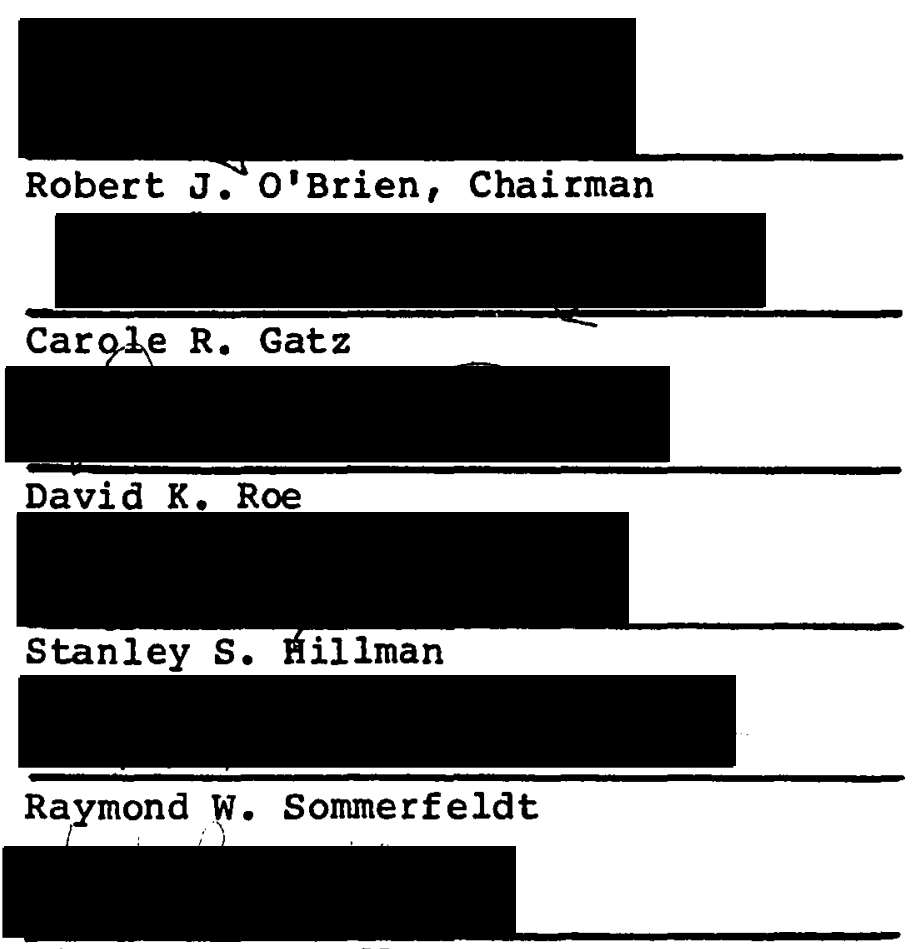

William W. Paudler

APPROVED :

David W. McClure, Head, Department of Chemistry Robert O. Tinnin, Director, Environmental Sciences and Resources

William W. Paudler, Dean, College of Liberal Arts and Sciences

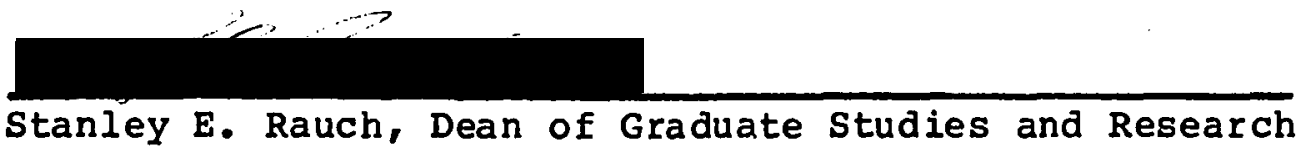




\section{ACKNOWLEDGEMENT}

Without the help from many, this project would not have been possible. My special gratitude is due to Dr. T.M. Hard for the support out of the grant for $\mathrm{OH}$ measurement and my thesis advisor Dr. R.J. O'Brien. 
TABLE OF CONTENTS

LIST OF TABLES ............................ vi

LIST OF FIGURES......................... ix

CHAPTER

I BACKGROUND........................

Importance of Hydroxyl Radical.............

Methods of Detection - LIF..............2

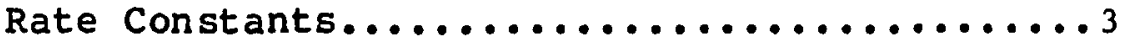

Time Correlated Photon Counting - Principle...7

Coates Correction and Constant Fraction Discriminator.....................11

Suitability of the Counting Method

for $\mathrm{OH}$ Measurement.................... 15

II THEORY........................... 17

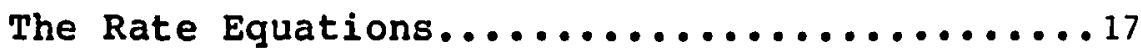

The Real Laser Pulse..................21

Methods of Deconvolution................25 
A Simulation.......................28

Discrete Convolution...................... 35

Minor Details........................38

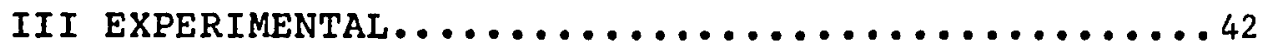

IV RESULTS .............................48

Data................................. 48

Analysis of Data......................69

Final Results and Literature Values.........80

V ERROR ASSESSMENT .....................98

Systematic and Random Errors..............98

Convergence Test.........................101

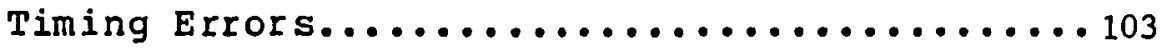

VI DISCUSSION............................ 114

REFERENCES................................. 123

APPENDICES ............................... 127

A SIMPLEX SEARCH........................ 128

B MCA TO AIM 65 INTERFACE...................... 136

C LASER POWER MONITOR............................ . 144 


\section{LIST OF TABLES}

TABLE

PAGE

I Rate constants used in the simulation exercise..29

II Discrete convolution algorithm............ 37

III Experimental results of $A^{\prime} s$ and $B^{\prime} s$ in argon at

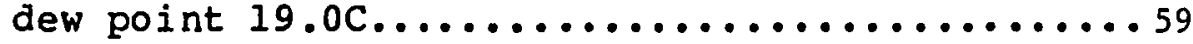

IV Experimental results of $A^{\prime} s$ and $B^{\prime} s$ in argon at dew point $16.0 \mathrm{0} \ldots \ldots \ldots \ldots . . \ldots \ldots$

$V$ Experimental results of $A^{\prime} s$ and $B^{\prime} s$ in argon at dew point 9.0 .........................60

VI Experimental results of $A^{\prime} s$ and $B^{\prime} s$ in argon at

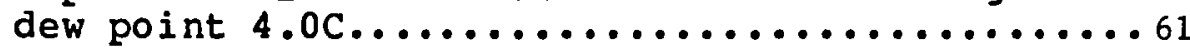

VII Experimental results of $A^{\prime} s$ and $B^{\prime} s$ in argon at dew point -7.0 C.......................61

VIII Experimental results of $A^{\prime} s$ and $B^{\prime} s$ in argon at dew point -16.0 . ......................6 62

IX Experimental results of $A^{\prime} s$ and $B^{\prime} s$ in nitrogen at dew point $-16.0 \mathrm{C} \ldots \ldots \ldots \ldots . . \ldots \ldots . . \ldots 6$

$X$ Experimental results of $A^{\prime} s$ and $B^{\prime} s$ in nitrogen and 28 oxygen at dew point $-16.0 \mathrm{C} \ldots \ldots \ldots . . .663$

XI Experimental results of $A^{\prime} s$ and $B^{\prime} s$ in nitrogen and 58 oxygen at dew point -16.0 C............64 
XII Results of linear least squares fits showing the slopes and intercepts................ 72

XIII Final results and literature values of argon....81

XIV Final results and literature values of water....83

XV Final results and literature values of nitrogen. 85

XVI Final results and literature values of oxygen...87

XVII Effects of channel resolution on the accuracy

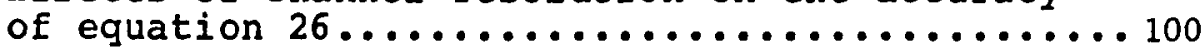

XVIII Effects of signal/noise ratio on the accuracy

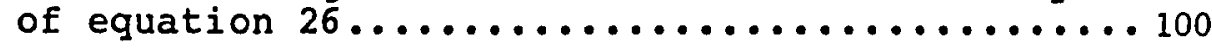

XIX Errors due to 0.3 ns shift of the laser profile. 113

$X X$ Effects on $A$ and $B$ by the spurious fluorescence signals of various amplitudes.............. 121

XXI Simplex program with the convolution subroutine. 133

XXII Logic sequences for executing commands to control the MCA through the interface adaptor

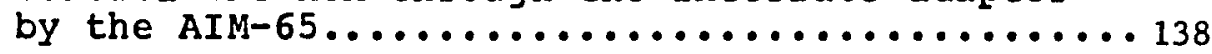

XXIII Assembly codes for executing the

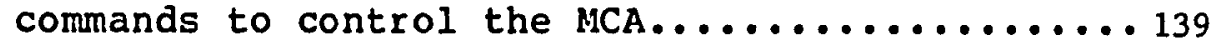

XXIV Commands for controlling the MCA in BASIC statements.......................... 142 
viii

TABLE

PAGE

XXVI Assembly codes for the laser power monitor...... 148 


\section{LIST OF FIGURES}

\section{FIGURE}

PAGE

1 Model representing the energy transfers of excited hydroxyl radical $(\mathrm{OH}) \ldots \ldots \ldots \ldots \ldots \ldots \ldots \ldots . . .4$

2 Principle of time correlated photon counting.....99

3 Schematics of time correlated photon counting experimental setup....................10

4 Errors due to difference in pulse heights........ 14

5 Derivation of the convolution - A.............22

6 Derivation of the convolution - B..............23

7 Input function, $f(t)$, for the simulation exercise............................31

8 Simulated fluorescence -- low pressure..........33

9 Semilog plot of simulated fluorescence at

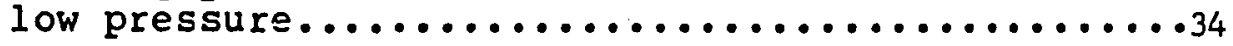

10 Simulated fluorescence -- atmospheric pressure...36

11 schematics of experimental setup.............43

12 OH fluorescence cell......................44

13 Fluorescence decay of $\mathrm{OH}$ in argon plus water (D.P. $-16.0 \mathrm{C})$ : $x$-laser profile; -fluorescence; solid line-least squares fit. Time scale is 0.4 ns per channel......................49 
14 Fluorescence decay of $\mathrm{OH}$ in argon plus water (D.P. -7.0C): $x$-laser profile; -fluorescence; solid line-least squares fit. Time scale is 0.4 ns per channel......................50

15 Fluorescence decay of $\mathrm{OH}$ in argon plus water (D.P. 4.0C). Laser profile is not shown. Time scale is 0.2 ns per channel.............51

16 Fluorescence decay of $\mathrm{OH}$ in argon plus water (D.P. 9.0C). Time scale is 0.2 ns per channel....52

17 Fluorescence decay of $\mathrm{OH}$ in argon plus water (D.P. 16.0C). Time scale is 0.1 ns per channel...53

18 Fluorescence decay of $\mathrm{OH}$ in argon plus water (D.P. 19.0C). Time scale is 0.1 ns per channel...54

19 Fluorescence decays of of in argon plus water. - - fluorescence at different water concentrations. $x$ - laser profile. The graph shows the drastic difference in the decay curves due to the change in water concentration........55

20 Fluorescence decay of $\mathrm{OH}$ in nitrogen (D.P. $-16.0 \mathrm{C}$ ). Time scale is 0.2 ns per channel...56

21 Fluorescence decay of $\mathrm{OH}$ in nitrogen plus 28 oxygen. Time scale is 0.1 ns per channel........57

22 Fluorescence decay of $\mathrm{OH}$ in nitrogen plus 58 oxygen. Time scale is 0.1 ns per channel.......58

23 Linear least squares $f$ it of $C / A B$ versus cumulative count $(\times 0.1)$ tabulated in Table $\times I \ldots .66$

24 Linear least squares fit to $A^{\prime} s$ and $B^{\prime} s$ in argon as a function of water concentration....70 
25 Linear least squares fit to $A^{\prime} s$ and $B^{\prime} s$ in nitrogen as a function of oxygen concentration....71

26 Ratio of fluorescence intensity at $309 \mathrm{~nm}$ to $314 \mathrm{~nm}$ in Helium as a function of water concentration...........................

27 Plot of $\log \left(k_{Q O N_{2}}\left[N_{2}\right]\right)$ against $\log \left[N_{2}\right] \ldots \ldots \ldots . . .91$

28 Plot of $\log \left(k_{Q O A r}[A r]\right)$ against $\log [A r] \ldots \ldots \ldots . . .92$

29 Plot of $\log \left(k_{Q O O O}[M]\right)$ against $\log [M] \ldots \ldots \ldots . . .993$

30 Plot of $\log \left(k_{Q_{O H}} \mathrm{O}[M]\right)$ against $\log [M] \ldots \ldots . . . .994$

31 Linear least squares fit to the literature values of $\mathrm{KaON}_{2}\left[\mathrm{~N}_{2}\right]$ as a function of experimental pressure...........................96

32 Values of $A^{\prime}$ 's and B's as a function of cumulative count in nitrogen/58 oxygen and argon/water at dew point $-16.0 \mathrm{C} \ldots \ldots \ldots \ldots . \ldots . \ldots 102$

33 Plot of $\log$ (er ror) versus $\log$ (count) of the experiment on $\mathrm{OH}$ fluorescence in nitrogen........104

34 Uncertainty check of the MCA. Time scale is

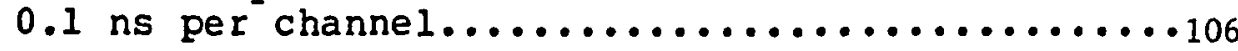

35 Uncertainty check of the high-speed photodiode. Time scale is 0.1 ns per channel..............107

36 Misalignment of the laser profiles showing the

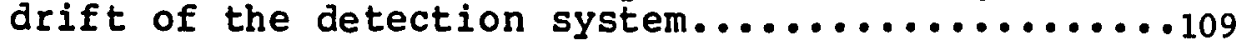

37 Misalignment of the laser profiles showing the rising portions of the profiles................110 
38 Plot of the half height times and half-width of the laser profiles as a function of days of operation.......................111

39 Fluorescence of $\mathrm{OH}$ in nitrogen due to the excitation by a laser of 10 ns half-width.......116

40 Spurious OH concentration profile produced by the

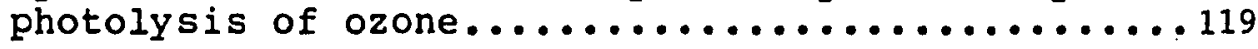

41 Flow chart of the simplex iteration procedure..... 132

42 Schematics of the MCA to AIM-65 interface

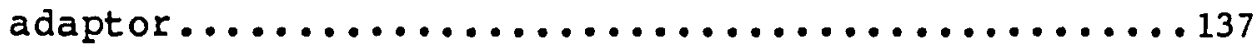

43 Laser power monitor........................ 145

44 Schematics of the peak detector............... 146 


\section{CHAPTER I}

\section{BACKGROUND}

The purpose of this investigation is to investigate the possibility of studying the high pressure energy transfers of electronically excited hydroxyl radical $(\mathrm{OH})$ with the Time Correlated Photon Counting technique. The history leading to this undertaking will be dealt with in this chapter.

Impertance of The OH Radical

The importance of the $\mathrm{OH}$ radical as a key intermediate in a wide variety of chemical, atmospheric and astrophysical systems has been appreciated for many years and accounts, in part, for numerous undertakings to characterize its fundamental physical properties. However, the long-standing interest in $\mathrm{OH}$, as pointed out by Lengel and Crosley (1), is the attempt of a basic understanding of a small molecule theoretically tractable. As in spectroscopy, the interest is due to the challenge of developing model Hamiltonians, which can accurately represent the experimental rotational-vibrational structures(2). The kinetic interest is mainly on the energy transfers involving the electronically excited $\mathrm{OH}$, especially the $A^{2} \sum$ states produced by photodecomposition 
of water as typified by the studies of Carrington(3), Kondrat'ev(4), Bunnett et al.(5) and Hooymayers et al.(6).

The reason for this undertaking, besides the kinetics interest, stems from the attempts to measure ambient $\mathrm{OH}$ concentration by Laser Induced Fluorescence (LIF) $(7,8)$. The $\mathrm{OH}$ radical itself has attracted considerable attention from atmospheric chemists (Crutzen(9), Levy (10), Wofsy et al.(11), Chameides et al.(12) and Davis et al.(8)). The major roles of the $\mathrm{OH}$ radical in tropospheric chemistry have been summarized by Logan et al.(13).

\section{Metheds of Detecting $\mathrm{OH}$}

Due to the crucial importance of $\mathrm{OH}$ to our understanding of the chemistry in the atmosphere, many attempts have been made to measure the ambient $O H$ concentration. Anderson used a molecular resonance method to measure the $\mathrm{OH}$ in the upper atmosphere(14). Burnett measured the $\mathrm{OH}$ concentration by monitoring the absorption of sunlight by terrestrial $\mathrm{OH}(15)$. Perner et al. used long path absorption $(7.8 \mathrm{~km})$ at $309.995 \mathrm{~nm}$ to monitor $\mathrm{OH}$ concentration(16). Campbell et al. ultilized radioactive cartion monoxide as a tracer to measure ambient $\mathrm{OH}$ concentration(17). The LIF method promoted by Baardsen and Terhune(18), Wang et al.(19) and Davis et al.(20) is central to this dissertation.

The LIF technique involves exciting the oH radical 
using one of the rotational-vibronic lines in the $2 \pi\left(v^{n}=0\right)$ $\rightarrow{ }^{2} \sum\left(v^{\prime}=1\right)$ transitions and observing the fluorescence emission associated with the ${ }^{2} \sum\left(v^{\prime}=1\right) \rightarrow{ }^{2} \pi\left(v^{n}=1\right)$ transition near $314.5 \mathrm{~nm}$ or the ${ }^{2} \Sigma\left(v^{\prime}=0\right) \rightarrow{ }^{2} \pi\left(v^{n}=0\right)$ transition near $309.0 \mathrm{~nm}$. The processes involved are pictured in Figure 1. The $k^{\prime} s$ in the Figure are the second order rate constants associated with the various energy transfers. These processes will be described in detail in chapter II.

The Importance of 0 H Quenching and Belaxation Rate constants

Generally, the LIF method requires a calibration standard. The resulting fluorescence signal of the sample of interest has to be matched against the fluorescence intensity of a known $\mathrm{OH}$ source subjected to the same irradiance and same conditions in order to deduce the absolute $\mathrm{OH}$ concentration of the unknown sample.

According to the method used by Davis et al.(20), the calibration correlates the fluorescence signal and the absolute $O H$ concentration via a cell containing a known amount of $\mathrm{OH}$ produced by $184.9 \mathrm{~nm}$ photolysis of a water, nitrogen and hydrogen mixture. However, when the medium is changed, the fluorescence efficiency of the $\mathrm{OH}$ is also changed. Hence, as indicated by the investigators, the known values of $\mathrm{kO}_{2} / \mathrm{k}_{2}$ and $\mathrm{k}_{2} \mathrm{O} / \mathrm{k}_{\mathrm{O}_{2}}$ are essential to the calculation of the absolute $\mathrm{OH}$ concentration. Here, $\mathrm{kO}_{2}$ 


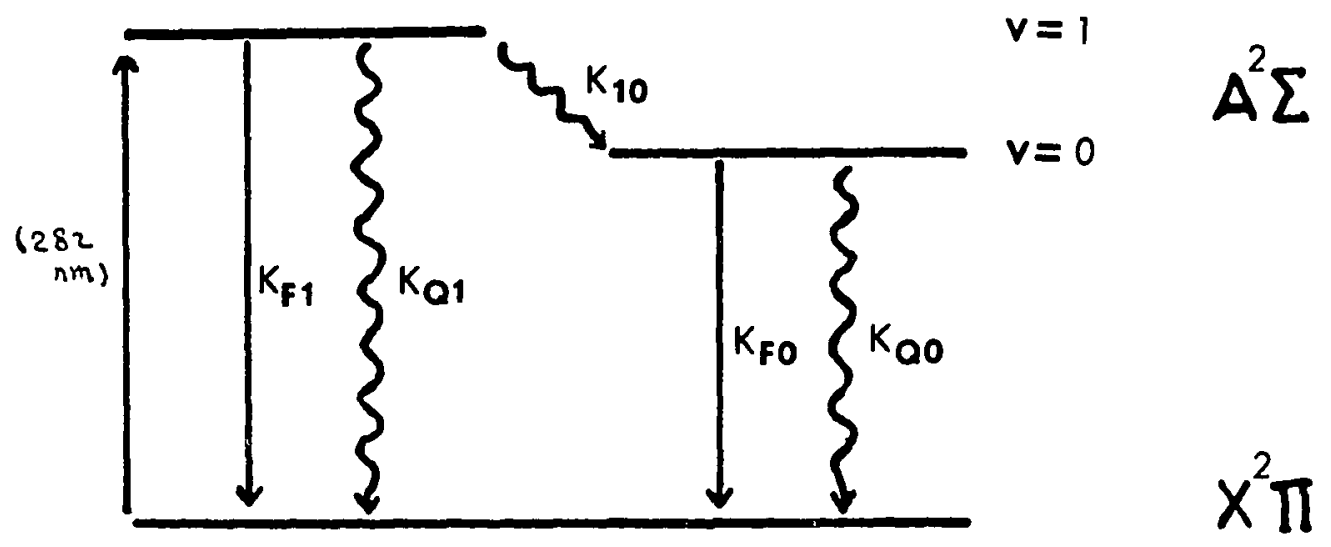

Figure 1 Model representing the energy transfers of excited hydroxyl radical $(\mathrm{OH})$. 
$\mathrm{k} \mathrm{N}_{2}$ and $\mathrm{k}_{2} \mathrm{O}$ are the electronic quenching rate constants of oxygen, nitrogen, and water respectively.

The other method of calibration as applied by Wang et al.(19) abandons the known source of $\mathrm{OH}$ all together, and relies on the intrinsic physical constants such as the absorption cross section of $\mathrm{OH}$ and the quenching and relaxation rate constants of nitrogen, oxygen and water. The investigators calculate the absolute $\mathrm{OH}$ concentration using the laser intensity (via nitrogen Raman scattering), the absorption coefficient and the fluorescence efficiency calculated from various rate constants.

As pointed out by wang et al.(22), the values of fluorescence efficiency (i.e. various rate constants) were scattered over an order of magnitude. Although efforts were made to narrow the range of uncertainty, according to their report, the errors were still in the range of 158 to 20\%. In fact, their later result on the ratio of $\mathrm{k}_{\mathrm{H}_{2} \mathrm{O}}$ to $k N_{2}$ (10:l at low pressure) contradicted their own earlier result (44:1; measured by relative fluorescence intensity as a function of water concentration in nitrogen at atmospheric pressure).

According to the review by schofield(24), the $A^{2} \Sigma$ states are the most important and best characterized of the electronically excited states of $\mathrm{OH}$ and give rise to the strong $A^{2} \Sigma \rightarrow X^{2} \pi$ allowed transitions. This fact has been used by the LIF method. The review article tabulates 
most of the measured electronic quenching, vibrational relaxation and rotational transfer rate constants. However, these reported values are mostly obtained from experiments carried out either at low pressure or at flame temperature, quite different from LIF measurements carried out under ambient conditions.

The reason that most of the earlier experiments are not carried out under ambient conditions has to do with the intention of the experiments and the experimental methods. For example, the usual way of producing high concentrations of $\mathrm{OH}$ is by the fast reaction of $\mathrm{H}+\mathrm{NO}_{2}$ to produce $\mathrm{OH}$ and NO. However, the $\mathrm{H}$ atoms are produced by $\mathrm{a}$ microwave discharge which has to be operated at low pressure. As a consequence, most of these measurements are made at low pressure. At high pressure labout one atmosphere), the fluorescence life-time is too short and the signal is too weak to be measured with ordinary instruments.

This undertaking is designed to overcome the difficulties of short fluorescence life-time and weak fluorescence signals. It is the first attempt to measure the fluorescence decay of $\mathrm{OH} \mathrm{A}^{2} \Sigma$ states at atmospheric pressure directly. The excitation scheme duplicates that of the actual LIF used by Wang et al. and Davis et al., that is, to excite $\mathrm{OH}$ at $282 \mathrm{~nm}$ and to monitor the fluorescence at $309 \mathrm{~nm}$. 
Principle ef Time correlated Rhoten counting

In the time correlated photon counting technique(25), the sample under investigation is repetitively excited with short pulses of light and the resulting fluorescence pulses are detected with a photomultiplier tube (PMT). In contrast to the ordinary method of light detection, the fluorescence signal is highly attenuated with an aperture before reaching the PMT. The light attenuation is adjusted so that the probability of detecting a photoelectron per fluorescence pulse is much less than one. Under this condition of low photoelectron arrival rate, a small number of excitation pulses produce one PMT pulse and a still smaller number of excitation pulses produce two or more pulses. For sufficiently high attenuation, each excitation pulse essentially produces zero or one PMT pulse. The detection system is then in the single photon mode. In this mode, the probability that a photoelectron is detected by the PMT at the time, $t$, after the firing of an excitation pulse is proportional to the fluorescence intensity at the same time, t. After many excitation pulses, a plot of the number of counts which arrive in time interval $t$ and $t+\Delta t$ versus time gives the time-intensity profile of the fluorescence or scattering pulses.

Two pieces of equipment are fundamental to the implementation of this kind of counting: a 
Time-to-Amplitude Converter (TAC) and a Multichannel Pulse Height Analyser (MCA). The excitation light source (a laser pulse in some cases) triggers a high-speed photodiode which in turn starts the TAC. The photoelectron pulse from the PMT triggers the Constant Fraction Discriminator which then stops the TAC. The TAC produces a pulse of amplitude proportional to the length of time between the start and stop pulses. The MCA measures the amplitude of the TAC output and adds a count to the corresponding channel. If no PMT pulse is detected, the TAC automatically stops without producing an output to the MCA. In any event, the TAC resets itself after several microseconds and awaits a new start pulse. After many laser pulses, a plot of counts versus channel number gives the time-intensity profile of the fluorescence or scattering pulses. The relation between channel numbers and time is established with calibrated delay lines or is factory calibrated. Figures 2 and 3 illustrate the principle.

Time correlated photon counting has been applied to nanosecond fluorescence measurements since the mid-1960's(26). Since that time there have been significant improvements in both the electronic measuring instruments and the excitation light sources. The traditional light sources have been gaseous gap-discharge arcs. Now high repetition laser sources, especially 


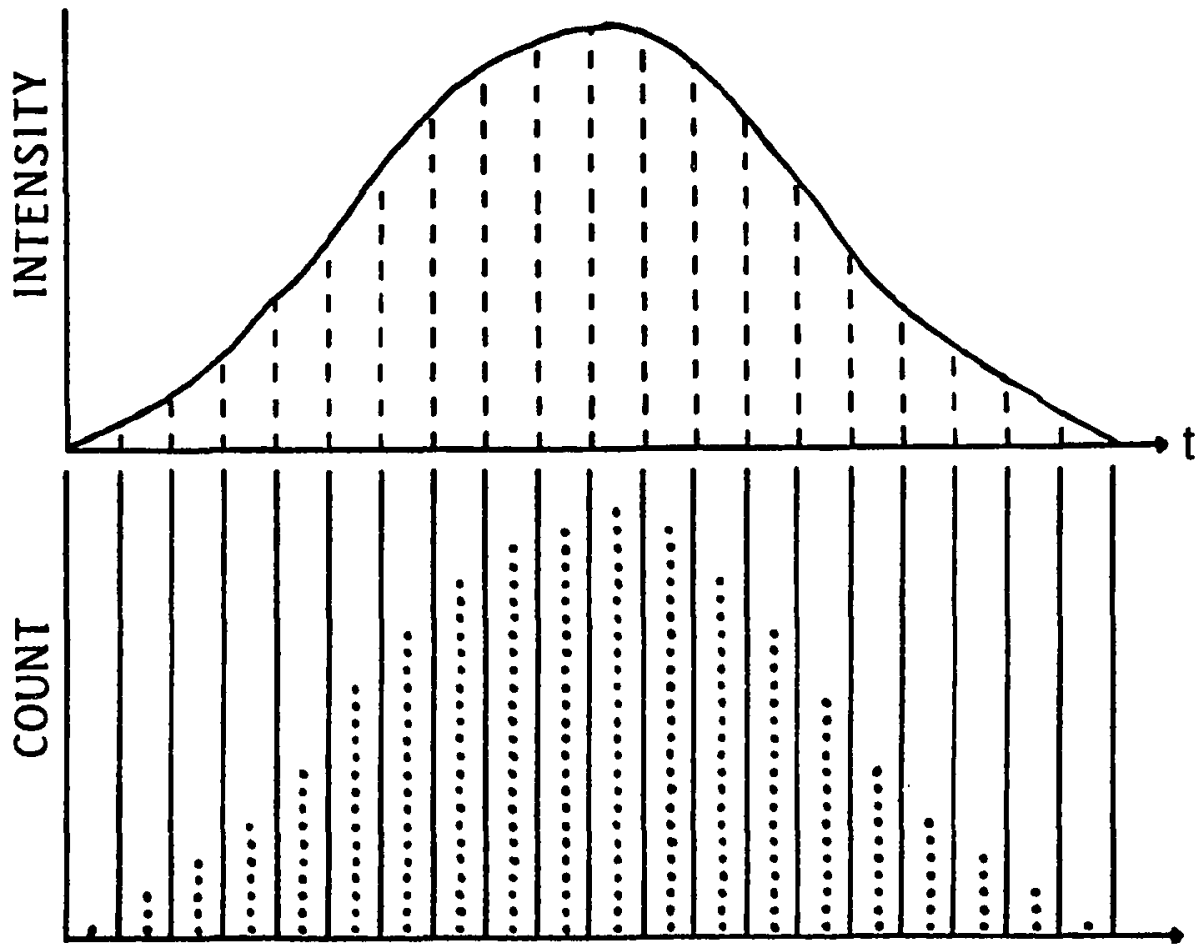

Figure 2 Principle of time correlated photon counting. The upper curve shows the intensity profile divided into time slots. The lower curve shows the distribution of counts which resembles the intensity profile. 


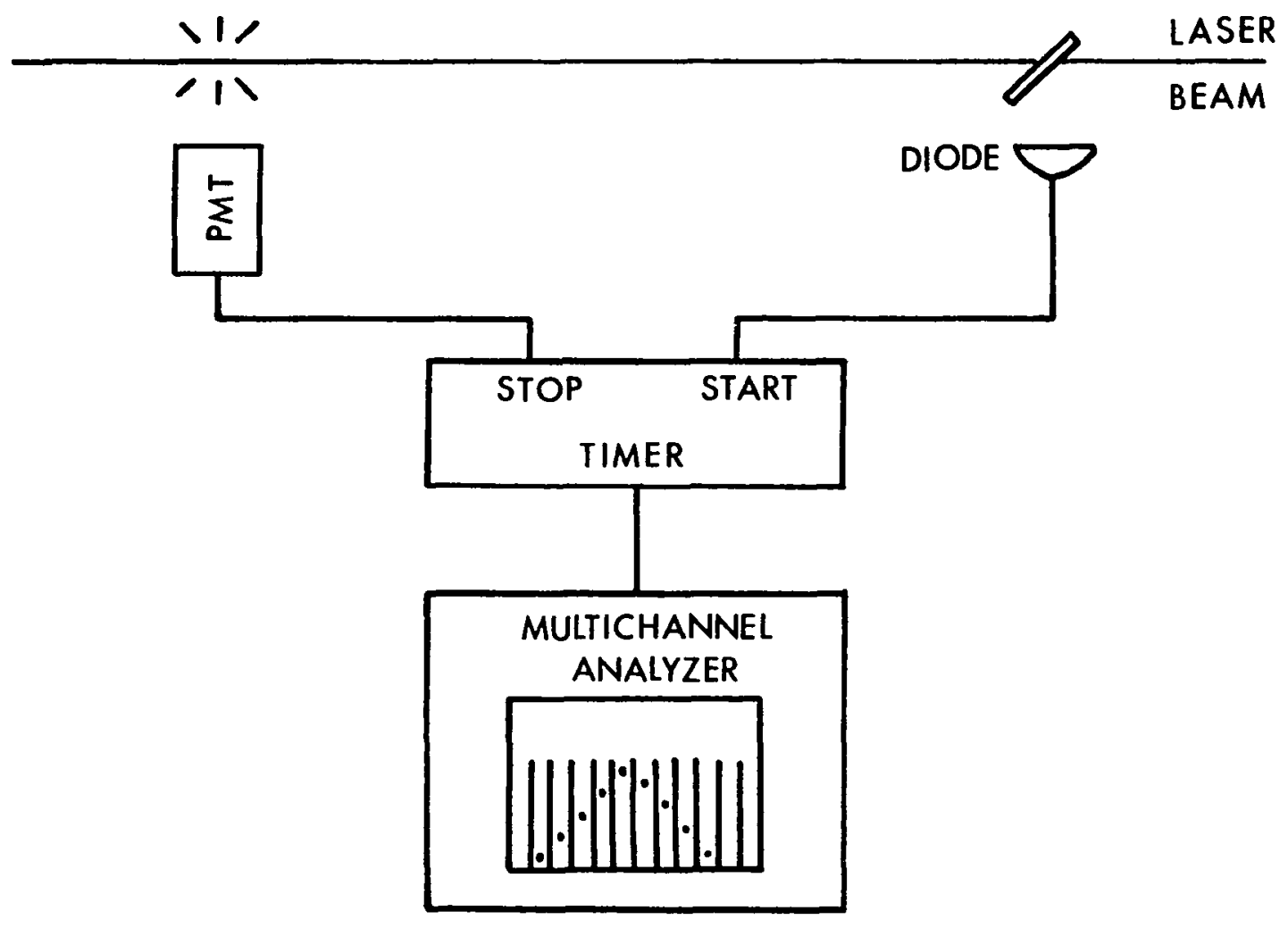

Figure 3 Schematics of time correlated photon counting experimental setup. 
tunable dye lasers, have almost replaced the gaseous-discharge arcs(26). The advantages of lasers over the discharge arcs were oulined by Koester (26) as:

1. Capable of very short (<35 ps) excitation pulses.

2. High excitation pulse power.

3. Capable of high repetition rate.

4. Comparatively constant pulse profile over short and long time ranges.

5. Monochromaric and polarized source.

6. Tunable excitation wavelength.

The advances in microcircuitry and hybrid circuits allow the detection system, essentially the TAC and the MCA, to be incorporated into a single piece of equipment. One example is the LeCroy QVT3001 which incorporates many functions into a single double width NIM module. The LeCroy QVT3001 operates on a slightly different principle from that of a TAC but its achieved results are the same.

\section{coates correction and Constant Eraction Discriminater}

The time correlated photon counting technique requires that zero or one fluorescence photoelectron per excitation pulse is detected. Statistically there are always a few laser pulses for which more than one photoelectron is generated. The effects of these multiple photon events result from the fact that the TAC and the MCA require several microseconds to process and recycle themselves after a PMT pulse has been detected. During 
this time, the recording system is incapable of registering a second PMT pulse. When two or more photoelectrons are detected by the PMT during one excitation, only the first photoelectron is recorded. This causes a loss of count in the later channels and a subsequent distortion of the fluorescence decay curve.

Several methods are available for circumventing this difficulty. One is to run the experiment at such a low intensity $(<0.02$ count per cycle) that it becomes highly improbable that more than one PMT pulse is produced. Another is the "live timer" $(27,28)$ method in which the circuits begin to process the first PMT pulse, but if another pulse arrives during the processing both the first and second pulses are discarded and the entire cycle is aborted. Therefore only cycles in which only one photoelectron is detected are accepted by the MCA. This electronic solution allows a somewhat higher arrival rate, but it does have an upper limit. The third approach is to deduce a mathematical algorithm which takes the recorded profile and derives the true spectrum of all arrivals. It turned out to be a rather simple statistical problem $(29,30)$. The coates correction is one such algorithm. Although the Coates correction requires that the actual number of laser pulses be known, this is only a small price to pay for a shorter experimental time. The PMT pulses are not always of the same height. 
This causes uncertainty in the timing of the TAC. The origin of this uncertainty (walk) is demonstrated in Figure 4. The Figure shows two PMT pulses of different heights reaching the discriminator at the same time. The timing error results from the use of the crossing of a certain voltage level as the arrival time of the pulse. This uncertainty can be serious for pulses of large height variation, especially in the case of scintillation counting. However, for single photon counting, the range of pulse heights is comparatively small. Modern PMT have risetimes of the order of 2 nanoseconds. This limits the walks somewhat. The uncertainty can be narrowed down further by a constant fraction discriminator (31).

The constant fraction discriminator does not use a fixed voltage level as the threshold. Instead it takes a fixed fraction of the maximum PMT pulse height as the threshold. This new threshold allows the arrival time to adjust itself to the PMT pulse height. In principle, the voltage rise of a short PMT pulse reaches the threshold earlier, because the threshold of a short pulse is relatively small as compared to a tall pulse. By the same token, the voltage rise of a tall PMT pulse will reach the threshold later, because the threshold is relatively higher. The effect is that the error, "walk", of the arrival time is reduced. For more details, see reference 31. 
14

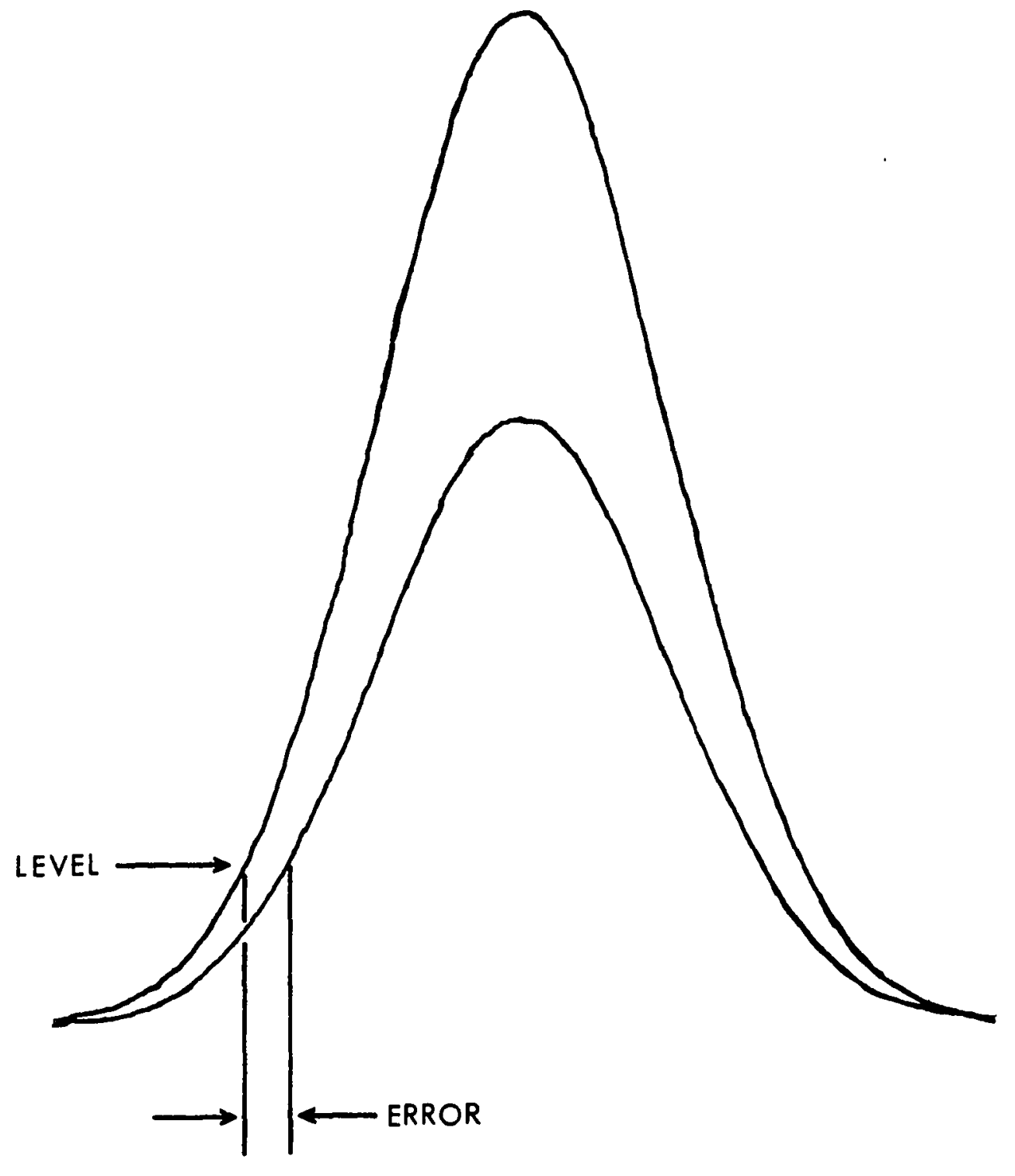

Figure 4 Errors due to difference in pulse heights. 
Timing accuracy is not just a problem of the discriminator alone. The instruments down-stream of the constant fraction discriminator are just as crucial in determining the overall uncertainty of the detection system. The TAC, the MCA and the high-speed photodiode combined have an overall uncertainty of about 0.2 ns as compared to the $0.12 \mathrm{~ns}(32)$ of the constant fraction discriminator.

\section{Suitability of the Method for of Measurement}

The time correlated photon counting method is especially suitable for mesuring $O H$ fluorescence decay at atmospheric pressure due to its inherent principle of operation.

The method requires that the photoelectron arrival rate be low. An arrival rate as high as 0.2 per laser pulse is still acceptable provided that the result is corrected by the coates algorithm. Laser induced $\mathrm{OH}$ fluorescence at atmospheric pressure is very weak due to the overwhelmingly fast nonradiative quenching by inert species. This counting technique uses the weak fluorescence signal very well. Other methods such as the Boxcar integrator, which are based on integrated signal, will require very slow scan rate or are unable to separate the background and the signal at all.

since the method performs well even with a weak fluorescence signal, low $O H$ concentration can still 
sustain a good signal to noise ratio for the experiment. In fact, photolysis of water vapor by mercury lamps with quartz jackets produces enough $\mathrm{OH}$ to sustain the experiments. This simplifies the experimantal setup a lot. No messy and complicated chemical flow systems are needed. This is the advantage that allows the direct measurement of $\mathrm{OH}$ fluorescence at atmospheric pressure, because no microwave discharge is required. The experimental setup consists simply of an enclosed cell with a pair of mercury lamps inside and a quartz window for the monochromator to see the fluorescence.

The resolution of the TAC and the MCA can be as short as 0.1 ns per channel over 1000 channels. This means high resolution. In other words, we can get about 100 points for a 10 ns long fluorescence phenomenon. This high resolution is made possible by recent advances in technology.

It is hard to compare the performances of methods such as the transient recorder, the waveform digitizer and other methods relying on integrated signals. Each method has its own advantages under certain circumstances. However, the time correlated photon counting method is clearly and unmistakenly suitable for the measurement of $\mathrm{OH}$ fluorescence decay at atmospheric pressure. 


\section{CHAPTER II}

\section{THEORY}

The excitation scheme used by the LIF detection method does not produce a simple exponential fluorescence decay. This chapter will elucidate the processes involved, derive mathematical formulae to describe the processes and establish grounds for experimental strategy.

\section{The Rate Equations}

The processes involved in the LIF detection scheme are pictured in Figure 1 . Since the repopulation of $\left(v^{\prime}=1\right)$ states from $\left(v^{\prime}=0\right)$ states is not favored, kol may be ignored without jeopardizing the applicability of the result to the real situation.

The energy transfer processes are represented by equations 1 to 5. Equations 1 and 4 show the spontaneous emissions with natural decay constants $k_{F l}$ and $k_{F O}$ of the $\left(v^{\prime}=1\right)$ and $\left(v^{\prime}=0\right)$ states respectively. Equations 2 and 5 represent non-radiative quenching by inert species $M$ into any states of the lower electronic energy level. Equation 3 is the vibrational relaxation from $\left(v^{\prime}=1\right)$ state into $\left(v^{\prime}=0\right)$ state through collisions with some inert species $M$.

$\begin{array}{ll}K_{F 1} \mathrm{OH}^{*} & \rightarrow \mathrm{OH}+h_{1} \\ K_{Q 1} \mathrm{OH}^{*}+M & \rightarrow \mathrm{OH}\end{array}$




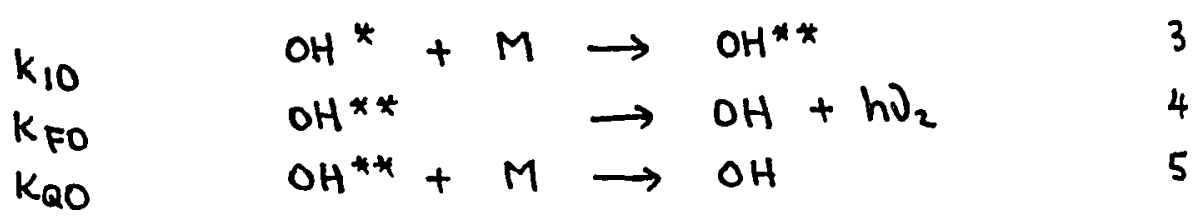

We consider excitation of $\mathrm{OH}$ radicals by a Dirac delta function or an impulse function at time $t=0$. The impulse function can be viewed as a laser pulse with infinitely narrow temporal width. This impulse function produces $\left[\mathrm{OH}^{*}\right]_{0}$ excited hydroxyl radicals in the upper vibrational state $A^{2} \sum\left(v^{\prime}=1\right)$. We denote the number of hydroxyl radicals at a subsequent time $t$, in the $\left(v^{\prime}=1\right)$ state by $\left[\mathrm{OH}^{*}\right]$ and $\left(\mathrm{V}^{\prime}=0\right)$ state by $\left[\mathrm{OH}^{* *}\right]$. The rates of change of $\left[\mathrm{OH}^{*}\right]$ and $\left[\mathrm{OH}^{* *}\right]$ with respect to time are given by

$$
\begin{aligned}
& \frac{d\left[O H^{*}\right]}{d t}=-K_{F 1}\left[O H^{*}\right]-K_{Q 1}\left[O H^{*}\right][M]-K_{10}\left[O H^{*}\right][M], \\
& \frac{d\left[O H^{* *}\right]}{d t}=K_{10}\left[O H^{*}\right][M]-K_{F O}\left[O H^{* *}\right]-K_{Q_{0}}\left[O H^{* *}\right][M]
\end{aligned}
$$

Since [M] can be considered constant as the time progresses, we denote

$$
\begin{aligned}
& K_{Q 1}[M]=K_{Q 1}^{\prime}, \\
& K_{Q 0}[M]=K_{Q 0}^{\prime}, \\
& K_{10}[M]=K_{10}^{\prime} .
\end{aligned}
$$

[M] is the pressure at which the experiment is carried out. We do the simplifications: 


$$
\begin{array}{ll}
A=K_{F 1}+K_{Q 1}^{\prime}+K_{10}^{\prime}, & 11 \\
B=K_{F O}+K_{Q O}^{\prime} . & 12
\end{array}
$$

The rate expressions become

$$
\frac{d[O H *]}{d t}=-A[O H *]
$$

and

$$
\frac{d\left[O H^{* *}\right]}{d t}=K_{10}^{\prime}\left[O H^{*}\right]-B\left[O H^{* *}\right]
$$

Equation 13 can be solved readily. Applying the initial condition, $\left[\mathrm{OH}^{*}\right]_{0}$, we get

$$
\left[O H^{*}\right]=\left[O H^{*}\right]_{0} \operatorname{EXP}(-A t) \text {. }
$$

15

Substituting equation 15 into equation 14 , we have

$$
\frac{d\left[O H^{* *}\right]}{d t}+B\left[O H^{* *}\right]=K_{10}^{\prime}\left[O H^{*}\right]_{0} E x P(-A t) .
$$

16

Multiplying both sides of equation 16 by $\operatorname{EXP}(B t)$ and using

$$
\left(\frac{d[O H * *]}{d t}+B\left[O H^{* *}\right]\right) \operatorname{ExP}(B t)=\frac{d}{d t}\left(\left[\mathrm{OH}^{* *}\right] \operatorname{ExP}(B t)\right),
$$

we have

$$
\frac{d}{d t}([O H * *] \operatorname{ExP}(B t))=K_{10}^{1}\left[O H^{*}\right] . \operatorname{ExP}[(B-A) t]
$$


Integrating and applying the initial condition that $[\mathrm{OH} * \star]=0$ at time $t=0$, we have

$$
\left[O H^{*} *\right]=\frac{K_{10}^{\prime}\left[O H^{*}\right]_{0}}{B-A}(\operatorname{Exp}(-A t)-\operatorname{ExP}(-B t))
$$

Lengel and Crosley(1) and German(33) arrived at similar equations relating the probability $P_{V}(t)$ of a molecule being in a given vibrational state $v$. In the notations used by German, the two equations are:

$$
\begin{gathered}
P_{1}(t)=\operatorname{Exp}(-t / \tau), \\
P_{0}(t)=\frac{n \sigma_{10} V}{\tau_{1}^{-1}-\tau_{0}^{-1}}\left(\operatorname{Exp}\left(-t / \tau_{0}\right)-\operatorname{Exp}\left(-t / \tau_{1}\right)\right) .
\end{gathered}
$$

Where $\tau_{v}^{-1}$ is the sum of the decay constants of vibrational state $v$. The corresponding equations are exactly the same if we set

$$
k_{10}^{\prime}=n \sigma_{10} V
$$

Finally, equations 15 and 19 are the desired relations. Since they are responses due to impulse functions, we call them impulse response functions. Since they are characteristic of the system (model), we also call them characteristic response functions. 
The Real Laser Pulse

Up to this point, all discussion has been based on the assumption that the laser pulse is an impulse function; it has an infinitely narrow temporal width. In reality, the laser pulse has a finite width. When the decay constant of the impulse response function is small (long life-time) compared to the temporal half-width of the laser pulse, the assumption is valid. However, when the reciprocal of the decay constant and the laser temporal half-width are comparable, the above assumption does not stand. For example, here the half-life of the excited $O H$ radicals at relatively high pressure (one atmosphere) is about one nanosecond and the laser temporal half-width is about 7ns. One definitely will not expect the assumption to hold true.

since we are considering measurement at atmospheric pressure the assumption can not be of too much help. Nevertheless, equation 19 is our starting point. We consider Figures 5 and 6 , where $I_{0} f^{\prime}(t)$ is the laser time-intensity profile; $g$ is the response function due to an impulse function; $h$ is the fluorescence output or the output function due to a laser pulse of finite temporal width. Assuming that Beer's law holds or, in other words, that we are dealing with a linear system, the concentration of the excited $\mathrm{OH},[\mathrm{OH} *]$ (initial concentration due to an impulse function at time $\tau$ ), is 


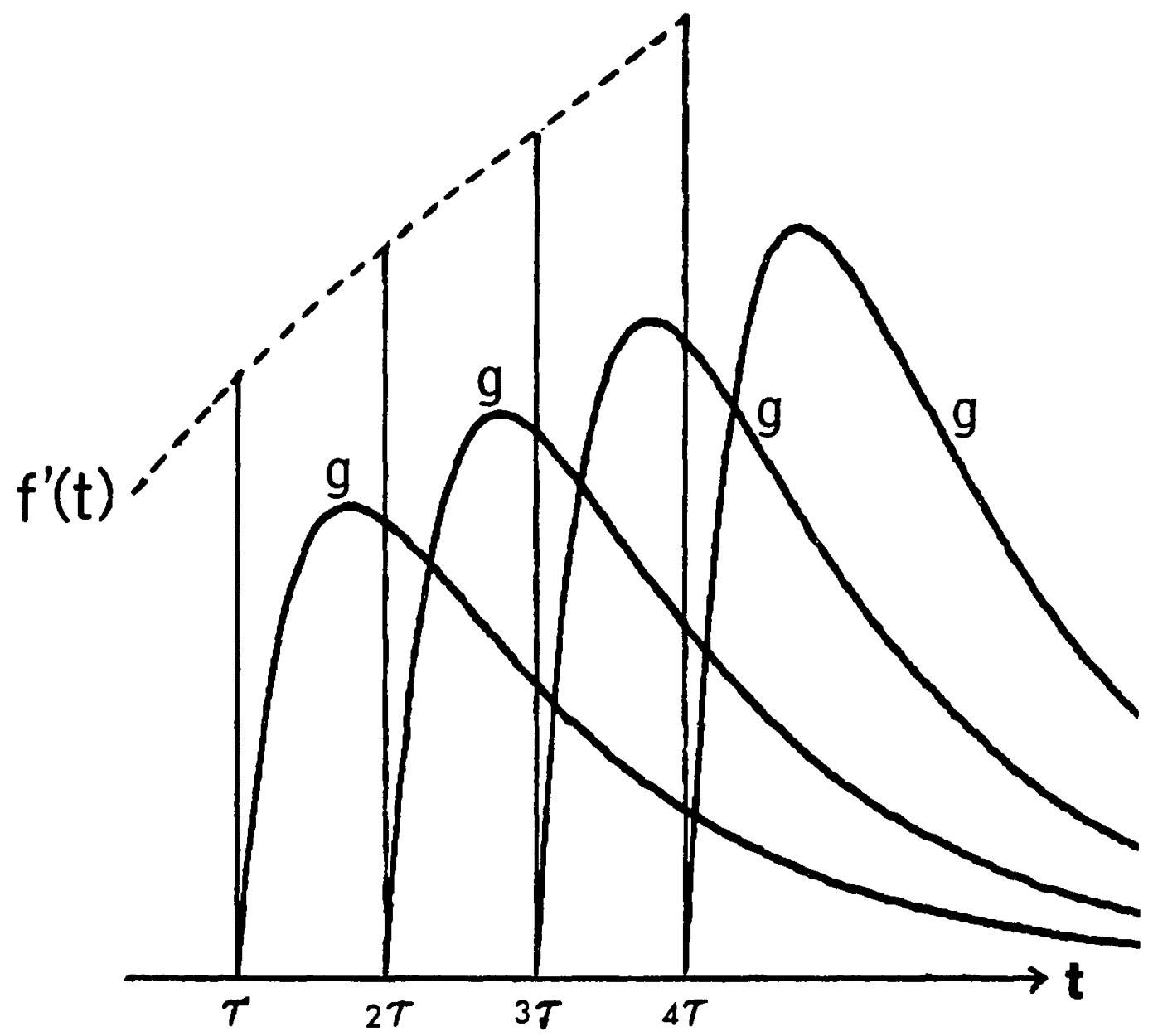

Figure 5 Derivation of the convolution - A. 


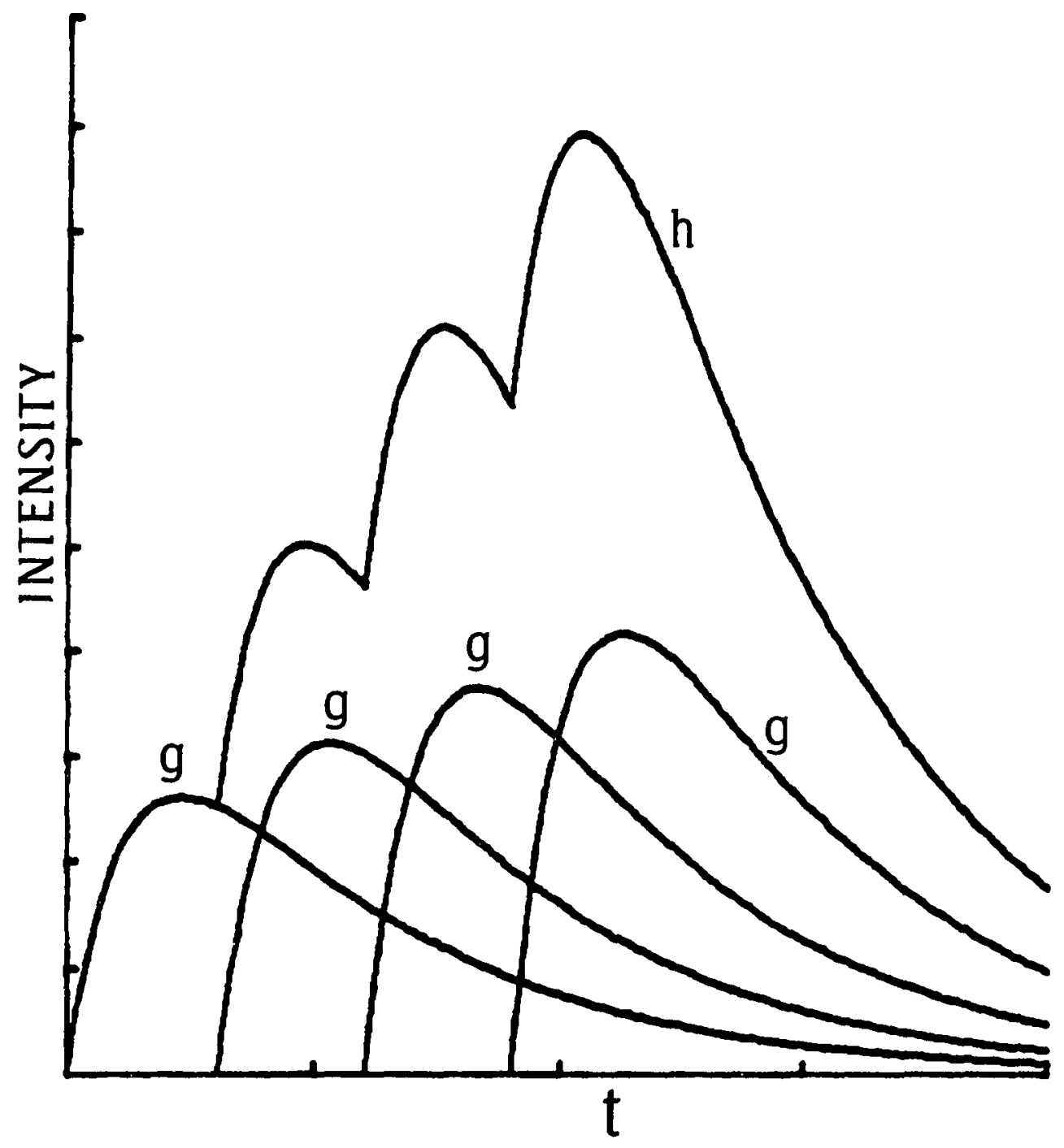

Figure 6 Derivation of the convolution - B. 
proportional to the concentration of the ground state $\mathrm{OH}$, $[\mathrm{OH}]$, and the laser intensity, $f(\tau)$, at time $\tau$. We define

$$
f(t)=I_{0} \in[O H] f^{\prime}(t)=c \cdot f^{\prime}(t) .
$$

Where $\epsilon$ is the absorption coefficient of $\mathrm{OH}$ radical and $I_{0} f^{\prime}(t)$ is the laser flux at time $t$. Essentially, $f(t)$ is the instantaneous production rate of $\left[\mathrm{OH}^{*}\right]$ in molecule $\mathrm{cc}^{-1} \mathrm{~s}^{-1}$. We call $f(t)$ the input function.

If we view the finite laser pulse as a succession of impulse functions spaced at intervals of $\tau$, then the output, $h(t)$, due to the impulse function at $\tau$ is

$$
h(t)=f(\tau) g(t-\tau) .
$$

24

After $t=2 \tau$, we have

$$
h(t)=f(\tau) g(t-\tau)+f(2 \tau) g(t-2 \tau) \text {. }
$$

Equation 25 has the $f(\tau) \cdot g(t-\tau)$ term, because after $2 \tau$, the output is the sum of the response due to the impulse function at $2 \tau$ and whatever remains from the previous response at $\tau$. If we proceed in this manner, we get

$$
h(t)=\sum_{n=0}^{N} f(n \tau) g(t-n \tau) .
$$

26

In the limit as the intervals between successive pulses 
approach zero, the summation can be replaced by an integration to become an exact solution:

$$
h(t)=\int_{0}^{t} f(\tau) g(t-\tau) d \tau .
$$

Equation 27 is the well known convolution integral. It says that the fluorescence decay one measures, at 309 nm, with a laser pulse of finite width is the convolution of the input function, $f(t)$, and the response function, $g(t)$. Of course, the response function contains all the relevant rate constants. Although equation 27 is the normal way of denoting convolution, equation 26 provides more insights when we are dealing with real discrete data with a digital computer.

\section{Deconvolution Method}

In the actual experimental procedure, $h(t)$ and $f(t)$ are measured by the time correlated photon counting technique, then $g(t)$ is extracted according to the relationship shown in equation 26 . It is no simple matter to solve for $g(t)$, although it has been worked out. Fortunately, the functional form of $g(t)$ is known in our case. We are more interested in the parameters $A$ and $B$ than the function $g(t)$ itself. Nevertheless, it is enlightening to see different ways of solving equation 27. General methods of resolving equation 27 are the method of moments $(34,35)$ and the methods of Fourier and 
Laplace transform(36). The method of moments requires that the impulse response function be a simple exponential function or a sum of exponential functions. Fourier and Laplace transforms are not constrained by such requirements.

The method of moments was first used in the study of radioactive decays. Isenberg and Dyson(37) and Schuyler and Isenberg(38) applied the method to multiexponential analysis. The general equations for the method of moments were derived by Bay(34). Suppose that $g(t)$ is a sum of $N$ exponentials,

$$
g(t)=\sum_{i=1}^{N} a_{i} \operatorname{Exp}\left(-k_{i} t\right) .
$$

The $k^{\text {th }}$ moments of $h(t)$ and $f(t)$ are defined by the equations:

$$
\begin{aligned}
& M_{k}(h)=\int_{0}^{\infty} t^{k} \cdot h(t) d t ; k=0,1, \ldots . \\
& M_{k}(f)=\int_{0}^{\infty} t^{k} f(t) d t ; k=0,1, \ldots .
\end{aligned}
$$

It can be shown that

$$
M_{k}(h)=k_{i} \sum_{s=1}^{k+1} \frac{G_{s} M_{k+1-s}(f)}{k+1-s} \text {, }
$$


where simplification

$$
G_{s}=\sum_{i=1}^{N} a_{i} / k_{i} s
$$

is made. These equations allow $a_{i}$ and $k i$ to be evaluated from the moments of the experimental data, namely $h(t)$ and $g(t)$, by constructing $2 \mathrm{~N}$ equations.

Laplace and Fourier transforms are very similar, so we group both together as integral transforms. We denote the integral transform of a function $I(t)$ as $I\{I(t)\}$. Then, based on the theorem of integral transform, if $h(t)$ is the convolution of $g(t)$ and $f(t)$, we have

$$
I\{h(t)\}=I\{g(t)\} \cdot I\{f(t)\} \text {. }
$$

The previous expression can be put in a more obvious form,

$$
I\{g(t)\}=\frac{I\{h(t)\}}{I\{f(t)\}} \text {. }
$$

Thus, one obtains the transformed form of the response function, $I\{g(t)\}$, by dividing the transformed forms of the experimental data, $I\{f(t)\}$ and $I\{h(t)\}$.

The advantage of Fourier transform is the Fast Fourier Transform (FFT) algorithm which saves a 
considerable amount of computer time.

In this case, the functional form of $g(t)$ is known. The interest is in the parameters $A$ and $B$. The method we will adopt is to use equation 26 directly. The equation will be summed for finite $\tau$ by a digital computer with $A$ and $B$ that give the lowest least squares errors to the data obtained. The trial and error search for optimum $A$ and $B$ is done using the method of simplex. Appendix $A$ contains details of the simplex method.

\section{A Simulation}

Simulation was the first step of checking the tenability of the theory before actual experimental work was begun. This kind of exercise provides information on what to expect in the actual experiments and predicts whether or not the results are practically observable. This section describes the simulation of the fluorescence decay of $\mathrm{OH}$ in nitrogen atmosphere using the published experimental values of rate constants. Table I shows the rate constants and their corresponding references.

For excitation of OH at the $v^{n}=0 \rightarrow v^{\prime}=1$ transtions and detection at $309 \mathrm{~nm}\left(v^{\prime}=0 \rightarrow v^{n}=0\right.$ transition) equation 27 becomes

$$
h(t)=\int_{0}^{t} f^{\prime}(\tau) \frac{a}{B-A}(\operatorname{ExP}[-A(t-\tau)]-\operatorname{ExP}[-B(t-\tau)]) d \tau,
$$


RATE CONSTANTS USED IN THE SIMULATION

Rate Constant
\[ \begin{array}{c}k_{F 1} \\ k_{F 0} \\ k_{Q 1} \\ k_{Q 0} \\ k_{10}\end{array} \]

Value
$1.10 \times 10^{6} \mathrm{sec}^{-1}$
$1.40 \times 10^{6} \mathrm{sec}^{-1}$
$0.765 \times 10^{-10} \mathrm{~cm}^{3} \mathrm{molecule} \mathrm{e}^{-1} \mathrm{sec}^{-1}$
$0.29 \times 10^{-10} \mathrm{~cm}^{3} \mathrm{molecule}^{-1} \mathrm{sec}^{-1}$
$1.61 \times 10^{-10} \mathrm{~cm}^{3} \mathrm{molecule} \mathrm{sec}^{-1}$

Reference

39

33

33

33

33 
30

where we define

$$
a=C K_{F O} K_{10} .
$$

32

$A$ and $B$ are the same as defined in equations 11 and 12 while $c$ is defined in equation 23. The laser profile (the input function) is simulated by

$$
f^{\prime}(t)=\alpha t^{2} \operatorname{Exp}(-\beta t)
$$

33

with

$$
\begin{array}{ll}
\alpha=1.18 \times 10^{18} \text { photon } / \mathrm{cm}^{3} \mathrm{~s}^{3} & 34 \\
\beta=8.0 \times 10^{8} \mathrm{~s}^{-1} & 35
\end{array}
$$

The term $\alpha$ is chosen to make $f(t)=1$ at its maximum. The $f(t)$ is plotted out in Figure 7. Its half-width is about 6 ns. The output, $h(t)$, according to equation 31 is

$$
h(t)=\int_{0}^{t} \alpha \tau^{2} \operatorname{Exp}(-\beta t) \frac{a}{B-A}[\operatorname{ExP}(-A)(t-c)
$$

$-\operatorname{Exp}(-B)(t-\tau)] d \tau$

36

or

$$
\begin{aligned}
h(t)= & \frac{\alpha Q}{B-A}\left[\operatorname{Exp}(-A t) \int_{0}^{t} \tau^{2} \operatorname{Exp}(A-\beta) \tau d \tau\right. \\
& \left.-\operatorname{Exp}(-B t) \int_{0}^{t} \tau^{2} \operatorname{Exp}(B-\beta) \tau d \tau\right] .
\end{aligned}
$$

37 


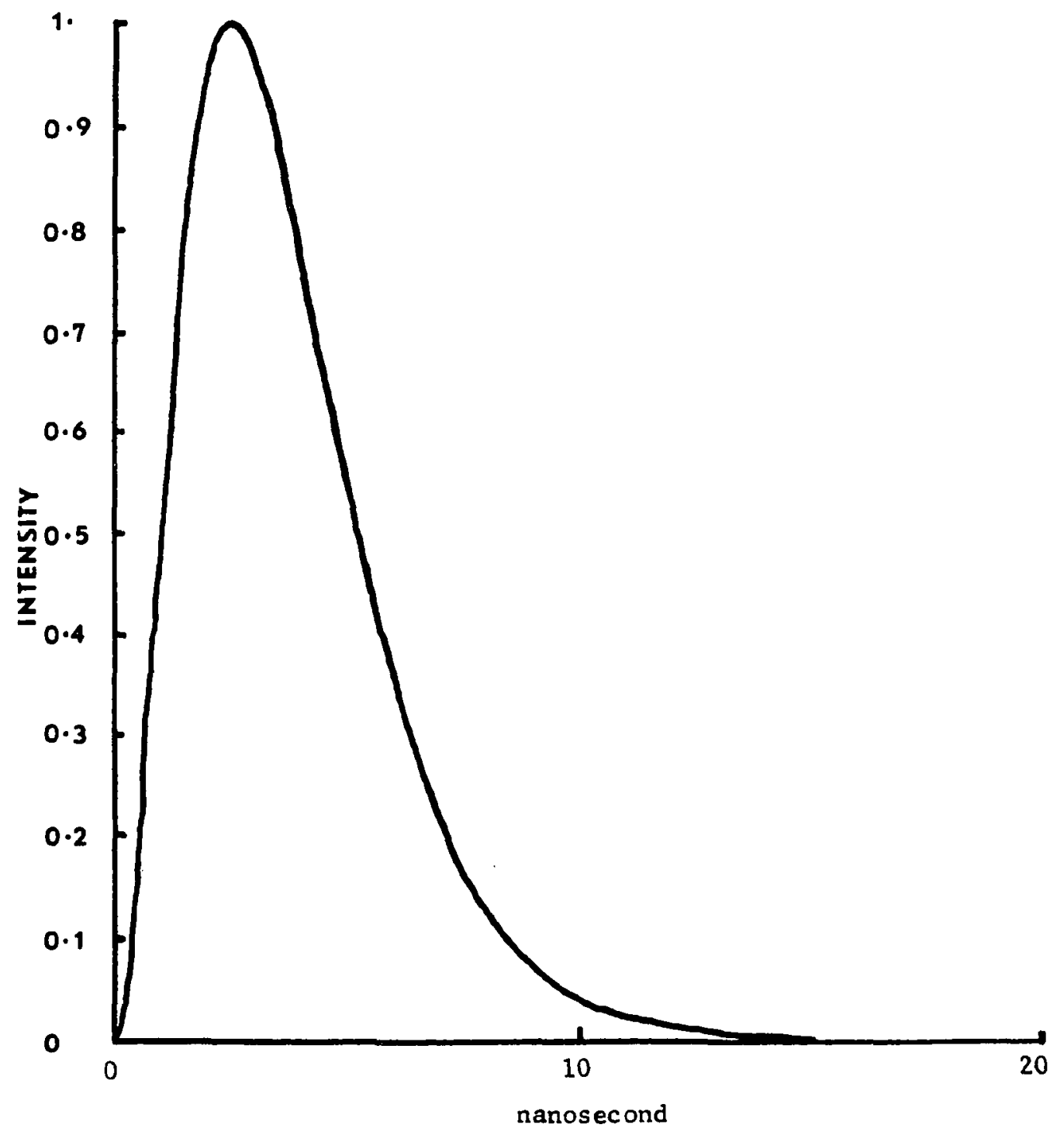

Figure 7 Input function, $f(t)$, for the simulation exercise. 
Integrating, we get

$$
\begin{aligned}
& P=\frac{\operatorname{ExP}(A-\beta) t}{A-\beta}\left(t^{2}-\frac{2 t}{A-\beta}+\frac{2}{(A-\beta)^{2}}\right)-\frac{2}{(A-\beta)^{3}}, 38 \\
& Q=\frac{\operatorname{ExP}(B-\beta) t}{B-\beta}\left(t^{2}-\frac{2 t}{B-\beta}+\frac{2}{(B-\beta)^{2}}\right)-\frac{2}{(B-\beta)^{3}}, 39 \\
& h(t)=\frac{a \alpha}{B-A}(P \operatorname{ExP}(-A t)-Q \operatorname{Exp}(-B t)) .40
\end{aligned}
$$

Under a pressure of one tor $x$, [M] is $3.32 \times 10^{16}$ molecules/cc. Using values in Table $I$, we get $A=8.99 \times 10^{6} \mathrm{sec}^{-1}$ and $B=2.36 \times 10^{6} \mathrm{sec}^{-1}$. Substituting $\alpha, \beta, A$ and $B$ into equations 38,39 and 40 and plotting out, one gets the graph shown in Figure 8. Figure 9 is a semilog plot of the same result. The slope in Figure 9 results from a linear least squares fit to the tail of the curve. It is equal to B! This indicates that when the decay time is long compared to the laser half-width, a simple exponential fit to the tail of the fluorescence curve will give $B$ as the slope. These two plots have the same general features of the data collected in reference 23. Thus the theory agrees with the experiment data obtained in reference 23 in general terms.

To investigate the feasibility of measuring fluorescence decay at one atmosphere, equations 38,39 and 


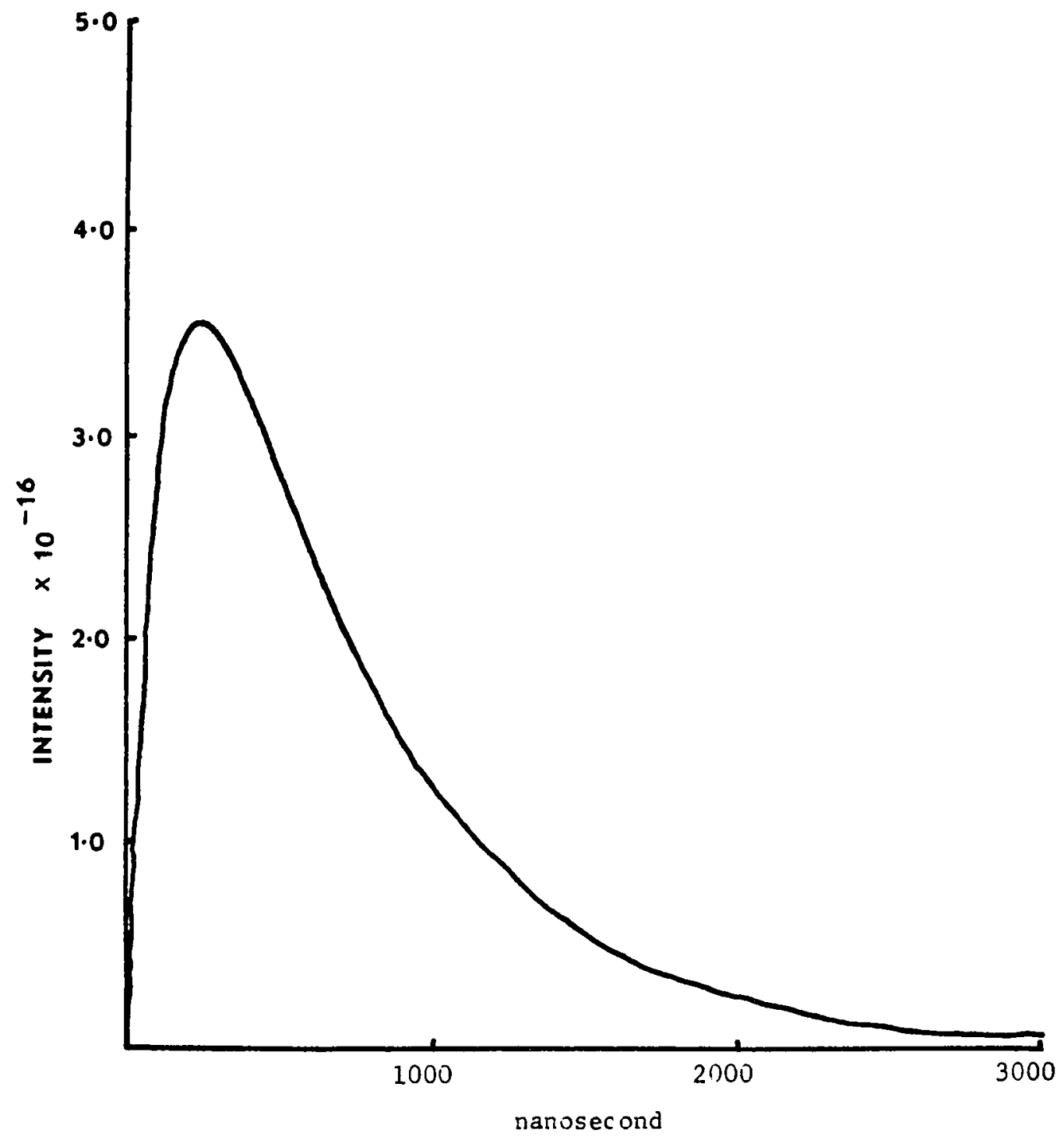

Figure 8 Simulated fluorescence - low pressure. 


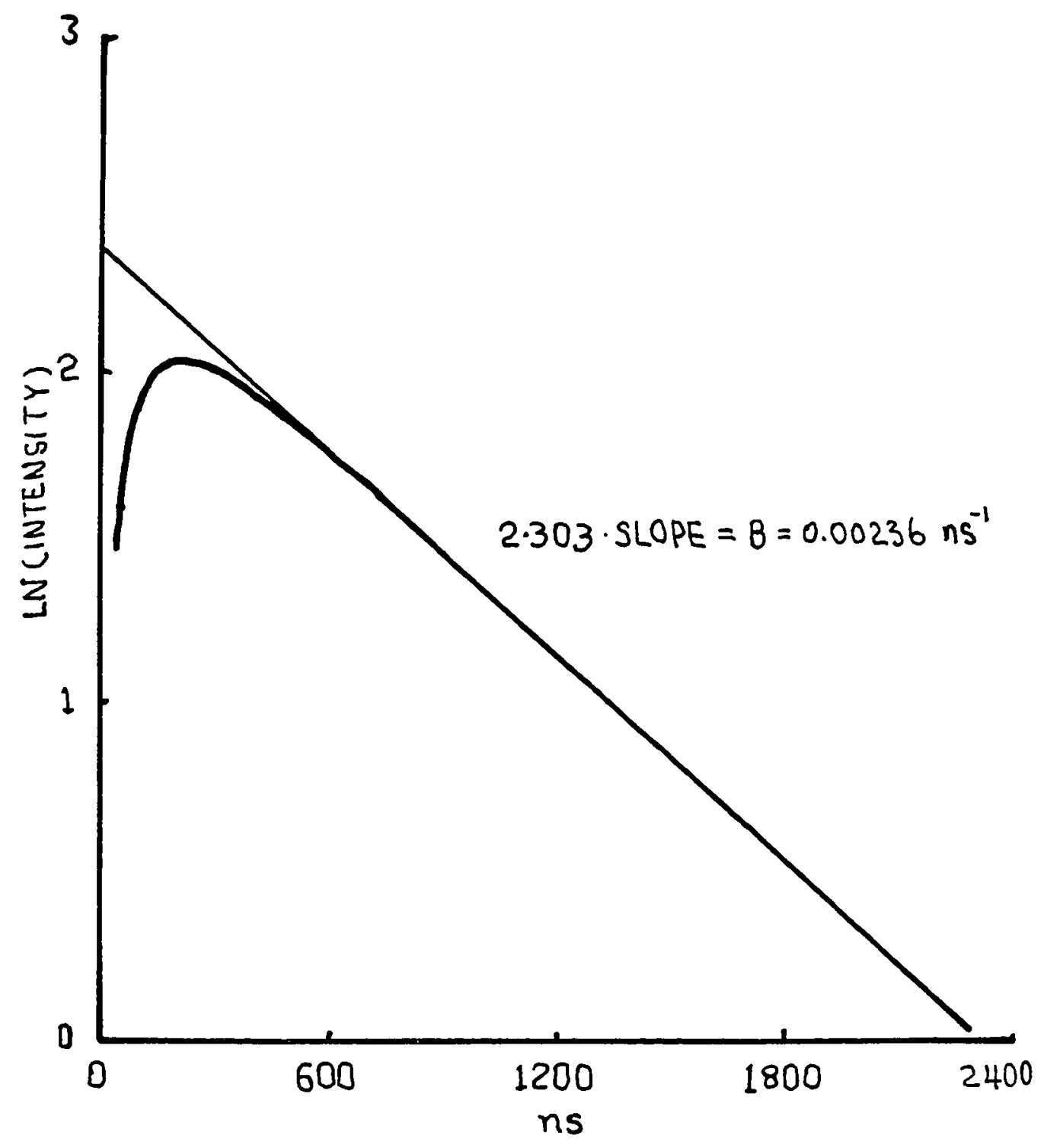

Figure 9 Semilog plot of simulated fluorescence at low pressure. 
40 are used again with $[M]=2.46 \times 10^{19}$ molecules/cc which manifests into $A=5.78 \times 10^{9}$ and $B=7.1 \times 10^{8} \mathrm{sec}^{-1}$. Substituting in $A, B, \alpha$ and $\beta$, one gets the plot shown in Figure 10. A similar linear least squares fit to the tail of the semilog plot gives a slope much smaller than $B$. This indicates that in high pressure fluorescence, convolution is required. For comparison purposes, the laser profile is plotted on the same graph. Notice that the output function is slightly broader and displaced a little to the right.

The convolution integral does not impose any limits on how large $A$ and $B$ can be. However, the noise in the actual data determines the practical limits. In general, the narrower the laser temporal half-width, the larger the $A$ and $B$ which can be resolved.

\section{Discrete Convolution}

Although the convolution integral, equation 27 , describes exactly what is going on, this equation has little practical value in our application because the mathematical form of the input function i.e. the laser profile is not known. On the other hand, the discrete form, equation 26 , is suitable for implementing on a digital computer. This equation only requires the input function be represented by a set of discrete values. This very same equation is translated into a computer algorithm (in BASIC) shown in Table II. To use this algorithm, the 


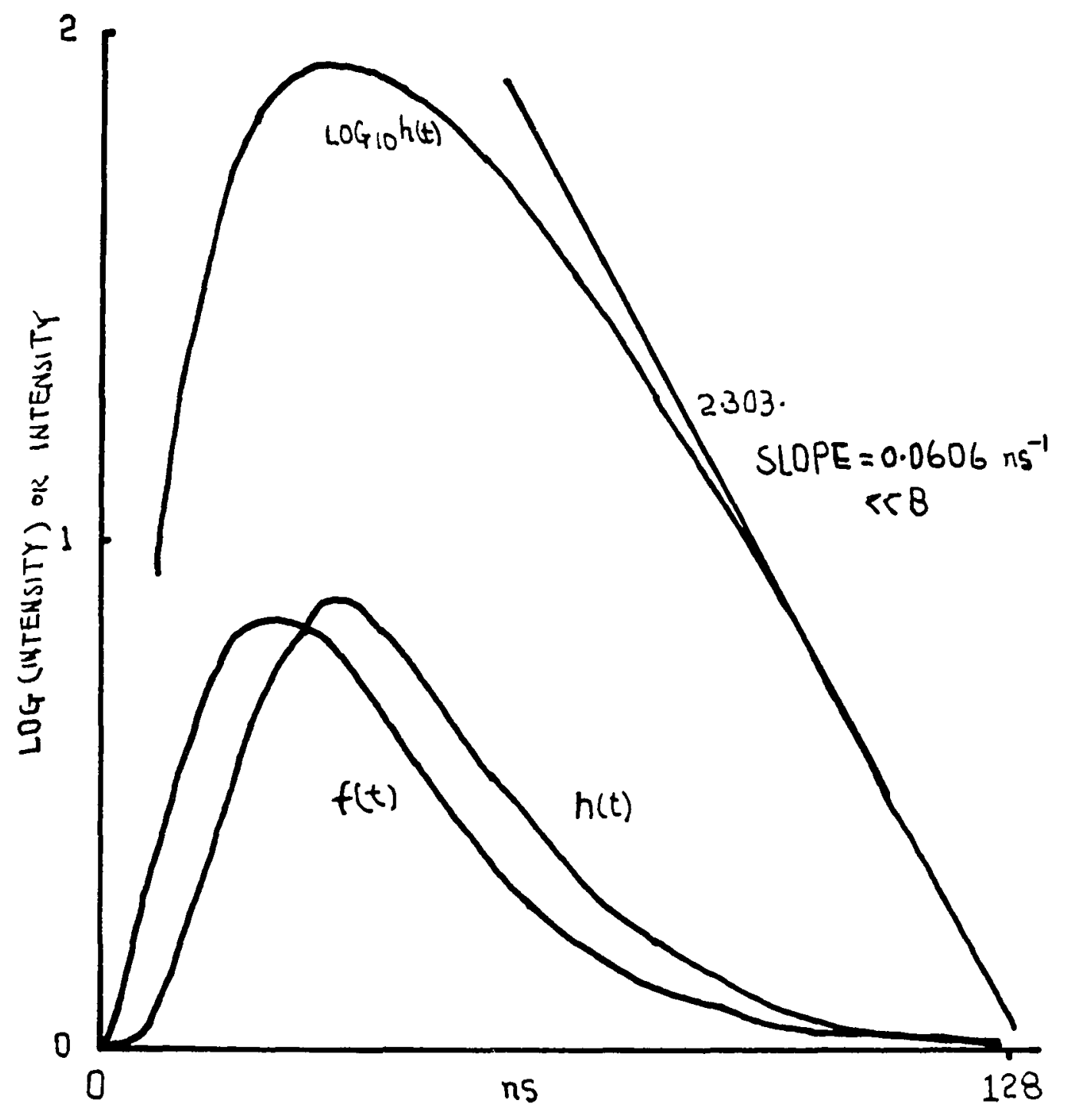

Figure 10 Simulated fluorescence - atmospheric pressure of nitrogen. 
TABLE II

DISCRETE CONVOLUTION ALGORITHM

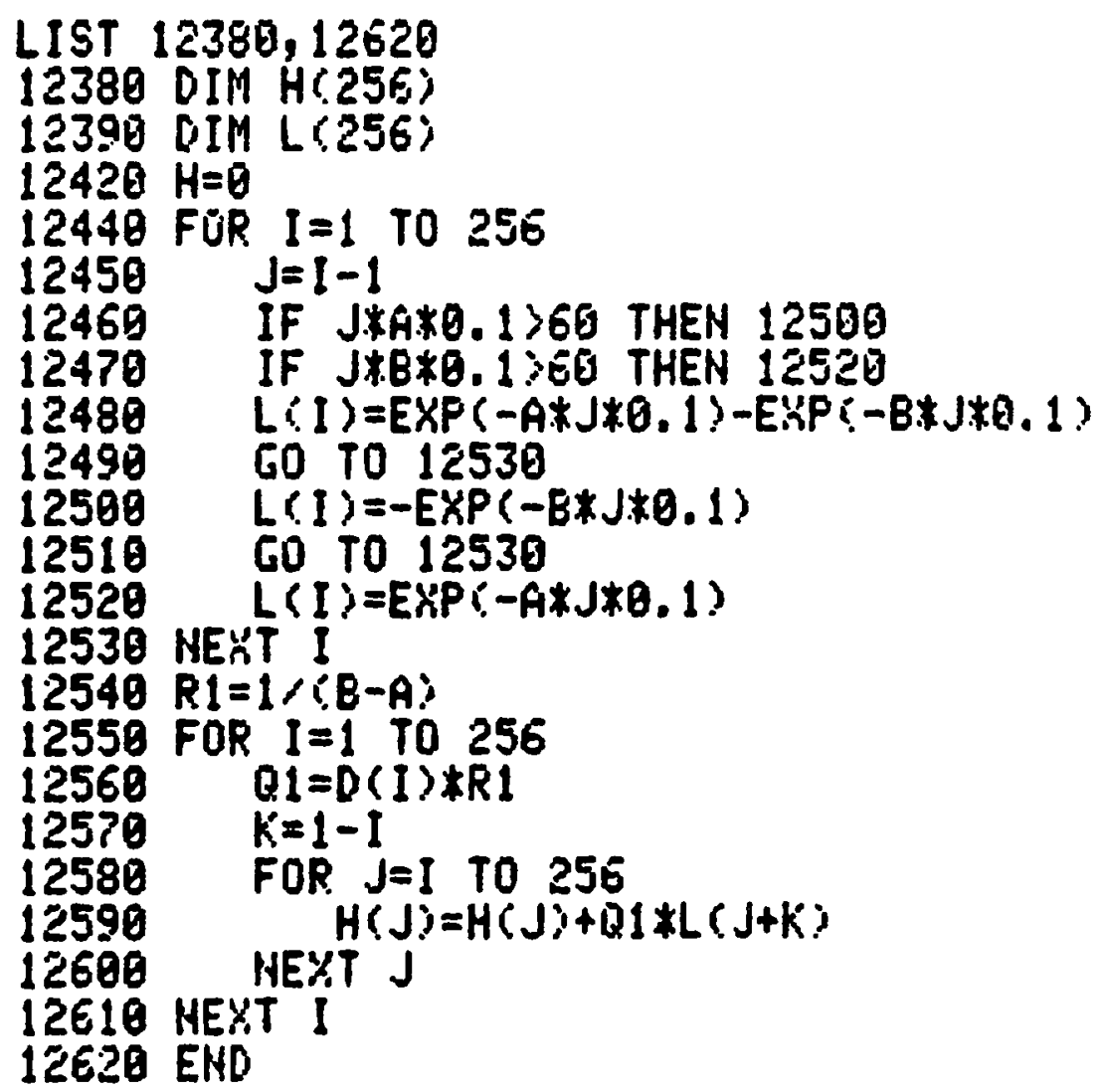


input function has to be stored in the one dimension array D. Matrix $L$ is a temporary storage and the resulting convolution is saved in array $H$. The time resolution is 0.1 ns and can be changed when required. Further discussion on the accuracy of equation 26 can be found in Chapter V.

\section{Miner Details}

So far, various rate constants have been lumped into two terms, namely $A$ and $B$. This section reviews what we can extract from them, so that we can plan the experiments accordingly.

The composition of $A$ and $B$ depends on the constituents of the gaseous medium which in turn is prepared according to the desired rate constants in which we are interested. Two cases are considered. The natural decay rates ( $\mathrm{k}_{\mathrm{FO}}\left[\mathrm{OH}^{* *}\right]$ and $\mathrm{k}_{\mathrm{Fl}}\left[\mathrm{OH}^{*}\right]$ ) are dropped out of our expressions, because fluorescence is very slow compared to the the quenching rates.

A. Argon and Water

When the medium consists of argon and water only, the term $A$ is

$$
A=K_{Q 1 H_{2}} \mathrm{O}\left[\mathrm{H}_{2} \mathrm{O}\right]+K_{1 \mathrm{OH}_{2}}\left[\mathrm{H}_{2} \mathrm{O}\right]+K_{\mathrm{QIA}_{2}}\left[\mathrm{Al}_{1}\right]+\mathrm{K}_{1 \mathrm{OAr}}\left[\mathrm{Al}_{2}\right] . \quad 41
$$

If we differentiate $A$ with respect to $\left[\mathrm{H}_{2} \mathrm{O}\right]$, we have 


$$
\frac{d A}{d\left[H_{2} \mathrm{O}\right]}=K_{Q 1 H_{2} O}+K_{10 H_{2}} \mathrm{O} .
$$

The term $B$ is

$$
B=K_{Q O H_{2} \mathrm{O}}\left[\mathrm{H}_{2} \mathrm{O}\right]+K_{Q D A r}[A r] \text {. }
$$

Differentiating, we get

$$
\frac{d B}{d\left[\mathrm{H}_{2} \mathrm{O}\right]}=\mathrm{K}_{\mathrm{QOH}} \mathrm{O} .
$$

In other words, if we measure $A$ and $B$ at various water concentrations, plots of A and B versus water concentration result in straight lines. These straight lines have their slopes equal to $\mathrm{K}_{10 \mathrm{H}_{2} \mathrm{O}}+\mathrm{K}_{\mathrm{QlH}} \mathrm{O}$ for $\mathrm{A}$ and $\mathrm{K}_{Q \mathrm{OH}} \mathrm{O}$ for $\mathrm{B}$. The intercepts

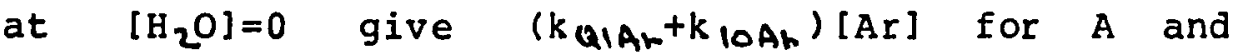
$k$ QOAr[Ar] for B.

B. Nitrogen, Oxygen and Water

Water is not of interest in this case. Its presence is needed only to produce a small number of OH radicals. The water concentration will be kept as low as possible. The term $A$ is

$$
\begin{aligned}
& A=K_{\mathrm{QIH}_{2} \mathrm{O}}\left[\mathrm{H}_{2} \mathrm{O}\right]+K_{1 \mathrm{OH}_{2}}-\left[\mathrm{H}_{2} \mathrm{O}\right]+\mathrm{KQIN}_{2}\left[\mathrm{~N}_{2}\right]+K_{1 \mathrm{ON}}\left[\mathrm{N}_{2}\right] \\
& +\mathrm{KaIO}_{2}\left[\mathrm{O}_{2}\right]+\mathrm{K}_{10 \mathrm{O}_{2}}\left[\mathrm{O}_{2}\right] \text {. }
\end{aligned}
$$


When $A$ is differentiated with respect to $\left[\mathrm{O}_{2}\right]$, we get

$$
\frac{d A}{d\left[\mathrm{O}_{2}\right]}=K_{Q 1 O_{2}}+K_{10 O_{2}} .
$$

46

The term $B$ is

$$
B=\mathrm{KQOO}_{2}\left[\mathrm{O}_{2}\right]+\mathrm{KQOH}_{2} \mathrm{O}\left[\mathrm{H}_{2} \mathrm{O}\right]+\mathrm{KQON}_{2}\left[\mathrm{~N}_{2}\right] \quad 47
$$

and when it is differentiated with respect to $\left[\mathrm{O}_{2}\right]$, we have

$$
\frac{d B}{d\left[\mathrm{O}_{2}\right]}=\mathrm{K}_{\mathrm{QOO}}
$$

48

Therefore, when $A$ and $B$ are measured at various oxygen concentrations, plots of $A$ and $B$ against the concentration of oxygen will result in straight lines with slopes equal to $\mathrm{KQ}_{\mathrm{O} O}+\mathrm{k} 10 \mathrm{O}_{2}$ for $A$ and $\mathrm{K}_{\mathrm{QOO}}$ for $\mathrm{B}$. The intercept at zero $\left[\mathrm{O}_{2}\right]$ for $\mathrm{A}$ is equal to

$$
\mathrm{KQIH}_{2}\left[\mathrm{H}_{2} \mathrm{O}\right]+\mathrm{K}_{\mathrm{OOH}_{2}}\left[\mathrm{H}_{2}\right]+\mathrm{KaIN}_{2}\left[\mathrm{~N}_{2}\right]+\mathrm{K}_{\mathrm{ION}_{2}}\left[\mathrm{~N}_{2}\right]
$$

and $B$ is equal to

$$
\mathrm{KaOH}_{2} \mathrm{O}\left[\mathrm{H}_{2} \mathrm{O}\right]+\mathrm{KaOH}_{2}\left[\mathrm{~N}_{2}\right] \text {. }
$$


of the laser profile and the fluorescence profile. The laser profile will be approximated by either the nitrogen Raman scattering at $302 \mathrm{~nm}$ or the Rayleigh scattering at $282 \mathrm{~nm}$. The fluorescence will be obtained at $309 \mathrm{~nm}$. For all the measurements, photoelectron arrival rate will be maintained around 0.05 per laser pulse whenever the signal is strong enough.

The ideal way to carry out the experiments is to alternate the measurements between the laser profile and the fluorescence profile to minimize the effect of drifting of the detection system. In reality, practical experimental difficuties necessitate measurement of the laser profile at the beginning and the end of an experiment. As many laser profiles as possible will be measured between fluorescence measurements. Then the sum of all these measured laser profiles will be considered as the input function.

Finally, since the theory assumes that the system is linear, we have to avoid saturation. Thus, the laser power will be kept low and the laser beam diameter will be made correspondingly large. 


\section{CHAPTER III}

\section{EXPERIMENTAL}

The experimental setup is illustrated in Figures 11 and 12 . OH radicals were generated by $185 \mathrm{~nm}$ photolysis of water by two mercury lamps at atmospheric pressure in the fluorescence cell. The laser beam was directed across the center of the OH cell. The 6 ns half-width laser pulses at $282 \mathrm{~nm}$ were obtained from a frequency-doubled Rh6G dye laser pumped by a frequency doubled Nd-YAG laser. The 282 $\mathrm{nm}$ pulses had an energy of about $0.1 \mathrm{~mJ}$ and a spectral FWHM of about $0.5 \mathrm{~cm}^{-1}$. Fluorescence in the detection zone was collected by a silica lens and unwanted Rayleigh and Raman scattering were filtered by a cellulose triacetate film and a $2.8 \mathrm{~nm}$ bandpass $1 / 4-\mathrm{m}$ monochromator.

The fluorescence signal was detected by a RCA 8575 photomultiplier attached to an ORTEC 270 constant fraction discriminator adjusted according to the specifications in the manufacturer's manual. The discriminator output was passed to the stop input of a LeCroy QVT3001 MCA used in the time mode. The start pulse was generated by a reverse-biased photodiode (Motorola MRD 500) looking at a portion of the undoubled $564 \mathrm{~nm}$ ouput of the frequency-doubling crystal and delayed for about 40 ns to compensate for the transit time of the PMT and the 


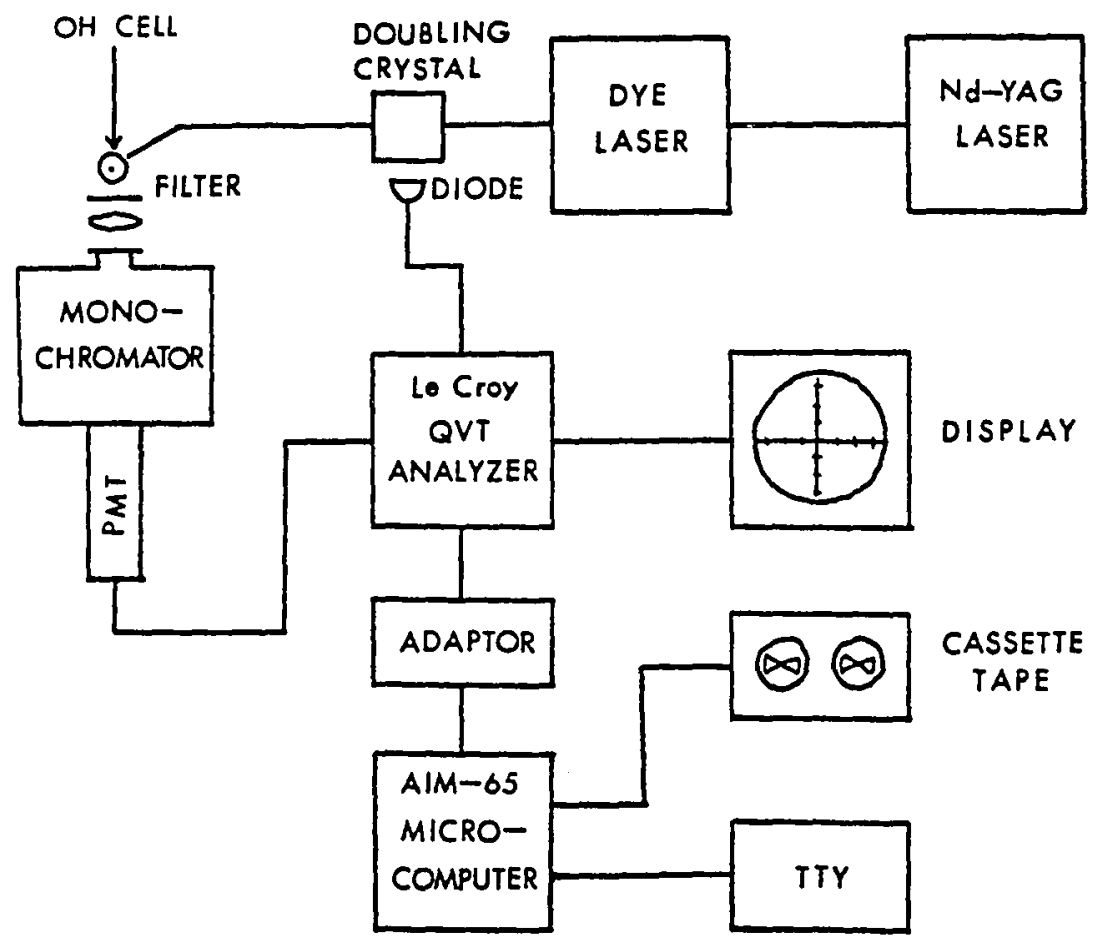

Figure 11 Schematics of experimental setup. 


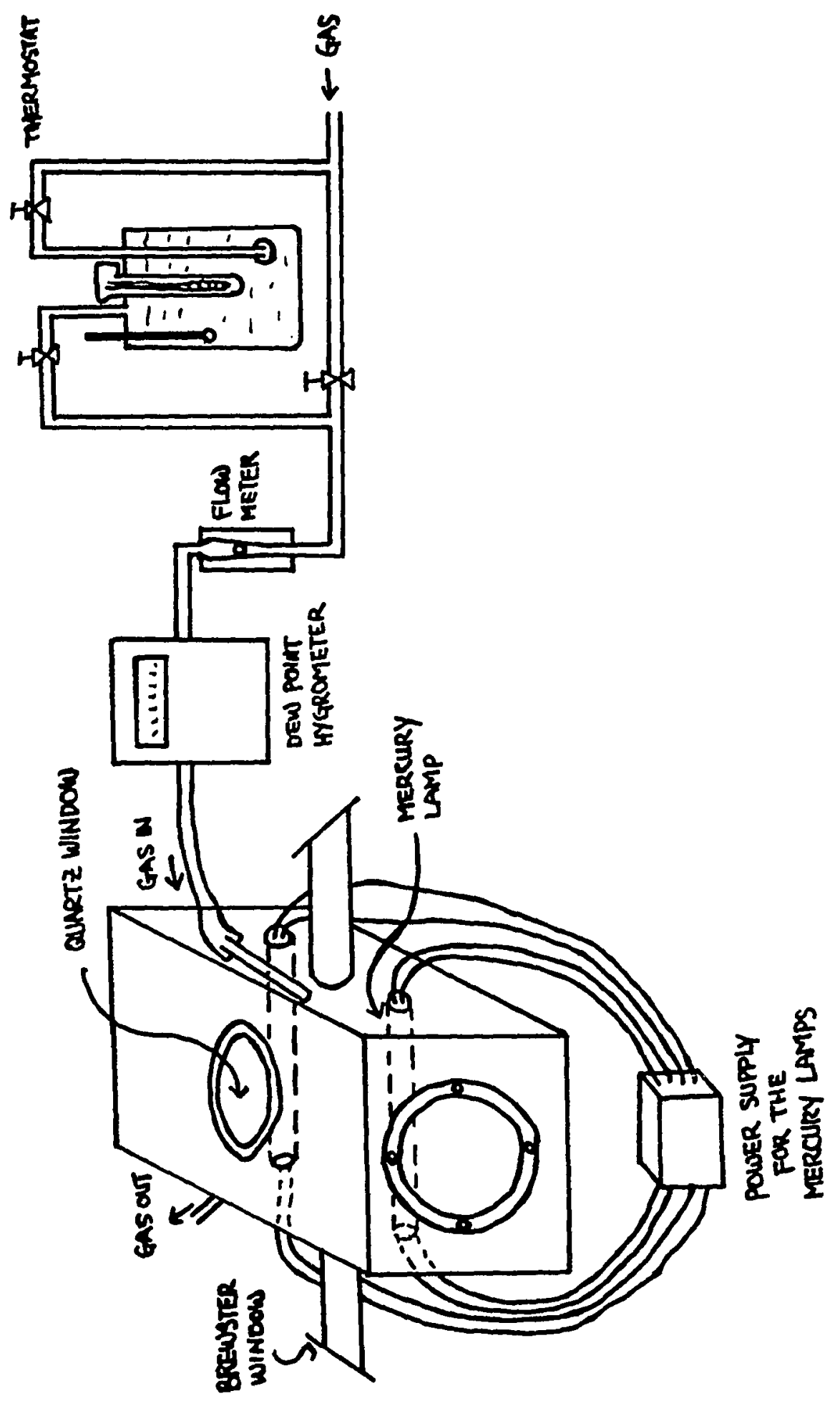


discriminator. The number of laser pulses fired since the beginning of the experiment was obtained by adding the no-event channel of the MCA and the total number of counts stored. This total number of cycles was used for Coates correction at the end of an experiment. The result recorded by the MCA could be displayed on an oscilloscope or read out, on command, into a Rockwell AIM-65 microcomputer through a home-made interface adaptor. The final result was stored on cassette tape and analyzed either on a Tektronix 4051 desk-top graphic microcomputer or on the Honeywell $66 / 40$ computer. The resolution of the MCA was set to 0.1 ns per channel or 0.4 ns per channel depending on the fluorescence decay rate.

The $\mathrm{OH}$ fluorescence cell was made of aluminum and both the inside and outside surfaces were black anodized. Openings, sealed off by removable lids, were made so that the inside could be reached for optical alignments. The cell was capable of being evacuated. To reduce the background from the two mercury lamps, both lamps were masked-off, leaving only two slots parallel to the detection zone exposed. The volume of the cell was about one liter. All the inside surfaces were roughened to reduce reflections of light.

Tygon tubing was used to deliver gas into the cell. The water content of the gas was monitored before it entered the cell by either a EG\&G 911 Dew-All or General 
Eastern 1100DP dew point hygrometer. Gas flow rate was maintained at about $200 \mathrm{cc}$ per minute to prevent contaminants from building up and to cool the contents of the cell. The lowest dew point which could be reached was between $-14.5 \mathrm{C}$ and $-18.0 \mathrm{C}$ and was dependent upon the room temperature and the purity of the gas source.

Signal attenuation was achieved by putting masks with various size holes in front of the quartz window. The cellulose triacetate film was moved from the entrance slit to the exit slit of the monochromator during the later experiments, to reduce the fluorescence of the acetate film induced by the light from the mercury lamps.

Further technical details on the electronics of the instruments which were designed and built in the laboratory can be found in appendices $B$ and $C$.

Some remarks on the practical side of the experiments are in order. The most distressing of all the problems encountered was that the computing time for evaluating equation 26 was tremendous. It took over 20 minutes to do one caluation of equation 26 by a Tektronix 4051 desk-top microcomputer. Each simplex search required evaluating equation 26 several hundred times. This long computing time made it impractical to do the computation on a small computer. The Honeywell $66 / 40$ could handle the job fairly well but computer time was costly, about 100 dollars per simplex analysis. 
The photon counting technique entailed a low arrival rate. This required many laser shots. Adding to the problem, the laser pulsed at 6 shots per second. Thus it took a very long time to complete one curve. The arrival rate was kept around 0.05 per laser pulse. In general, each gas mixture required from 40 to 80 hours of experimental time.

In some experiments, a background persisted when the lasex was tuned off resonance. This compounded the problem, for it required extra experiments to characterize the background in order to subtract the background from the fluorescence curves.

At first, the background was due to stray light at $282 \mathrm{~nm}$ sneaking through the monochromator. This problem was corrected with the cellulose triacetate film. Then another problem crept up after the dye oscillator was modified from a grating to a mirror. The new background had a certain long decay time. This again compounded the problem of lengthy experimental time.

The laser itself was a huge and complex system. Components had limited operational life-time, so down times were inevitable after continuous operation. In conclusion, these experiements were not as easy as they looked! 
CHAPTER IV

RESULTS

\section{Data and Comments}

The experimental results of $\mathrm{OH}$ fluorescence in both the argon plus water and the nitrogen/oxygen/water cases are summarized in Figures 13 to 22 . Each graph represents the cumulative data collected for one gas mixture. The data are corrected according to the Coates algorithm and smoothed by a five point running average. The laser profiles are shown in Figures 13 and 14 to illustrate the drastic difference between the laser and the fluorescence curves. The solid lines are the least squares fits of equation 26 to the data found via the simplex method.

Tables III to XI summarize the experimental results. The $A, B$ and $C$ in the Tables are the results of the simplex searches. The error column in the Tables are calculated according to the definition:

$$
\sigma=\frac{1}{N} \sqrt{\sum_{i=1}^{N} \frac{\left(f(i)-f_{c}(i)\right)^{2}}{f_{c}(i)}}
$$

Where $f(i)$ is the datum and $f_{c}(i)$ is the calculated value of the least squares fit.

The unweighed least squares fits are the results of a three parameter search. The third parameter, besides A 


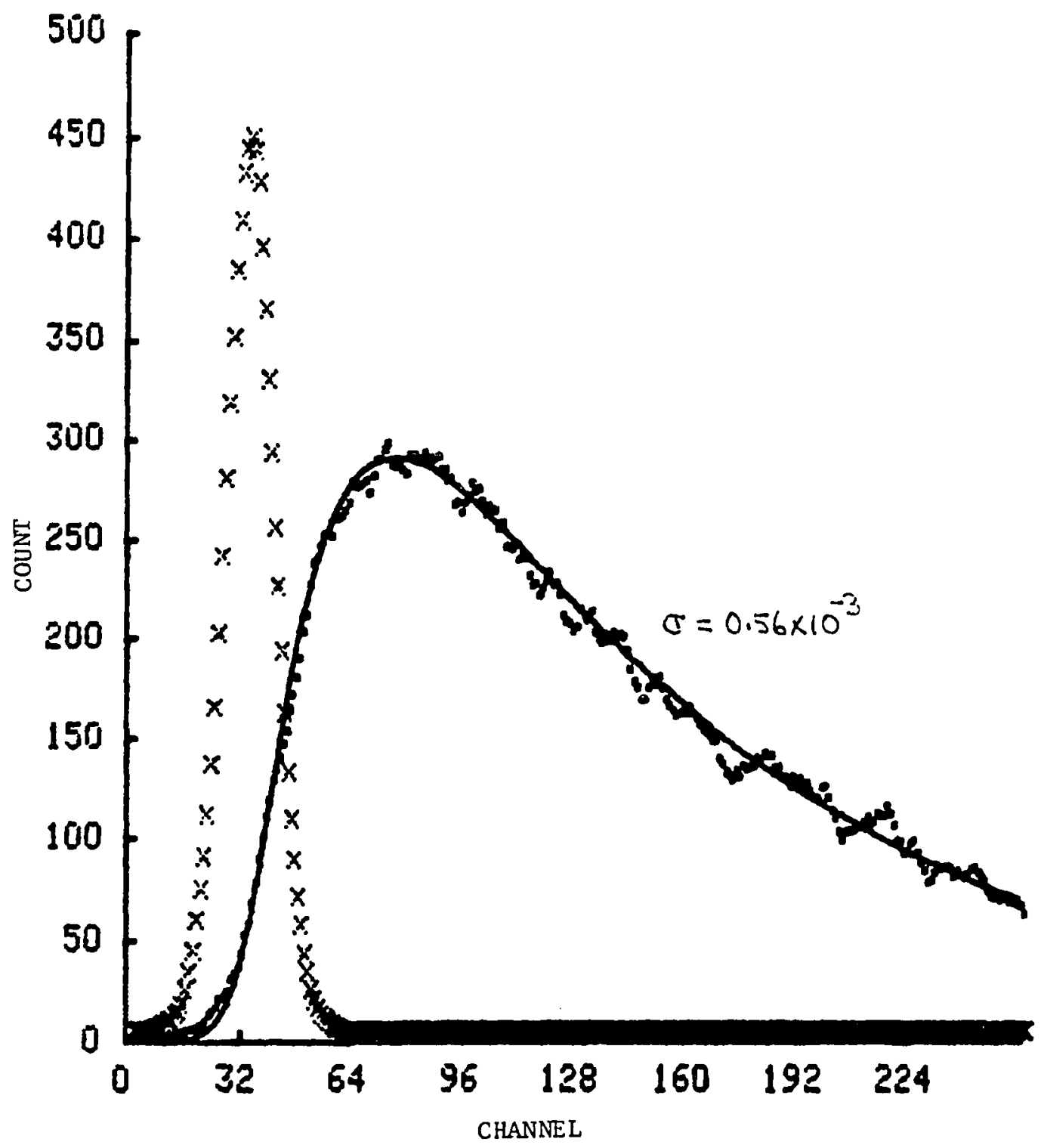

Figure 13 Fluorescence decay of $\mathrm{OH}$ in argon plus water (D.P. $-16.0 C$ ): $x$-laser profile; -fluorescence; solid line-least squares fit. Time scale is 0.4 ns per channel. 


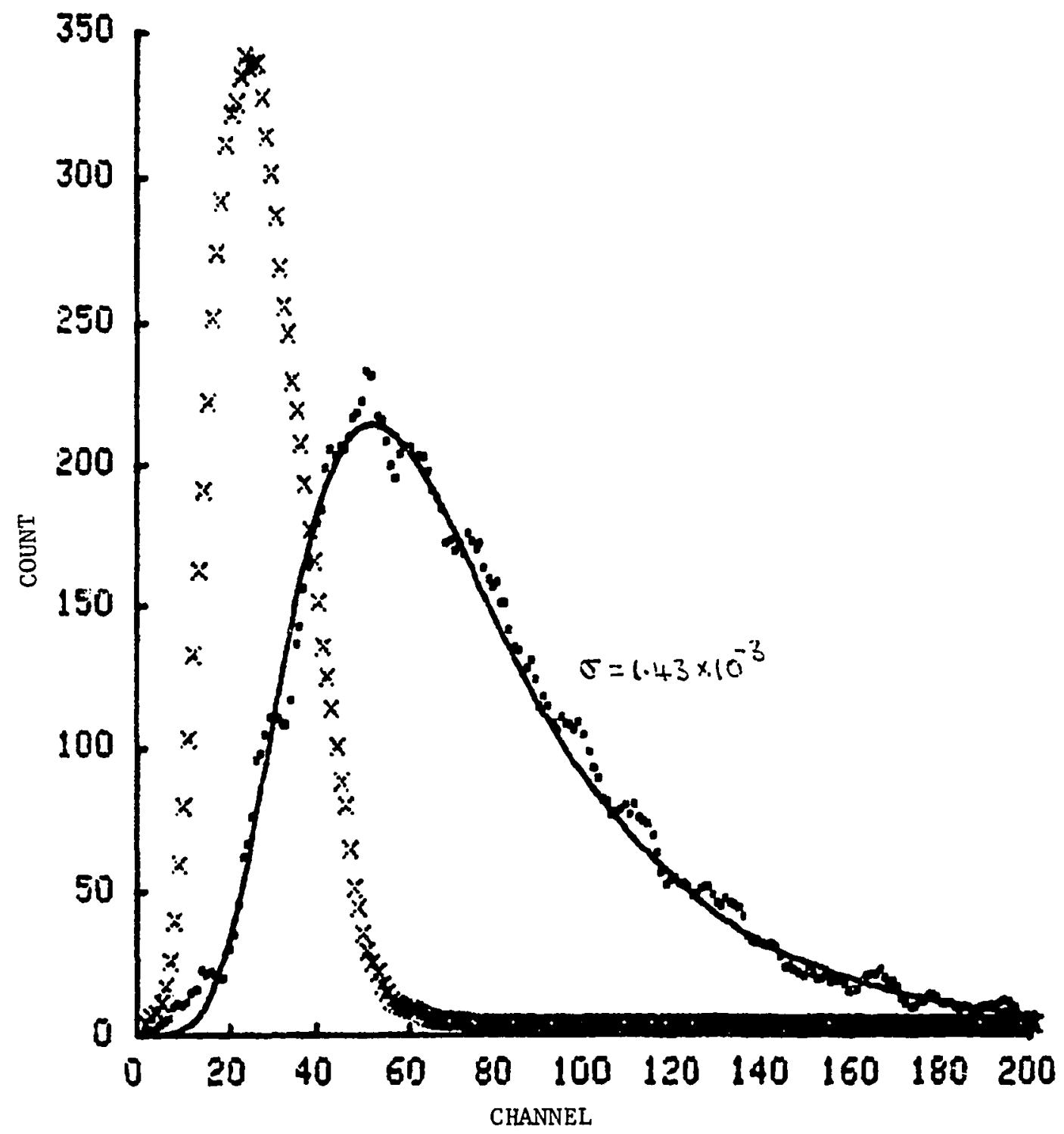

Figure 14 Fluorescence decay of $O H$ in argon plus water (D.P. -7.OC): $x$-laser profile; -fluorescence; solid line-least squares fit. Time scale is 0.4 ns per channel. 


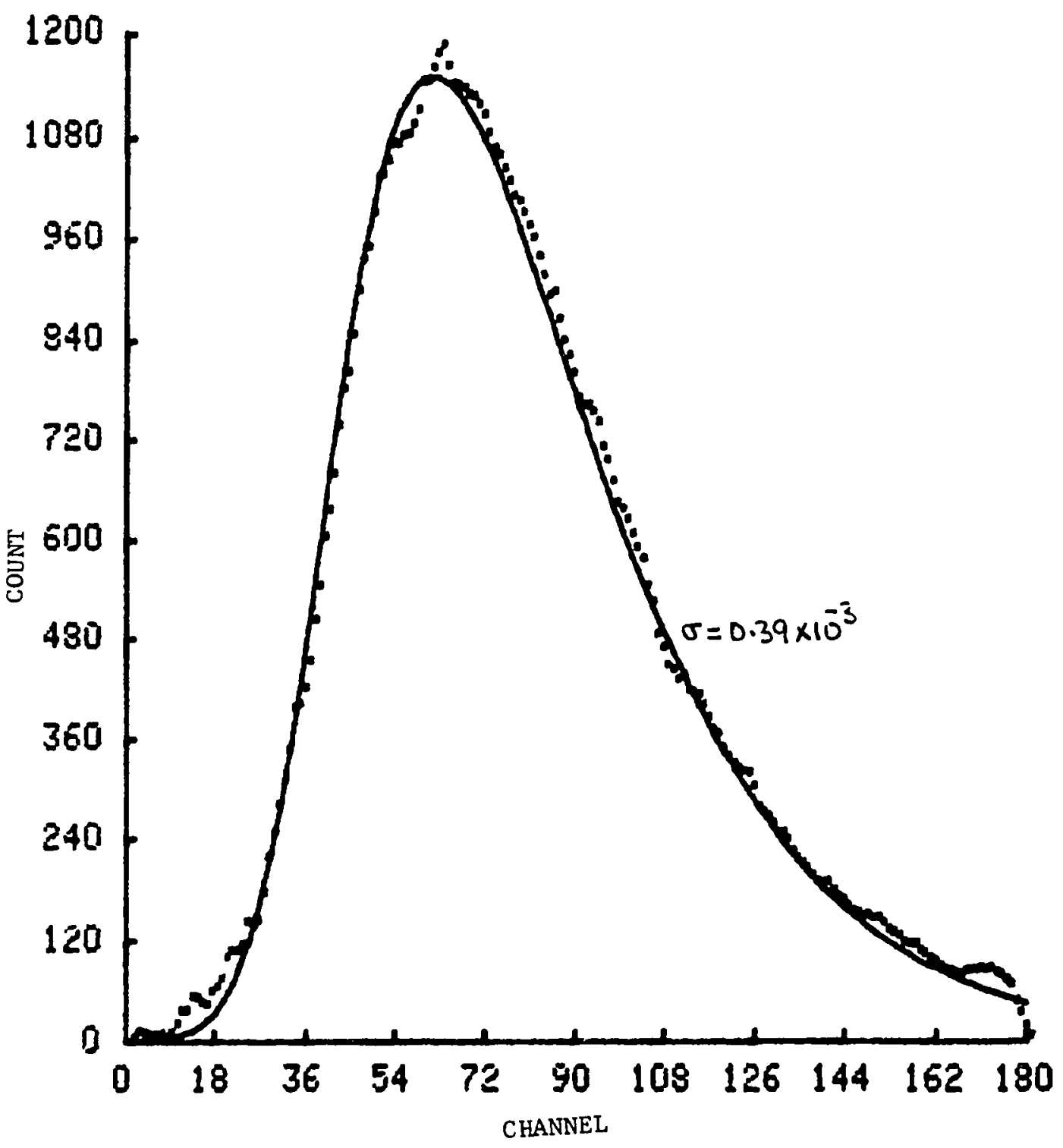

Figure 15 Fluorescence decay of $\mathrm{OH}$ in argon plus water (D.P. 4.0C). Laser profile is not shown. Time scale is 0.2 ns per channel. 


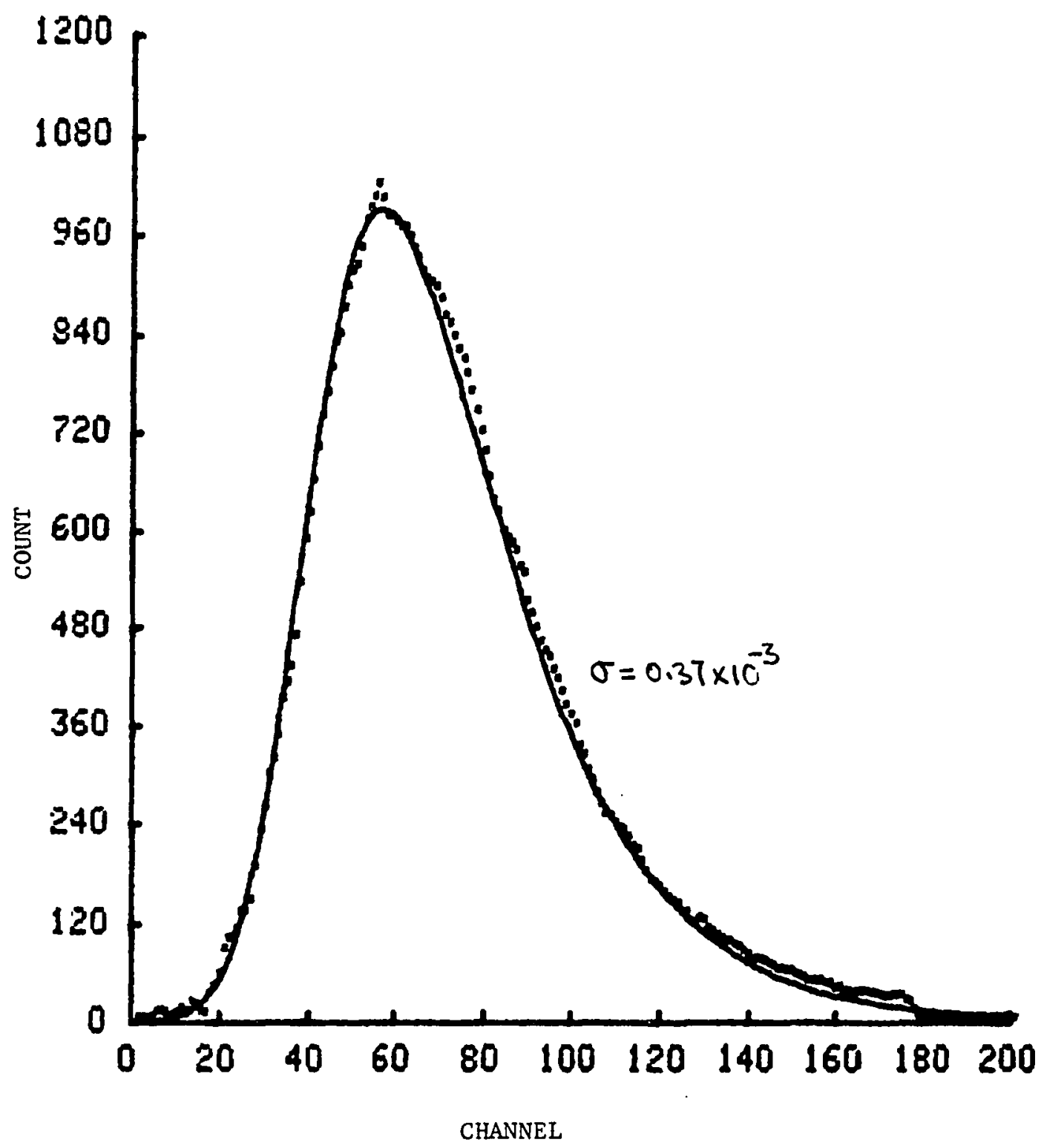

Figure 16 Fluorescence decay of $\mathrm{OH}$ in argon plus water (D.P. 9.0C). Time scale is 0.2 ns per channel. 


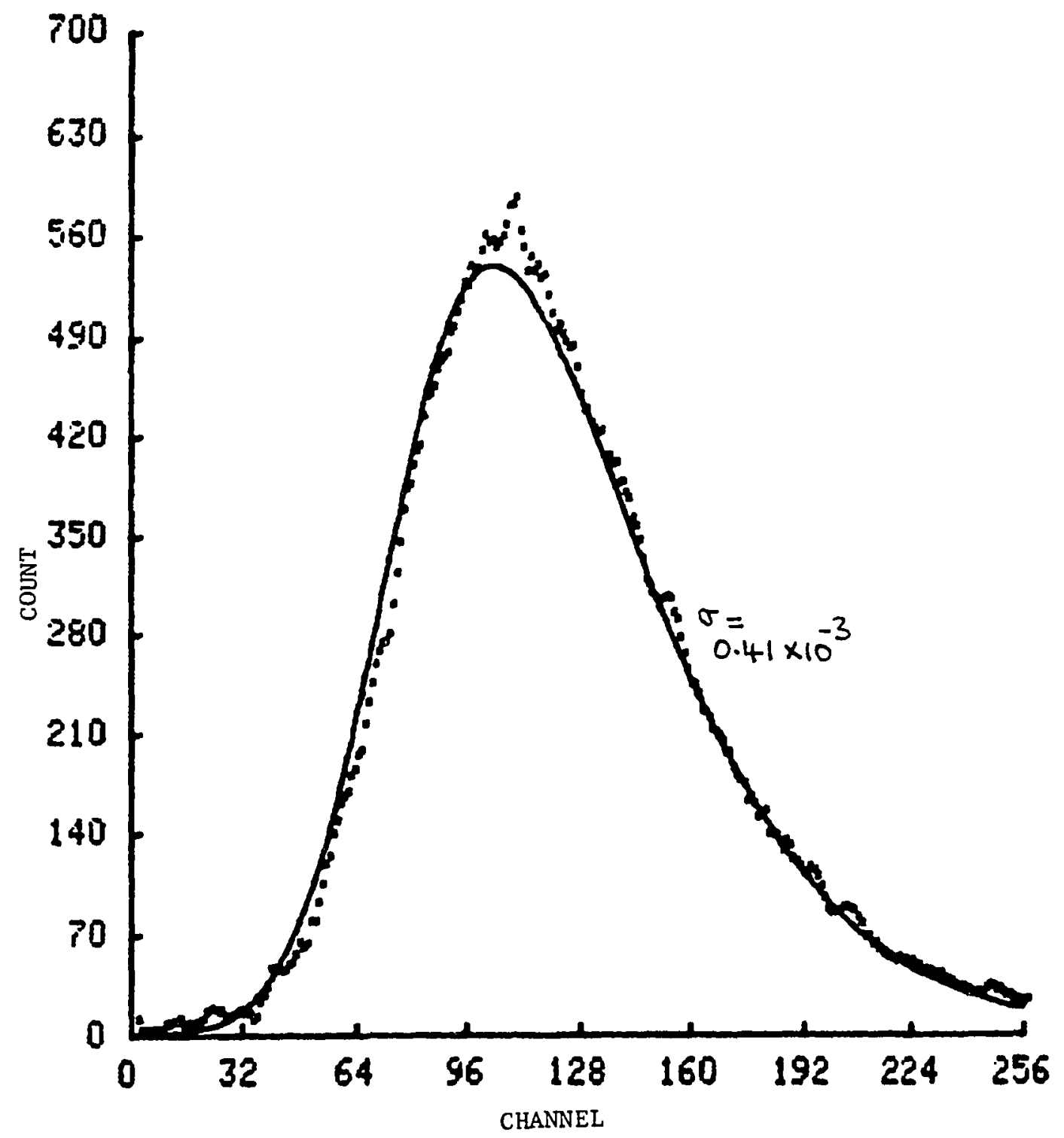

Figure 17 Fluorescence decay of oH in argon plus water
(D.P. 16.0C). Time scale is 0.1 ns per channel. 


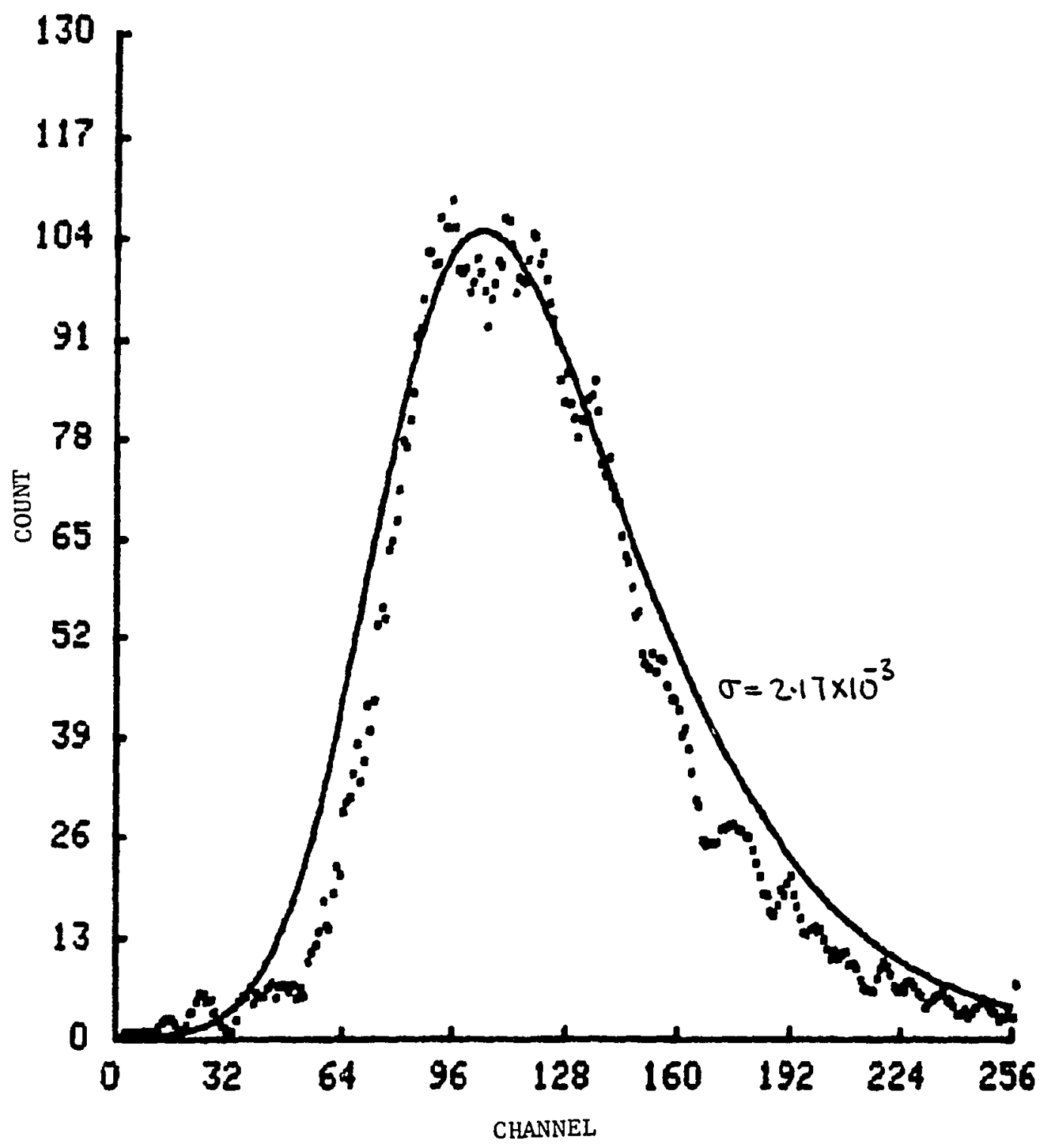

Figure 18 Fluorescence decay of $\mathrm{OH}$ in argon plus water (D.P. 19.0C). Time scale is 0.1 ns per channel. It is a bad result; see text for discussion. 


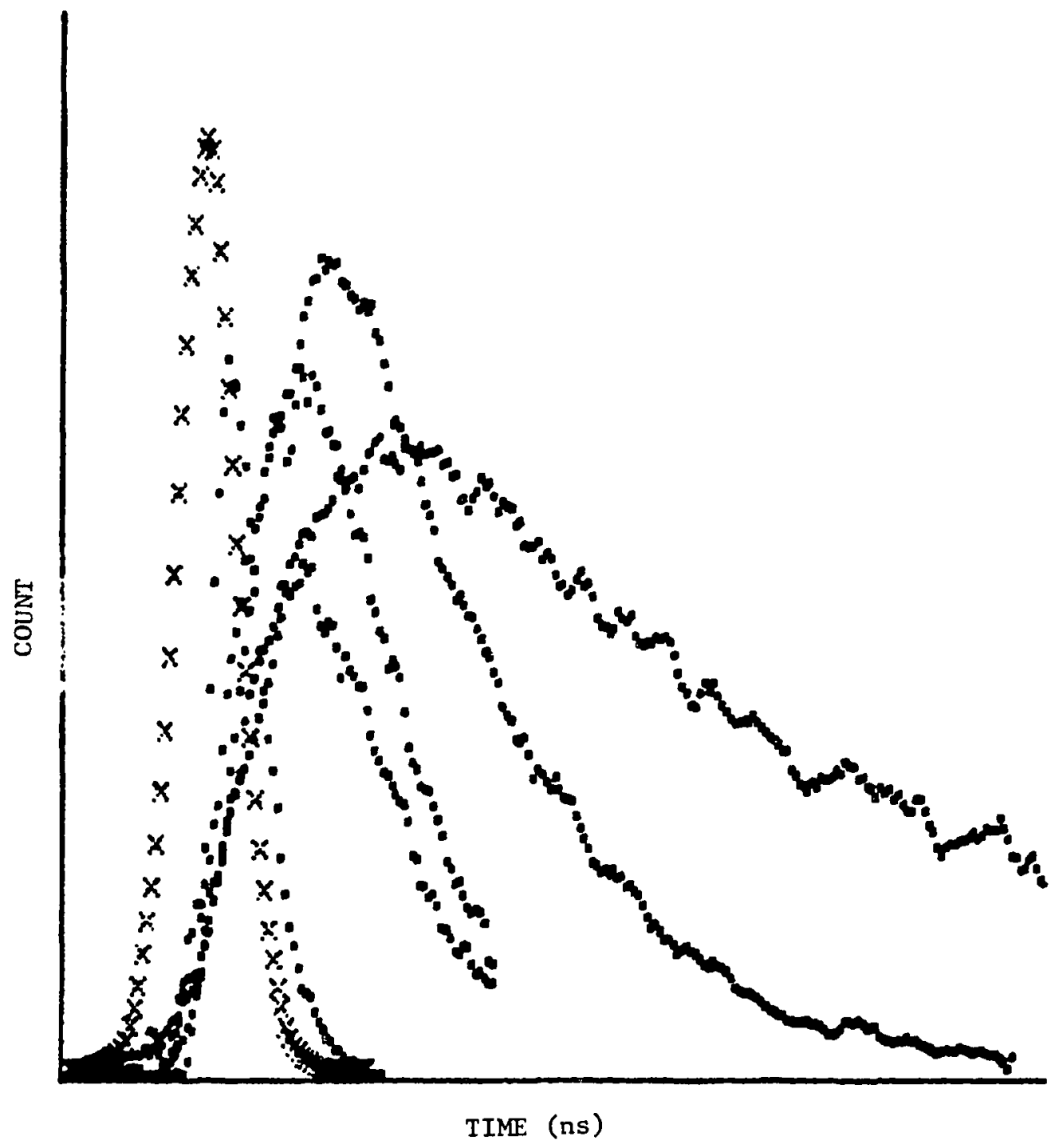

Figure 19 Fluorescence decays of $\mathrm{OH}$ in argon plus water - fluorescence at different water concentrations. $x$ - laser profile. The graph shows the drastic difference in the decay curves due to the change in water concentration. 


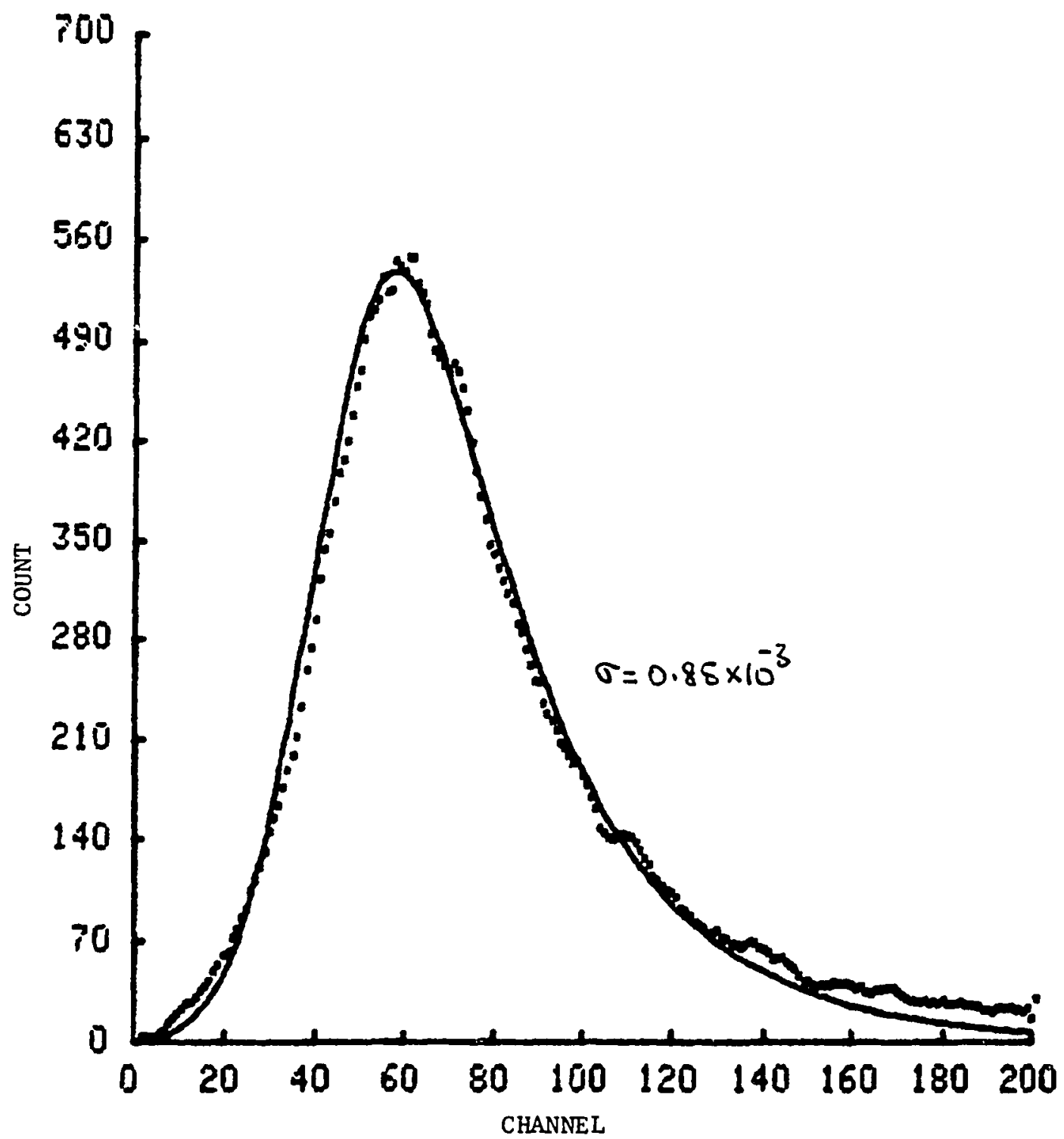

Figure 20 Fluorescence decay of $\mathrm{OH}$ in nitrogen (D.P. $-16.0 \mathrm{C}$ ). Time scale is $0.2 \mathrm{~ns}$ per channel. 
57

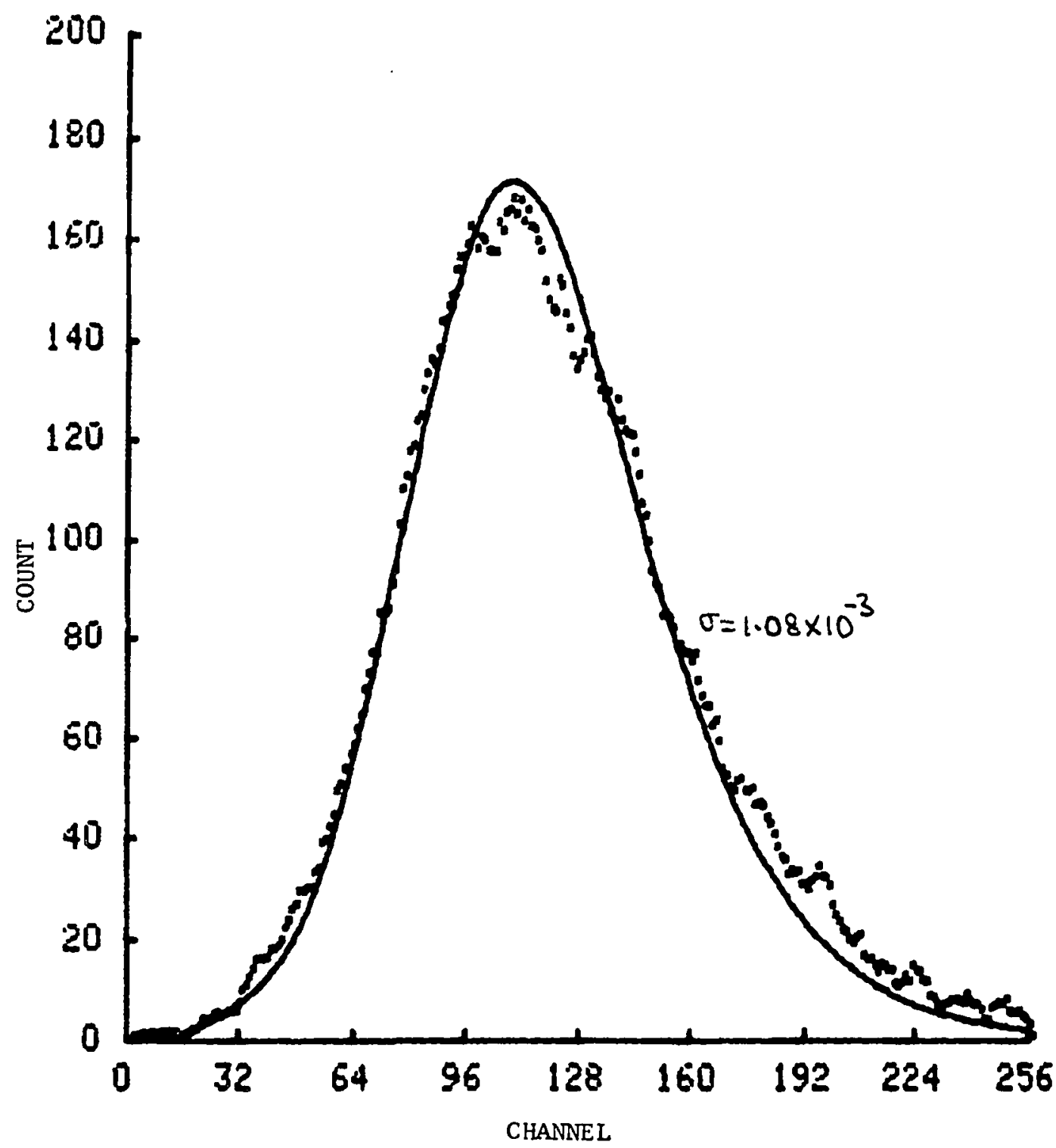

Figure 21 Fluorescence decay of OH in nitrogen plus 28 oxygen. Time scale is 0.1 ns per channel. 


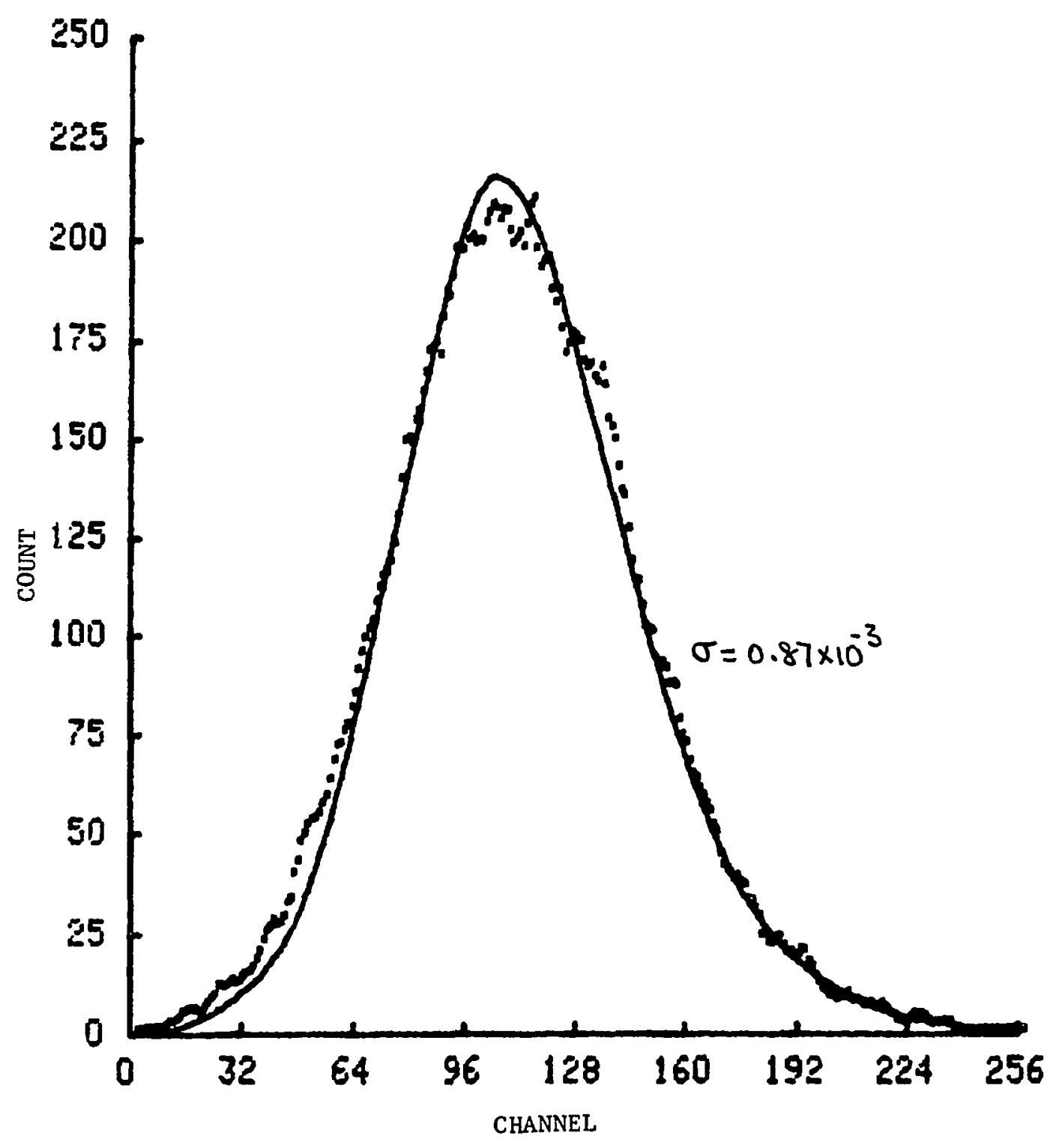

Figure 22 Fluorescence decay of $\mathrm{OH}$ in nitrogen plus 58 oxygen. Time scale is 0.1 ns per channel. 
TABLE III

RESULTS OF SIMPLEX SEARCH

Argon/water (dew point 19.0C).

Water concentration; $\left(5.33^{ \pm 0.5}\right) \times 10^{17}$ molecule/cc. Units of $A$ and $B$ are $n s^{-1}$.

$\begin{array}{rccccc}\text { Count } & B & A & C & \sigma\left(\times 10^{-3}\right) \\ & 8933 & 0.42 & 0.35 & 0.0029 & 2.17 \\ \text { Uncertainty } & -- & 0.1 & 0.1 & -- & --\end{array}$


TABLE IV

RESULTS OF SIMPLEX SEARCH

Argon/water (dew point $16.0 \mathrm{C}$ ). Water concentration; $(4.53 \pm 0.15) \times 10^{17}$ molecule/cc. Units of $A$ and $B$ are $n s^{-1}$.

$\begin{array}{rccccc} & \text { Count } & \text { B } & \text { A } & \text { C } & \sigma\left(x 10^{-3}\right) \\ & & & & & \\ 14199 & 0.334 & 0.335 & 0.0038 & 1.43 \\ 10048 & 0.338 & 0.337 & 0.0027 & 2.47 \\ 10559 & 0.419 & 0.413 & 0.0038 & 2.82 \\ & 15052 & 0.396 & 0.355 & 0.0043 & 1.75 \\ \text { Cumulative } & 51576 & 0.371 & 0.367 & 0.0154 & 0.41 \\ \text { Average } & -- & 0.371 & 0.361 & -- & -- \\ \text { Uncertainty } & -- & 0.037 & 0.032 & -- & --\end{array}$

TABLE V

RESULTS OF SIMPLEX SEARCH

Argon/water (dew point 9.0C).

Water concentration; $(2.78 \pm 0.08) \times 10^{17}$ molecule/cc. Units of $A$ and $B$ are $n s^{-1}$.

\begin{tabular}{|c|c|c|c|c|c|}
\hline & Count & B & $A$ & C & $\sigma\left(\times 10^{-3}\right)$ \\
\hline & $\begin{array}{l}9335 \\
18994 \\
13247\end{array}$ & $\begin{array}{l}0.222 \\
0.263 \\
0.238\end{array}$ & $\begin{array}{l}0.231 \\
0.279 \\
0.265\end{array}$ & $\begin{array}{l}0.00217 \\
0.00614 \\
0.00374\end{array}$ & $\begin{array}{l}2.25 \\
0.75 \\
1.2\end{array}$ \\
\hline $\begin{array}{l}\text { Cumulative } \\
\text { Average } \\
\text { Uncertainty }\end{array}$ & $\begin{array}{l}59542 \\
-- \\
y=-\end{array}$ & $\begin{array}{l}0.222 \\
0.236 \\
0.049\end{array}$ & $\begin{array}{l}0.348 \\
0.281 \\
0.019\end{array}$ & $\begin{array}{c}0.0198 \\
-- \\
--\end{array}$ & $\begin{array}{c}0.37 \\
-- \\
--\end{array}$ \\
\hline
\end{tabular}


TABLE VI

RESULTS OF SIMPLEX SEARCH

\begin{tabular}{|c|c|c|c|c|c|}
\hline \multicolumn{6}{|c|}{$\begin{array}{l}\text { Argon/water (dew point } 4.0 \mathrm{C} \text { ). } \\
\text { Water concentration; }(1.96 \pm 0.05) \times 10^{17} \text { molecule/cc. } \\
\text { Units of } A \text { and } B \text { are } \mathrm{ns}^{-1} \text {. }\end{array}$} \\
\hline & Count & B & A & C & $\sigma\left(\times 10^{-3}\right)$ \\
\hline & $\begin{array}{l}16041 \\
16082 \\
18296 \\
27417\end{array}$ & $\begin{array}{l}0.213 \\
0.190 \\
0.199 \\
0.190\end{array}$ & $\begin{array}{l}0.248 \\
0.297 \\
0.210 \\
0.193\end{array}$ & $\begin{array}{l}0.00367 \\
0.00395 \\
0.00344 \\
0.0045\end{array}$ & $\begin{array}{l}1.60 \\
0.91 \\
1.13 \\
1.08\end{array}$ \\
\hline $\begin{array}{l}\text { Cumulative } \\
\text { Average } \\
\text { Uncertainty }\end{array}$ & $\begin{array}{c}103617 \\
- \\
--\end{array}$ & $\begin{array}{l}0.213 \\
0.201 \\
0.012\end{array}$ & $\begin{array}{l}0.218 \\
0.233 \\
0.041\end{array}$ & $\begin{array}{c}0.0164 \\
-- \\
--\end{array}$ & $\begin{array}{c}0.39 \\
-- \\
--\end{array}$ \\
\hline
\end{tabular}

TABLE VII

RESULTS OF SIMPLEX SEARCH

Argon/water (dew point -7.0)

Water concentration; $(0.81 \pm 0.02) \times 10^{17}$ molecule/cc. Units of $A$ and $B$ are $n s^{-1}$.

\begin{tabular}{ccccc} 
Count & B & A & \multicolumn{1}{c}{$C$} & $\sigma\left(\times 10^{-3}\right)$ \\
15548 & 0.066 & 0.198 & 0.0048 & 1.43 \\
21688 & - & $0.135^{*}$ & 0.045 & 1.69
\end{tabular}

$\begin{array}{llllll}\text { Average } & -- & 0.066 & 0.167 & -- & -- \\ \text { Uncertainty } & -- & 0.007 & 0.03 & -- & --\end{array}$

* Result of $314 \mathrm{~nm}$ measurement. 
TABLE VIII

RESULTS OF SIMPLEX SEARCH

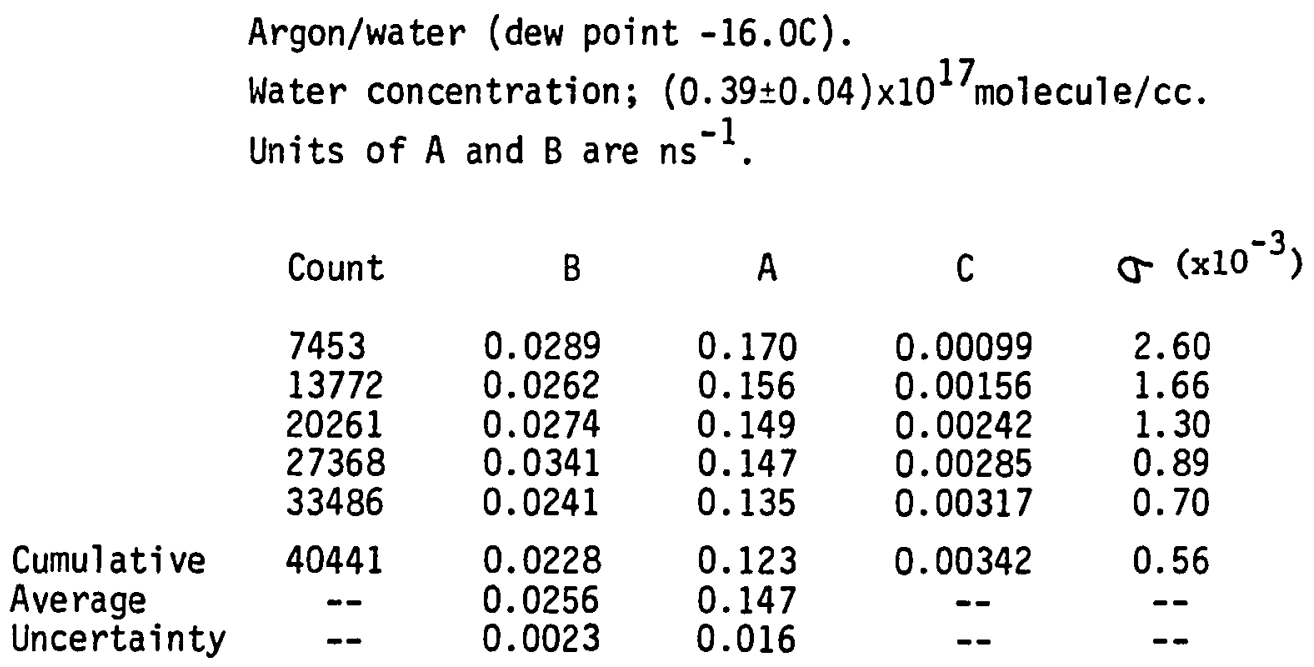


TABLE IX

RESULTS OF SIMPLEX SEARCH

Nitrogen/water (dew point $-16.0 \mathrm{C}$ ).

Water concentration; $(0.39 \pm 0.04) \times 10^{17}$ molecule/cc.

Units of $A$ and $B$ are $n s^{-1}$.

$\begin{array}{cccccc} & \text { Count } & \text { B } & \text { A } & C & \sigma\left(\times 10^{-3}\right) \\ & 6245 & 0.19 & 2.02 & 0.0397 & 4.08 \\ 7016 & 0.17 & 1.97 & 0.0415 & 2.65 \\ 7017 & 0.19 & 1.92 & 0.0431 & 2.96 \\ 7049 & 0.15 & 2.49 & 0.048 & 2.45 \\ & 5083 & 0.17 & 1.27 & 0.021 & 4.29 \\ \text { Coumulative } & 32409 & 0.17 & 1.87 & 0.179 & 0.85 \\ \text { Average } & -- & 0.17 & 1.92 & -- & - \\ \text { Uncertainty } & -- & 0.015 & 0.39 & - & -\end{array}$

TABLE X

RESULTS OF SIMPLEX SEARCH

Nitrogen/2\% oxygen/water (dew point $-16.0 \mathrm{C}$ ).

Water concentration; $(0.39 \pm 0.04) \times 10^{17}$ molecule/cc. Units of $A$ and $B$ are $n s^{-1}$.

$\begin{array}{lccccc} & \text { Count } & \text { B } & \text { A } & \text { C } & \sigma\left(\times 10^{-3}\right) \\ & 7220 & 0.40 & 2.25 & 0.022 & 1.98 \\ & 7931 & 0.39 & 4.49 & 0.048 & 1.51 \\ & & & & & \\ \text { Cumulative } & 15343 & 0.40 & 3.91 & 0.082 & 1.08 \\ \text { Average } & -- & 0.40 & 3.55 & -- & -- \\ \text { Uncertainty } & -- & 0.006 & 1.16 & -- & --\end{array}$


TABLE XI

RESULTS OF SIMPLEX SEARCH

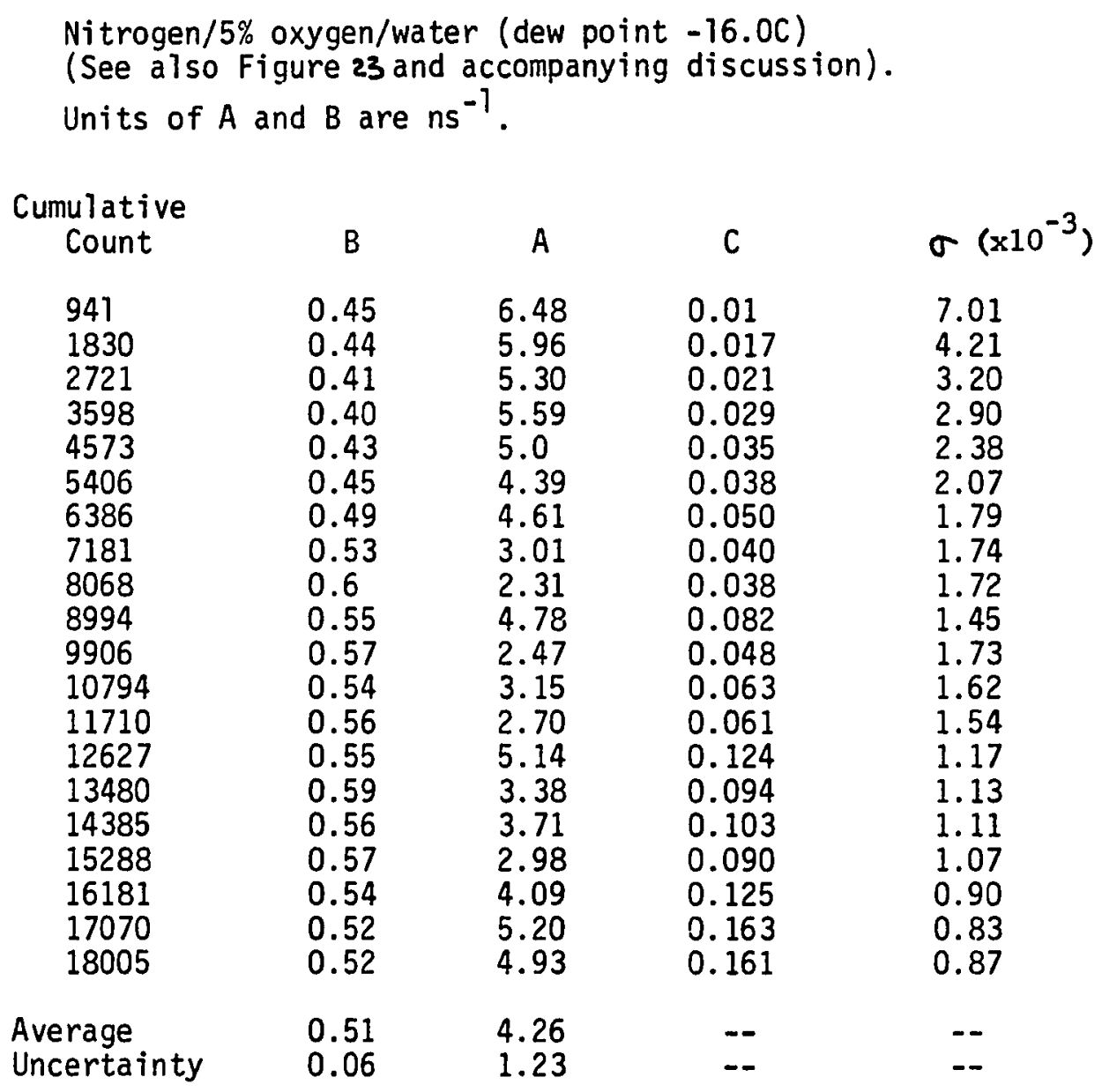


and $B$ as defined in equations 11 and 12 , is a normalizing factor, C. This normalizing factor is required because the total count, thus the area, of each curve varies. Figure 19 displays the fluorescence of $\mathrm{OH}$ in argon with different water concentrations. Please notice the marked change in the decay rates.

The parameter $\mathrm{C}$ is only a mathematical normalization constant. It has no relation to the small letter $c$ defined in equation 23. The value of $C$ can be changed either by changing the total count of the laser profile or the fluorescence profile. To measure $c$, we need an absolute intensity measurement not statistical counting. The statistical nature of the experimental approach has rendered $\mathrm{c}$ inaccessible.

The results shown in Table XI will be used to illustrate the point. It can be shown

Area of fluorescence curve $=$ Area of laser $\times \mathrm{C} / \mathrm{AB} 52$ If we plot $C / A B$ versus count $(x 0.1)$ shown in Table $X I$, a straight line with the reciprocal of the slope equal to the area of the laser profile results, because the same laser profile was used throughout all the simplex analysis shown in Table XI. Figure 23 shows such a plot. The reciprocal of the slope of the straight line is 28944 . The actual total count of the laser profile is 28098. The two differ by 38 . 


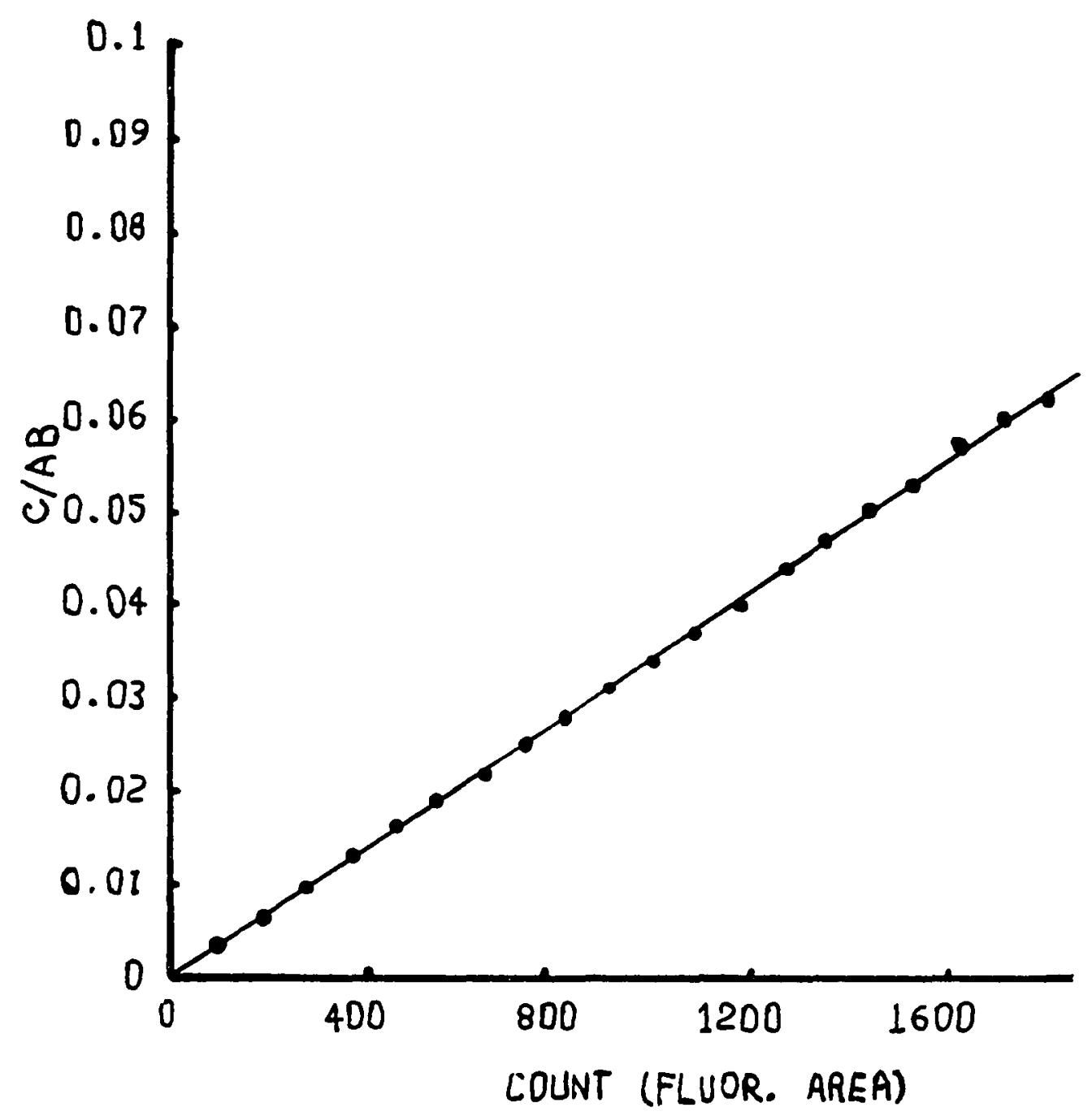

Figure 23 Linear least squares fit of $C / A B$ versus cumulative count $(x 0.1)$ tabulated in Table XI. 
Figure 18 shows the fluorescence decay of $\mathrm{OH}$ in argon and water at a concentration around that corresponding to a dew point $19.0 \mathrm{C}$. The result is obviously not satisfactory. Dew point $19.0 \mathrm{C}$ was close to the saturation point at room temperature (winter). The room temperature varied over the period of the experiment so it was hard to maintain a constant water concentration. At the time of this experiment, there was no dew point hygrometer available but a simple detector which did not operate too well at high water concentration. In brief, it is preferred not to carry out experiments at dew points close to room temperature. Instead of discarding the result, it is presented here as an illustration of what a bad fit looks like. The other reasonable fits are no coincidences. All the other results indicate that the model is indeed correct.

Due to the statistical nature of the photon counting method, there is no standard on how many counts could be accumulated before an experiment is terminated. By the same token, the result of large total count is an experiment while lesser count result could be considered an individual experiment only with less accuracy. The interesting consequence of this is that we can add all the experiments into a single giant experiment. Table IV to Table $\mathrm{X}$ except VII show more than one experimental result for each gas mixture, while Figures 13 to 21 show 
collective experimental data representing all the data for each gas mixture. These experiments with smaller counts can be viewed as results from breaking down the giant experiments. On the other hand, each individual experiment can be considered as an independent experiment. Generally, large count experiments are more accurate, so that the collective data should constitute the final results. But this is not always the case as will be discussed in the Convergence Test section of Chapter $V$, because a large count requires a long experimental time. But, a long experimental time increases other experimental errors due to such factors as changes in room temperature. Eventually these uncontrollable errors are large enough to wipe out the gain by increasing count. As the final decision, the average of all the small count results was taken as the final result for that gas mixture and the standard deviation among the small count results was given as the estimated error. 


\section{Data Analysis}

All the evidence indicates that the two parameter model is indeed consistent with the data. The next logical step, as a further check on the tenability of the model, is to analyze $A^{\prime} s$ and $B^{\prime} s$ and compare the results to the available literature values.

Figure 24 shows graphically the linear least squares fits to the the $A^{\prime} s$ and $B^{\prime} s$ of argon plus water as a function of water concentration. Figure 25 shows similar plots for A's and B's of nitrogen and oxygen as a function of oxygen concentration. Table XII summarizes the results of the least squares fits.

Due to the nature of the characteristic response function, $A$ and $B$ are indistinguishable. That is, A and B of equation 19 can be interchanged without affecting the function. This creates the problem of labeling the two values obtained by the simplex search. The problem in the argon/water case can be broken into two parts. One is how to group the experimental results into two groups, $A$ 's and B's, and the other is how to identify the two groups.

From each experiment at a water concentration in argon, we obtain a pair of values. After several experiments at different water concentrations, we obtain several pairs of values. A value from each pair is assigned to a group in such a way that the resulting group forms a straight line when plotted against water 


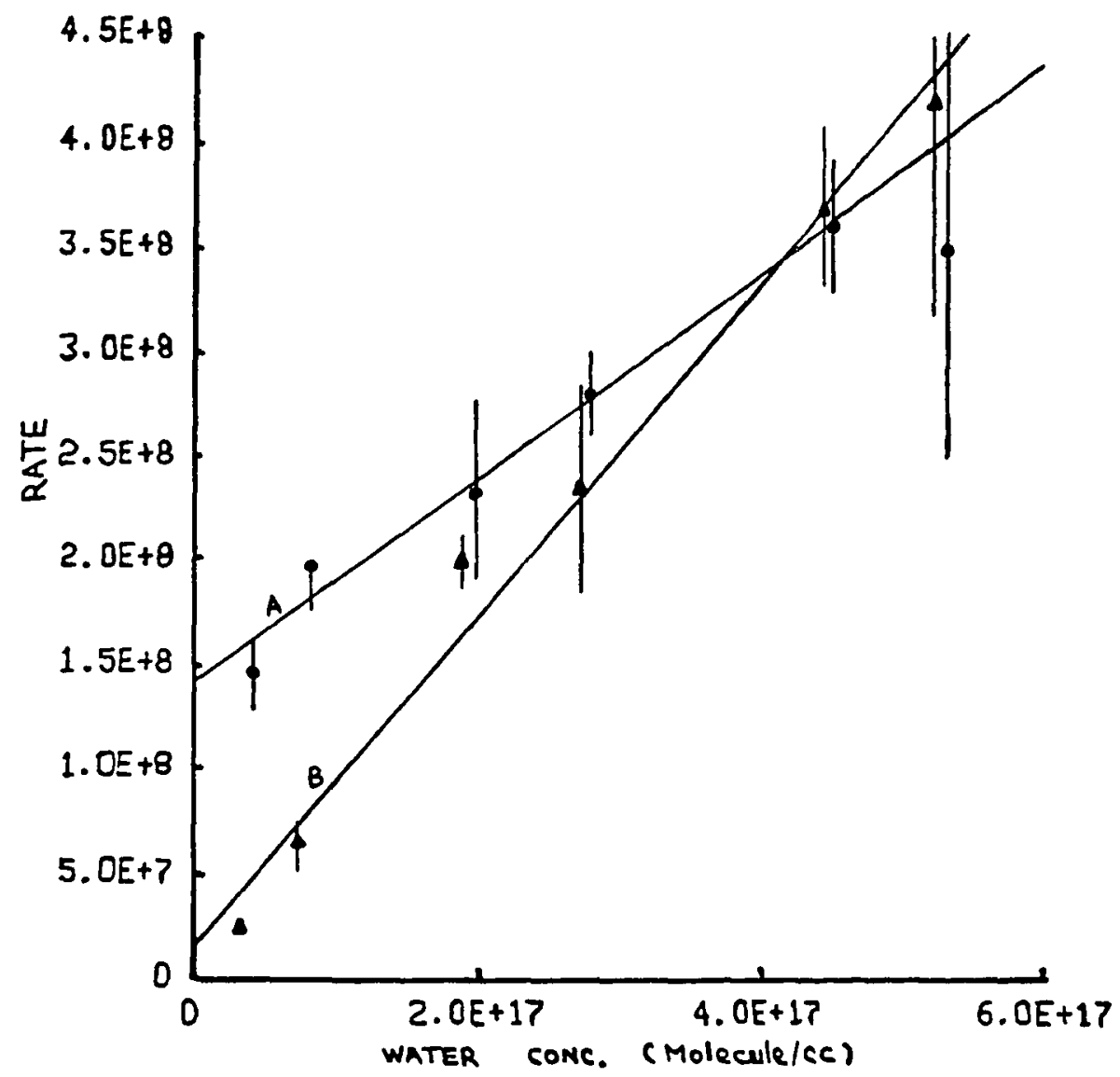

Figure 24 Linear least squares fit to $A^{\prime} s$ and $B^{\prime} s$ in argon as a function of water concentration. 


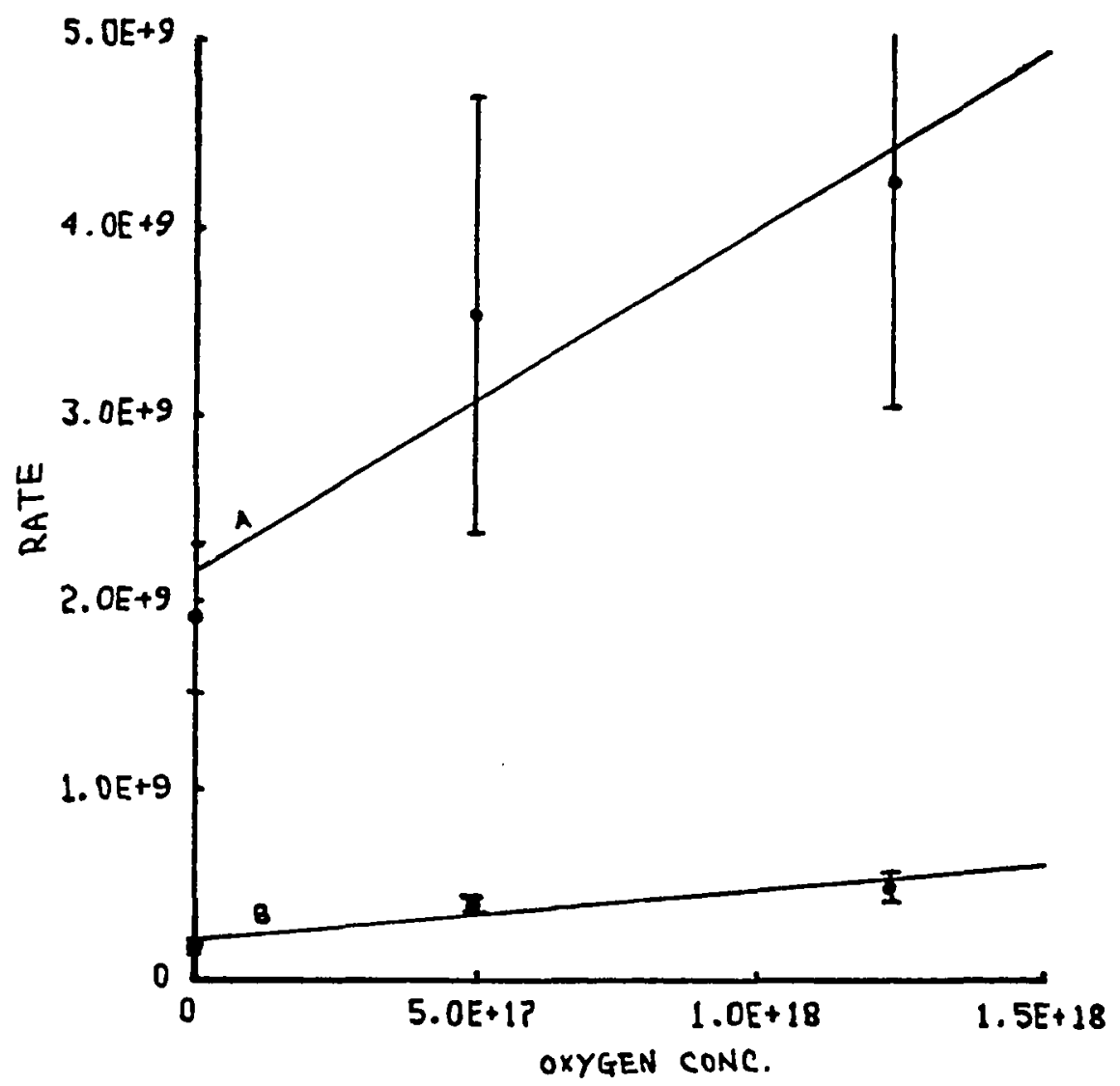

Figure 25 Linear least squares fit to $A^{\prime} s$ and $B^{\prime} s$ in Nitrogen and Oxygen. 
TABLE XII

RESULTS OF LINEAR LEAST SQUARES FITS

TO A's AND B's

Units of slopes are $\mathrm{cm}^{3} \mathrm{sec}^{-1}$ molecule $\mathrm{e}^{-1}$. Units of intercepts are $\mathrm{sec}^{-1}$.$$
\mathrm{N}_{2}+\mathrm{O}_{2}
$$$$
\mathrm{H}_{2} \mathrm{O}+\mathrm{Ar}
$$
S1ope Error Intercept Error
A $1.83 \times 10^{-9} \quad 0.43 \times 10^{-9} \quad 2.18 \times 10^{9} \quad 0.16 \times 10^{9}$
Slope Error
Intercept Error
$4.88 \times 10^{-10} 0.44 \times 10^{-10} \quad 1.41 \times 10^{8} \quad 0.03 \times 10^{8}$
B $2.65 \times 10^{-10} 0.57 \times 10^{-10} 2.06 \times 10^{8} 0.21 \times 10^{8}$
$7.9 \times 10^{-10} \quad 0.47 \times 10^{-10} \quad 1.17 \times 10^{7} \quad 0.34 \times 10^{7}$ 
concentration, Figure 24. The straight-line criterion results from the linear dependency of $A$ and $B$ on water concentration. The general guideline for grouping is that below water concentration of $5 \times 10^{17}$ molecule/cc the high values of the pairs belong to one group and the low values belong to the other group.

After grouping the values, the next step is to indentify which group is $A$ and which group is B. Notice that $A$ denotes the relaxation from the $v^{\prime}=1$ state. The identification process involves measuring the fluorescence intensity at $309 \mathrm{~nm}$ and $314 \mathrm{~nm}$ under controlled conditions. The rationale behind this experiment is given by the following arguments.

Based on equation 19 and 27 we can write the fluorescence decay at $309 \mathrm{~nm}$ as

$$
h(t)_{309}=\int_{0}^{t} f(\tau) \frac{k_{10}^{\prime} c^{\prime}\left(e^{-A(t-\tau)}-e^{-B(t-\tau)}\right)}{B-A} d \tau
$$

The $c^{\prime}$ is defined as $c^{\prime}=c \cdot k F O$ and $c$ is defined in equation 23. Based on equation 15 and 27 , we have the fluorescence at $314 \mathrm{~nm}$ as

$$
h(t)_{314}=\int_{0}^{t} f^{\prime}(\tau) c^{\prime} e^{-A(t-\tau)} d \tau .
$$


The corresponding integrated fluorescence (I) at $309 \mathrm{~nm}$ and $314 \mathrm{~nm}$ can be shown to be

$$
\begin{array}{ll}
I(309)=\frac{k^{\prime} 10 c^{\prime}}{A B} \operatorname{Area}(\text { Lase } r), & \text { ss } \\
I(314)=\frac{C^{\prime}}{A} \quad \text { Area (Laser). } & 56
\end{array}
$$

The Area(Laser) denotes the integrated area of the laser profile. Therefore, the ratio of $I(309)$ to $I(314)$ is

$$
\frac{I(309)}{I(314)}=\frac{k^{\prime} / 0}{B} \text {. }
$$

$k^{\prime} 10$ and $B$ depend on the constituents of the gas. For the argon/water case, we have

$$
\frac{I(309)}{I(314)}=\frac{k_{1 \mathrm{OH}_{2} \mathrm{O}}\left[\mathrm{H}_{2} \mathrm{O}\right]+k_{1 \mathrm{OAr}}[\mathrm{Ar}]}{\mathrm{k}_{\mathrm{QOH}_{2} \mathrm{O}}\left[\mathrm{H}_{2} \mathrm{O}\right]+\mathrm{kOOAr}_{\mathrm{OOF}}[\mathrm{Ar}} \text {. }
$$

The first experiment was to measure the ratio $k / 0 \mathrm{H}_{2} \mathrm{O} / \mathrm{kQOH}_{2} \mathrm{O}$. Since Helium is the least effective quencher,

$$
\frac{I(309)}{I(314)}=\frac{k_{10 H_{2} \mathrm{O}}\left[\mathrm{H}_{2} \mathrm{O}\right]+k_{1 \mathrm{OHe}}[\mathrm{He}]}{k_{\mathrm{QOH}_{2} \mathrm{O}}\left[\mathrm{H}_{2} \mathrm{O}\right]+k_{Q O H e}[\mathrm{He}]} .
$$

At high enough water concentration equation 57 becomes

$$
\frac{I(309)}{I(314)}=\frac{k_{1 \mathrm{OH}_{2} \mathrm{O}}}{\mathrm{k} \mathrm{COH}_{2} \mathrm{O}} \text {. }
$$


This assumption was checked by measuring the ratios at various water concentrations. The result is shown in Figure 26. The result indeed shows that at dew point 17.0C, the ratio does approach the limit of $\mathrm{k} / \mathrm{OH}_{2} \mathrm{O} / \mathrm{k} \mathrm{QOH}_{2} \mathrm{O}$. The value is $0.43 \pm 0.07$. By fitting equation 57 to the four points shown in Figure 25, we obtain the rough estimate of $k_{\text {QOHe }}\left(3.4 \times 10^{-14}\right)$ and $k_{10 H e}\left(1.4 \times 10^{-12}\right)$. Based on the ratio, equation 58 , and the least squares fits of $\mathrm{A}^{\prime} \mathrm{s}$ and B's (Table XII), we have the following two choices:

$\begin{array}{ccc}\text { Choice } & 1 & 2 \\ k_{Q O H} \mathrm{O} & 7.9 \times 10^{-10} & 4.88 \times 10^{-10} \\ k_{Q 1 H_{2} O} & 1.48 \times 10^{-10} & 5.8 \times 10^{-10} \\ k_{10 H_{2} O} & 3.4 \times 10^{-10} & 2.1 \times 10^{-10} \\ k_{Q O A h} & 4.76 \times 10^{-13} & 5.73 \times 10^{-12} \\ k_{\text {QIAn }}+k_{1 O A n} & 5.73 \times 10^{-12} & 4.76 \times 10^{-13}\end{array}$

To decide whether choice 1 or choice 2 is correct, the fluorescence intensity ratio at $309 \mathrm{~nm}$ to $314 \mathrm{~nm}$ in argon at dew point $-14.0 \mathrm{C}$ was measured. The ratio $I(309) / I(314)$ is $1.99 \pm 0.25$. Using this ratio and various $k$ 's from each choice, $k$ IOAr can be calculated according to equation 56. It turns out that only choice 1 can produce a reasonable value of $k$ loAr. Choice 2 results in a $k$ lOAr larger than the value of $k_{\text {QIAr }}+k_{1 O A h}$. Thus the identity of $A$ and $B$ in Figure 24 is determined. 


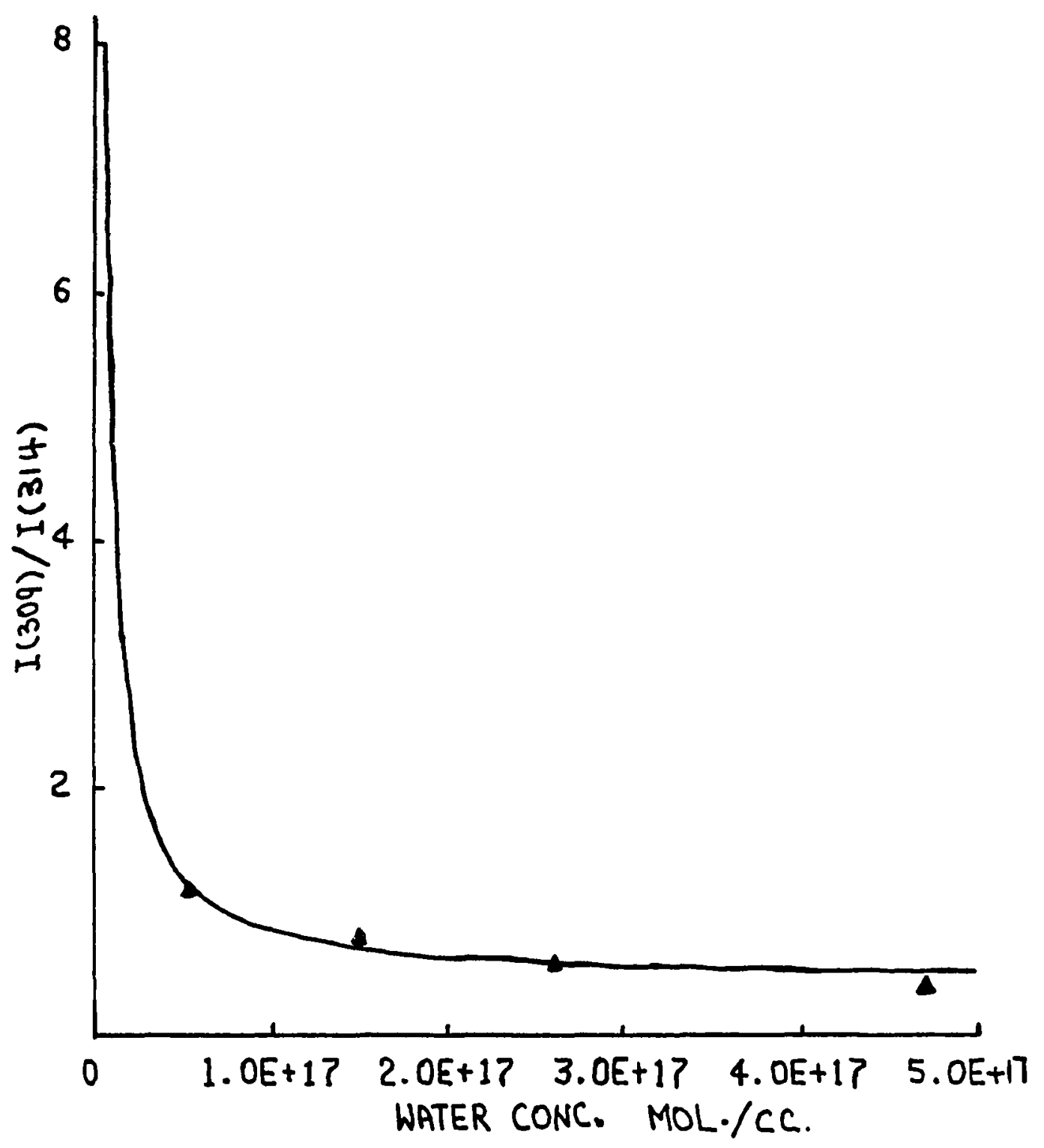

Figure 26 Ratio of fluorescence intensity at $309 \mathrm{~nm}$ to that at $314 \mathrm{~nm}$ in helium as a function of water concentration. 
To further confirm which is $A$ and which is $B$, the fluorescence decay at $314 \mathrm{~nm}$ in argon at dew point $-7.0 \mathrm{C}$ was measured. Fluorescence at $314 \mathrm{~nm}$ is due to the decay from the $v^{\prime}=1$ state, therefore the decay constant must be A. The result $\left(A=0.135 \times 10^{9}\right)$ indicated that $A$ indeed was the larger of the two values measured at $309 \mathrm{~nm}$ (see Table VII).

The analysis of the data follows the logic discussed in the Minor Details section of Chapter II. The deduction falls into two sections: $A^{\prime}$ s and B's of argon plus water and $A^{\prime} s$ and $B^{\prime} s$ of nitrogen plus oxygen.

Argon plus water:

$\mathrm{B}:$ slope $=\mathrm{KQOH}_{2} \mathrm{O}=7.9 \pm 0.47 \times 10^{-10}$

intercept $=k$ QOAr $[\mathrm{Ar}]=1.17 \pm 0.34 \times 10^{7}$

$k_{\text {QOAn }}=\frac{1.17 \pm 0.34 \times 10^{7}}{2.46 \times 10^{19}}=0.48 \pm 0.14 \times 10^{-12}$

A: $\quad$ slope $=k_{\text {alH }_{2} \mathrm{O}}+\mathrm{k}_{10 \mathrm{H}_{2} \mathrm{O}}=4.88 \pm 0.44 \times 10^{-10}$

Based on the measurement of the fluorescence at $314 \mathrm{~nm}$ and $309 \mathrm{~nm}$ in Helium, we have

$k_{10 H_{2} \mathrm{O}} / \mathrm{k}_{Q_{\mathrm{QOH}} \mathrm{O}}=0.43 \pm 0.07$

$k_{10 H_{2} \mathrm{O}}=0.43 \pm 0.07 \times 7.9 \pm 0.47 \times 10^{-10}$

$=3.4 \pm 0.59 \times 10^{-10}$

$k$ QIH $H_{2}=(4.88 \pm 0.44-3.4 \pm 0.59) \times 10^{-10}$

$=1.48 \pm 0.74 \times 10^{-10}$

intercept $=\left(k_{Q_{1 A r}}+k_{10 A r}\right)[A r]=1.41 \pm 0.03 \times 10^{8}$ 


$$
=k_{\text {alAr }}+k_{10 A t}=5.73 \pm 0.12 \times 10^{-12}
$$

Based on the measurement of $I(309) / I(314)$ at dew

point $-14.0 \mathrm{C}$ in Argon, we have

$\frac{k_{1 O H_{2} \mathrm{O}}\left[\mathrm{H}_{2} \mathrm{O}\right]+k_{1 \mathrm{OAr}}[\mathrm{Ar}]}{\mathrm{kQOH}_{2} \mathrm{O}\left[\mathrm{H}_{2} \mathrm{O}\right]+\mathrm{k}_{\mathrm{OOAh}}[\mathrm{Ar}]}=1.99 \pm 0.25$

At dew point $-14.0 \mathrm{C},\left[\mathrm{H}_{2} \mathrm{O}\right]=0.48 \times 10^{17}$

$k_{1 \mathrm{OH}_{2} \mathrm{O}}\left[\mathrm{H}_{2} \mathrm{O}\right]=3.4 \pm 0.59 \times 10^{-10} \times 0.48 \times 10^{17}$

$$
=1.63 \pm 0.28 \times 10^{7}
$$

$\mathrm{K}_{\mathrm{OOH}} \mathrm{O}\left[\mathrm{H}_{2} \mathrm{O}\right]=7.9 \pm 0.47 \times 10^{-10} \times 0.48 \times 107$

$$
=3.79 \pm 0.23 \times 10^{7}
$$

$K_{Q O A}[A Y]=4.8 \pm 1.4 \times 10^{-13} \times 2.46 \times 10^{19}$

$$
=1.18 \pm 0.34 \times 10^{7}
$$

$k_{10 H_{2} \mathrm{O}}\left[\mathrm{H}_{2} \mathrm{O}\right]+k_{10 \mathrm{Ar}}[\mathrm{Ar}]=4.97 \pm 0.34 \times 10^{7}$

$k_{10 A R}=3.36 \pm 0.59 \times 10^{-12}$

$k$ QIAn $=5.74 \pm 0.12 \times 10^{-12}-3.36 \pm 0.59 \times 10^{-12}$

$k_{Q 1 A t}=2.37 \pm 0.6 \times 10^{-12}$

Nitrogen plus oxygen:

$B:$ slope $=k_{\mathrm{QOO}_{2}}=2.65 \pm 0.57 \times 10^{-10}$

$$
\begin{aligned}
\text { intercept } & =k_{Q O N_{2}}\left[\mathrm{~N}_{2}\right]+k_{Q_{0 O H} O}\left[\mathrm{H}_{2} \mathrm{O}\right] \\
& =2.06 \pm 0.2 \times 10^{8}
\end{aligned}
$$

At dew point $-16.0 \mathrm{C} ;\left[\mathrm{H}_{2} \mathrm{O}\right]=0.4 \times 10^{17}$

$$
\begin{aligned}
k_{\mathrm{QOH}_{2} \mathrm{O}}\left[\mathrm{H}_{2} \mathrm{O}\right] & =7.9 \pm 0.47 \times 10^{-10} \times 0.4 \times 10^{17} \\
& =3.16 \pm 0.19 \times 10^{7} \\
k_{\mathrm{QON}_{2}\left[\mathrm{~N}_{2}\right]} & =(2.06 \pm 0.2-0.316 \pm 0.09) \times 10^{8} \\
= & 1.74 \pm 0.20 \times 10^{8}
\end{aligned}
$$


79

$k_{\text {ON }_{2}}=0.71 \pm 0.08 \times 10^{-11}$

$$
\text { A: } \begin{aligned}
& \text { slope }=k_{10 O_{2}}+k_{Q 1 O_{2}}=1.83 \pm 0.43 \times 10^{-9} \\
& \text { Present results only allow us to obtain } \\
& k_{10 O_{2}}+k_{Q 1 O_{2}}=1.83 \pm 0.43 \times 10^{-9} \\
& \text { intercept }=\left(k_{10 N_{2}}+k_{Q\left(N_{2}\right.}\right)\left[\mathrm{N}_{2}\right]+\left(k_{10 H_{2} O}+k_{Q 1 H_{2} O}\right)\left[\mathrm{H}_{2} \mathrm{O}\right] \\
&=2.18 \pm 0.16 \times 109
\end{aligned}
$$

At dew point $-16.0 \mathrm{C} ;\left[\mathrm{H}_{2} \mathrm{O}\right]=0.4 \times 10^{17}$

$$
\begin{aligned}
\left(k_{1 \mathrm{H}_{2} \mathrm{O}}+k_{Q 1 H_{2} \mathrm{O}}\right)\left[\mathrm{H}_{2} \mathrm{O}\right] & =0.4 \times 10^{17} \times 4.88 \pm 0.44 \times 10^{-10} \\
& =1.95 \pm 0.18 \times 10^{7} \\
\left(k_{1 O N_{2}}+k_{Q_{1}}\right)\left[N_{2}\right]= & (2.18-0.0195) \pm 0.16 \times 10^{9} \\
= & 2.16 \pm 0.16 \times 109
\end{aligned}
$$

$k_{10 N_{2}}+k_{Q 1 N_{2}}=8.78 \pm 0.65 \times 10^{-11}$

Since $k_{Q 1 N_{2}}<k_{1 O N_{2}}$, we assume $k_{Q O N_{2}}=k_{Q 1 N_{2}}$

$$
\begin{aligned}
k_{10 N_{2}} & =8.78 \pm 0.65 \times 10^{-11}-0.76 \pm 0.08 \times 10^{-11} \\
& =8.07 \pm 0.65 \times 10^{-11}
\end{aligned}
$$


Einal Results

The results are tabulated in Tables XIII to XVI together with the available literature values. The literature values are mostly those taken from references 24 and 39.

Rate constants of argon and water are in good agreement with the low pressure literature values.

Nitrogen results are smaller than the more recent reported values. The measured $k Q 0\left(0.71 \pm 0.08 \times 10^{-11}\right)$ agrees with the values of kley an Welge(40) and Becker and Haaks (39). These two groups also produced $\mathrm{OH}$ radicals by photolysis of water. But, further checking with the values collected by Schofield(24) shows that, since 1974, the reported values, primarily due to German and Lengel and crosley, have been around $3.0 \times 10^{-11}$ which is about 4 times larger than our measured value. One possible explanation is that their experiments $(23,24,41,44)$ generated $\mathrm{OH}$ by the reaction of $\mathrm{H}+\mathrm{NO}_{2}$. The gas mixtures might be contaminated by untitrated $\mathrm{NO}_{2}$ and $\mathrm{H}$ and the product NO. The $\mathrm{NO}_{2}$ by itself is about 10 times more effective than nitrogen. It only takes 208 of the total pressure to double the quenching rate. The other support to this speculation is that the measurements $(39,40)$ ultilizing photolysis of water at low pressure also produce lower values. The low value of the measured vibrational relaxation constant can also be explained by the same 
TABLE XIII

RATE CONSTANTS FOR ARGON $\left(10^{-11} \mathrm{CC} \mathrm{MOLECULE}^{-1} \mathrm{~s}^{-1}\right)$

\begin{tabular}{|c|c|c|c|c|}
\hline${ }^{k_{Q 0 A r}}$ & $\begin{array}{l}\text { Exp. } \\
\text { Temp. } \mathrm{K}\end{array}$ & $\begin{array}{c}\text { Exp. } \\
\text { Pressure }\end{array}$ & Comment & Ref. \\
\hline 0.02 & 295 & $0.5-5.3 \mathrm{kPa}$. & Photolysis of water & $\begin{array}{l}\text { cited } \\
\text { in } 24\end{array}$ \\
\hline$<2$ & $850-1500$ & $0.4-0.8 \mathrm{kPa}$ & $\begin{array}{l}\mathrm{C}_{2} \mathrm{H}_{2} / \mathrm{O}_{2} \text { low pressure } \\
\text { flames. }\end{array}$ & 3 \\
\hline$<0.007$ & 295 & $0.67 \mathrm{kPa}$. & $\begin{array}{l}\text { Flow cell. Kr } 123.6 \mathrm{~nm} \\
\text { photolysis of water. }\end{array}$ & 40 \\
\hline 0.1 & 295 & $0.013 \mathrm{kPa}$ & $\begin{array}{l}\text { Kr } 123.6 \mathrm{~nm} \text { pulsed } \\
\text { photolysis. }\end{array}$ & 39 \\
\hline$<0.6$ & 298 & $0.3 \mathrm{kPa}$. & $\begin{array}{l}\text { Discharge flow system. } \\
\text { OH from } \mathrm{H}^{\mathrm{NO}}{ }_{2} \cdot \mathrm{OH} \\
\text { source induced fluoresc- } \\
\text { ence. }\end{array}$ & 41 \\
\hline 0.05 & 295 & $0.13 \mathrm{kPa}$. & $\begin{array}{l}\mathrm{OH} \text { for } \mathrm{H}+\mathrm{NO}_{2} \cdot \text { Dye laser } \\
\text { fluorescence. }\end{array}$ & $\begin{array}{l}\text { cited } \\
\text { in } 24\end{array}$ \\
\hline 0.034 & 300 & $\begin{array}{l}\text { not spec- } \\
\text { ified-1ow }\end{array}$ & $\begin{array}{l}\text { OH from } \mathrm{O}_{3} / \mathrm{H}_{2} \\
\text { photolysis, aye laser } \\
\text { flinorescence. }\end{array}$ & 43 \\
\hline$<0.004$ & 300 & $0.27 \mathrm{kPa}$ & $\begin{array}{l}121.5 \mathrm{~nm} \text { pulsed pho- } \\
\text { tolysis of water. High } \\
\text { rotational levels. }\end{array}$ & $\begin{array}{l}\text { cited } \\
\text { in } 24\end{array}$ \\
\hline $0.048 \pm 0.014$ & 297 & $101 \mathrm{kPa}$. & $\begin{array}{l}\text { Photolysis of water, } \\
\text { dye laser fluorescence. }\end{array}$ & $\begin{array}{l}\text { This } \\
\text { work }\end{array}$ \\
\hline
\end{tabular}


TABLE XIII CONTINUED

\begin{tabular}{|c|c|c|c|c|}
\hline $\mathrm{k}_{\mathrm{Q} 1 \mathrm{Ar}}$ & $\begin{array}{c}\text { Exp. } \\
\text { Temp. } K\end{array}$ & $\begin{array}{c}\text { Exp. } \\
\text { Pressure }\end{array}$ & Comment & Ref. \\
\hline 0.4 & 300 & $0.27 \mathrm{kPa}$. & $\begin{array}{l}121.5 \mathrm{~nm} \text { pulsed pho- } \\
\text { tolysis of water. } \\
\text { High rotational } \\
\text { levels. }\end{array}$ & $\begin{array}{l}\text { cited } \\
\text { in } 24\end{array}$ \\
\hline $0.24 \pm 0.6$ & 297 & $101 \mathrm{kPa}$. & $\begin{array}{l}\text { Photolysis of water, } \\
\text { dye laser fluore- } \\
\text { scence. }\end{array}$ & $\begin{array}{l}\text { This } \\
\text { work }\end{array}$ \\
\hline $\mathrm{k}_{10 \mathrm{Ar}}$ & $\begin{array}{c}\text { Exp. } \\
\text { Temp. K }\end{array}$ & $\begin{array}{c}\text { Exp. } \\
\text { Pressure }\end{array}$ & Comment & Ref. \\
\hline 0.29 & 320 & $0.15 \mathrm{kPa}$. & $\begin{array}{l}\mathrm{OH} \text { from } \mathrm{H}+\mathrm{NO}_{2} \cdot \text { Pulsed } \\
\text { dye laser. }\end{array}$ & $\begin{array}{l}\text { cited } \\
\text { in } 24\end{array}$ \\
\hline 0.13 & 300 & unspecified & $\begin{array}{l}\text { OH from } \mathrm{O}_{3} / \mathrm{H}_{2} \text { photo- } \\
\text { lysis. Questionable } \\
\text { data ( ref. 1) }\end{array}$ & 43 \\
\hline $0.34 \pm 0.06$ & 297 & $101 \mathrm{kPa}$. & $\begin{array}{l}\text { Photolysis of water. } \\
\text { Pulsed dye laser } \\
\text { fluorescence. }\end{array}$ & $\begin{array}{l}\text { This } \\
\text { work }\end{array}$ \\
\hline
\end{tabular}


TABLE XIV

RATE CONSTANTS FOR WATER $\left(10^{-10} \mathrm{CC} \mathrm{MOLECULE}^{-1} \mathrm{~s}^{-1}\right)$

\begin{tabular}{|c|c|c|c|c|}
\hline${ }^{\mathrm{k}} \mathrm{QOH}_{2} \mathrm{O}$ & $\begin{array}{l}\text { Exp. } \\
\text { Temp. } \mathbf{K}\end{array}$ & $\begin{array}{c}\text { Exp. } \\
\text { Pressure }\end{array}$ & Comment & Ref. \\
\hline 2.9 & 295 & $0.67 \mathrm{kPa}$. & $\begin{array}{l}\mathrm{Kr} 123.6 \mathrm{~nm} \text { photo- } \\
\text { lysis of water. }\end{array}$ & 40 \\
\hline 3.5 & 298 & $0.3 \mathrm{kPa}$. & $\begin{array}{l}\mathrm{OH} \text { from } \mathrm{H}^{+\mathrm{NO}_{2}} \cdot \mathrm{OH} \\
\text { source induced fluo- } \\
\text { rescence. }\end{array}$ & 41 \\
\hline 4.5 & 295 & $0.013 \mathrm{kPa}$ & 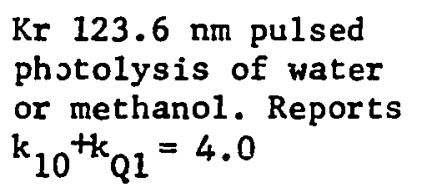 & 39 \\
\hline 5.0 & 300 & $\leqslant 0.5 \mathrm{kPa}$. & $\begin{array}{l}\mathrm{Kr} 123.6 \mathrm{~nm} \text { photo- } \\
\text { lysis of water. }\end{array}$ & 42 \\
\hline 5.6 & 300 & $0.27 \mathrm{kPa}$. & $\begin{array}{l}121.5 \mathrm{~nm} \text { pulsed phot- } \\
\text { olysis. High rotatio- } \\
\text { nal levels. }\end{array}$ & $\begin{array}{l}\text { cited } \\
\text { in } 24\end{array}$ \\
\hline 6.1 & 315 & $0.007 \mathrm{kPa}$ & $\begin{array}{l}\text { Static system, } 200 \mathrm{eV} \\
\text { e-beam. }\end{array}$ & 5 \\
\hline 9.2 & 300 & $0.021 \mathrm{kPa}$ & $\begin{array}{l}\text { Narrow band photo- } \\
\text { lysis of water. High } \\
\text { rotational level. }\end{array}$ & $\begin{array}{l}\text { cited } \\
\text { in } 24\end{array}$ \\
\hline 4.0 & 300 & $3.3 \mathrm{kPa}$. & $\begin{array}{l}\text { Microwave discharge } \\
\text { of water. Pulsed } \\
\text { dye laser. }\end{array}$ & 23 \\
\hline $7.9 \pm 0.47$ & 297 & $101 \mathrm{kPa}$. & $\begin{array}{l}\text { Photolysis of water. } \\
\text { Pulsed dye laser. }\end{array}$ & $\begin{array}{l}\text { This } \\
\text { work }\end{array}$ \\
\hline
\end{tabular}




\begin{tabular}{|c|c|c|c|c|}
\hline${ }^{\mathrm{k}} \mathrm{Q}_{2} \mathrm{H}_{2} \mathrm{O}$ & $\begin{array}{l}\text { Exp. } \\
\text { Temp. K }\end{array}$ & $\begin{array}{l}\text { Exp. } \\
\text { Pressure }\end{array}$ & Comment & Ref. \\
\hline 4.0 & 295 & $0.013 \mathrm{kPa}$ & $\begin{array}{l}\mathrm{Kr} 123.6 \mathrm{~nm} \text { pulsed } \\
\text { photolysis of water } \\
\text { or methanol. } \mathrm{k}_{10}+ \\
\mathrm{k}_{\mathrm{Q} 1} \text {. }\end{array}$ & 39 \\
\hline 5.6 & 300 & $0.27 \mathrm{kPa}$. & $\begin{array}{l}121.5 \mathrm{~nm} \text { pulsed photo- } \\
\text { lysis of water. High } \\
\text { rotational levels. }\end{array}$ & $\begin{array}{l}\text { cited } \\
\text { in } 24\end{array}$ \\
\hline 9.2 & 300 & $0.021 \mathrm{kPa}$ & $\begin{array}{l}\text { Narrow band photo- } \\
\text { lysis of water. High } \\
\text { rotational levels. }\end{array}$ & $\begin{array}{l}\text { cited } \\
\text { in } 24\end{array}$ \\
\hline $1.48 \pm 0.74$ & 297 & $101 \mathrm{kPa}$. & $\begin{array}{l}\text { Photolysis of water. } \\
\text { Pulsed dye laser. }\end{array}$ & $\begin{array}{l}\text { This } \\
\text { work }\end{array}$ \\
\hline${ }^{k} \mathrm{OH}_{2} \mathrm{O}$ & $\begin{array}{l}\text { Exp. } \\
\text { Temp. K }\end{array}$ & $\begin{array}{l}\text { Exp. } \\
\text { Pressure }\end{array}$ & Comment & Ref. \\
\hline $3.4 \pm 0.59$ & 300 & $101 \mathrm{kPa}$. & $\begin{array}{l}\text { Photolysis of water. } \\
\text { Pulsed dye laser. }\end{array}$ & $\begin{array}{l}\text { This } \\
\text { work }\end{array}$ \\
\hline
\end{tabular}


TABLE XV

RATE CONSTANTS FOR NITROGEN $\left(10^{-11}\right.$ CC MOLECULE $\left.\mathrm{s}^{-1}\right)$

\begin{tabular}{|c|c|c|c|c|}
\hline $\mathrm{k}_{\mathrm{QON}}$ & $\begin{array}{l}\text { Exp. } \\
\text { Temp. K }\end{array}$ & $\begin{array}{c}\text { Exp. } \\
\text { Pressure }\end{array}$ & Comment & Ref. \\
\hline 0.05 & 295 & $0.3-5.3 \mathrm{kPa}$ & $\begin{array}{l}\text { Photolysis of } \\
\text { water. }\end{array}$ & $\begin{array}{l}\text { cited } \\
\text { in } 24\end{array}$ \\
\hline 4.0 & 300 & $\leqslant 0.5 \mathrm{kPa}$. & $\begin{array}{l}\mathrm{Kr} 123.6 \mathrm{~nm} \text { photo- } \\
\text { lysis of water. }\end{array}$ & 42 \\
\hline 0.51 & 295 & $0.67 \mathrm{kPa}$. & $\begin{array}{l}\mathrm{Kr} 123.6 \mathrm{~nm} \text { photo- } \\
\text { lysis of water. }\end{array}$ & 40 \\
\hline 1.0 & 295 & $0.013 \mathrm{kPa}$ & $\begin{array}{l}\mathrm{Kr} 123.6 \mathrm{~nm} \text { pulsed } \\
\text { photolysis of water } \\
\text { or methanol. }\end{array}$ & 39 \\
\hline 1.6 & 298 & $0.3 \mathrm{kPa}$ & $\begin{array}{l}\mathrm{OH} \text { from } \mathrm{H}+\mathrm{NO}_{2} \text {, dye } \\
\text { laser fluorescence. }\end{array}$ & 41 \\
\hline 4.3 & 320 & $0.13 \mathrm{kPa}$. & $\begin{array}{l}\mathrm{OH} \text { from } \mathrm{H}+\mathrm{NO}_{2} \text {, dye } \\
\text { laser fluorescence. }\end{array}$ & 44 \\
\hline 2.3 & 300 & unspecified & $\begin{array}{l}\text { OH from } \mathrm{O}_{3} / \mathrm{H}_{2} \text { pho- } \\
\text { tolysis, dye laser } \\
\text { fluorescence. }\end{array}$ & 43 \\
\hline 2.6 & 295 & $0.13 \mathrm{kPa}$. & $\begin{array}{l}\text { Flow system, Or! } \\
\text { from } \mathrm{H}^{+} \mathrm{NO}_{2} \text {, dye la- } \\
\text { ser fluorescence. }\end{array}$ & 33 \\
\hline 1.6 & 300 & $1 \mathrm{kPa}$. & $\begin{array}{l}\mathrm{OH} \text { from } \mathrm{H}+\mathrm{NO}_{2} \\
\text { Pulsed dye } \mathrm{l}^{\circ} \text { ser } \\
\text { fluorescence. }\end{array}$ & $\begin{array}{l}\text { cited } \\
\text { in } 24\end{array}$ \\
\hline 4.2 & 320 & $0.15 \mathrm{kPa}$. & $\begin{array}{l}\mathrm{OH} \text { from } \mathrm{H}^{+\mathrm{NO}_{2}} \text {. Pul- } \\
\text { sed dye laser fluor- } \\
\text { escence. }\end{array}$ & 47 \\
\hline 3.1 & 300 & $3.3 \mathrm{kPa}$. & $\begin{array}{l}\text { Microwave discharge } \\
\text { of water, dye laser } \\
\text { fluorescence. }\end{array}$ & 23 \\
\hline $0.71 \pm 0.08$ & 297 & $101 \mathrm{kPa}$. & $\begin{array}{l}\text { Photolysis of wat- } \\
\text { er. Dye laser } \\
\text { fluorescence. }\end{array}$ & $\begin{array}{l}\text { This } \\
\text { work }\end{array}$ \\
\hline
\end{tabular}


TABLE XV CONTINUED

\begin{tabular}{|c|c|c|c|}
\hline $\mathrm{k}_{10 \mathrm{~N}_{2}}$ & $\begin{array}{c}\text { Exp. } \\
\text { Temp. } \mathrm{K}\end{array}$ & $\begin{array}{c}\text { Exp. } \\
\text { Pressure }\end{array}$ & Comment \\
\hline 18.3 & 320 & $0.15 \mathrm{kPa}$. & $\begin{array}{l}\mathrm{OH} \text { from } \mathrm{H}+\mathrm{NO}_{2} \cdot \text { Pulsed } \\
\text { dye laser fluorescence. }\end{array}$ \\
\hline 15.0 & 295 & $0.13 \mathrm{kPa}$. & $\begin{array}{l}\mathrm{OH} \text { from } \mathrm{H}+\mathrm{NO}_{2} \cdot \text { Dye } \\
\text { laser fluorescence. }\end{array}$ \\
\hline $8.07 \pm 0.65$ & 297 & $101 \mathrm{kPa}$. & $\begin{array}{l}\text { Photolysis of water. } \\
\text { Pulsed dye laser } \\
\text { fluorescence. }\end{array}$ \\
\hline
\end{tabular}


TABLE XVI

RATE CONSTANTS FOR OXYGEN $\left(10^{-11}\right.$ CC MOLECULE $\left.\mathrm{s}^{-1}\right)$

\begin{tabular}{|c|c|c|c|c|}
\hline $\mathrm{k}_{\mathrm{QOO}}$ & $\begin{array}{l}\text { Exp. } \\
\text { Temp. } \mathrm{K}\end{array}$ & $\begin{array}{c}\text { Exp. } \\
\text { Pressure }\end{array}$ & Comment & Ref. \\
\hline 10.4 & 295 & $0.13 \mathrm{kPa}$. & $\begin{array}{l}\text { Flow system, } \mathrm{OH} \text { from } \\
\mathrm{H}+\mathrm{NO}_{2} \text { - Dye laser fluor- } \\
\text { escence. }\end{array}$ & 33 \\
\hline 30 & $1500-1790^{\# ⿰}$ & $101 \mathrm{kPa}$. & $\begin{array}{l}\mathrm{H}_{2} / \mathrm{O}_{2} / \mathrm{N}_{2} / \mathrm{Ar} \text { atmosph- } \\
\text { eric pressure flames. }\end{array}$ & 6 \\
\hline 8.0 & $800-1500^{\# ~}$ & $0.4-0.8 \mathrm{kPa}$ & $\begin{array}{l}\mathrm{C}_{2} \mathrm{H}_{2} / \mathrm{O}_{2} \text { low pressure } \\
\text { flames. }\end{array}$ & 3 \\
\hline 9.9 & 300 & $3.3 \mathrm{kPa}$. & $\begin{array}{l}\text { Microwave discharge } \\
\text { of water. Dye laser } \\
\text { fluorescence. }\end{array}$ & 23 \\
\hline $26.5 \pm 5.7$ & 297 & $101 \mathrm{kPa}$. & $\begin{array}{l}\text { Photolysis of water. } \\
\text { Pulsed dye laser } \\
\text { fluorescence. }\end{array}$ & $\begin{array}{l}\text { This } \\
\text { work }\end{array}$ \\
\hline${ }^{\mathrm{k}} \mathrm{Q1O}_{2}$ & $\begin{array}{l}\text { Exp. } \\
\text { Temp. K }\end{array}$ & $\begin{array}{c}\text { Exp. } \\
\text { Pressure }\end{array}$ & Comment & Ref. \\
\hline 13.0 & 295 & $0.13 \mathrm{kPa}$. & $\begin{array}{l}\mathrm{OH} \text { from } \mathrm{H}+\mathrm{NO}_{2} \text {, dye } \\
\text { laser fluorescence. }\end{array}$ & 33 \\
\hline $183 \pm 43$ & 297 & $101 \mathrm{kPa}$. & $\begin{array}{l}\text { Photolysis of water. } \\
\text { Pulsed dye laser } \\
\text { fluorescence. *kelect. } \\
+k_{\text {vibr. }}\end{array}$ & $\begin{array}{l}\text { This } \\
\text { work }\end{array}$ \\
\hline
\end{tabular}

\# Range of applicable temperature. 
TABLE XVI CONTINUED

\begin{tabular}{|c|c|c|c|c|}
\hline $\mathrm{k}_{10 \mathrm{O}_{2}}$ & $\begin{array}{c}\text { Exp. } \\
\text { Temp. } \mathrm{k}\end{array}$ & $\begin{array}{c}\text { Exp. } \\
\text { Pressure }\end{array}$ & Comment & Ref. \\
\hline 1.5 & 295 & $0.13 \mathrm{kPa}$. & $\begin{array}{l}\mathrm{Flow} \text { system, } \mathrm{OH} \text { from } \\
\mathrm{H}^{\mathrm{NO}}{ }_{2} \text {, dye laser fluor- } \\
\text { escence. }\end{array}$ & 33 \\
\hline $183 *$ & 297 & $101 \mathrm{kPa}$. & $\begin{array}{l}\text { OH from photolysis of } \\
\text { water. Pulsed dye laser } \\
\text { fluorescence. } \\
{ }^{*} \mathrm{k}_{100_{2}}+\mathrm{k}_{\mathrm{Q} 1 \mathrm{O}_{2}}\end{array}$ & $\begin{array}{l}\text { This } \\
\text { work }\end{array}$ \\
\hline
\end{tabular}


arguments. Of course, the other possibility is the pressure effect.

Wang and Davis measured the ratio of $\mathrm{k}_{\mathrm{QOH}_{2} \mathrm{O}}$ to $\mathrm{k}_{\mathrm{QON}}$ at atmospheric pressure(22). The reported ratio is $44 \pm 14$. KaON2can be calculated by taking $k_{\text {QOH }} \mathrm{O}$ to be $7.9 \pm 0.47 \times 10^{-10}$. The result is $1.8 \pm 0.6 \times 10^{-11}$ which is at the lower end of the more recent literature values.

Selzer and Wang(23) remeasured the values for nitrogen again in 1979. This time their experiments were done at low pressure and $\mathrm{OH}$ was generated by passing moist gases through a microwave discharge. The reported value of $\mathrm{kQON}_{2}$ was $3.1 \times 10^{-11}$ which agreed with the higher values in the literature. Now here are two experiments performed by the same group at two different pressures and their results disagree. Is it an indication of pressure dependence of the rate constants? At this point in time, it would be naive to draw such a conclusion, but at least such a possibility should be considered.

The rate constants of oxygen as expected, are fast. The value of $\mathrm{k}_{\mathrm{OOO}_{2}}$ is about twice the literature values and $\mathrm{KQOO}_{2}+\mathrm{k}_{10 O}$ is about 10 times larger. If we assume $k_{Q 1}=k_{Q 0}$, the $k_{1002}$ will be one hundred times larger than the only available literature valuel It may be possible that the deactivation by oxygen molecules is more complicated than the simple explanation offered by the hard sphere collision model. Ozone interference was ruled 
out by the experiments to be discussed in Chapter VI. Although the rate constants are higher than the hard-sphere collision rate, a rate constant $\left(A r F^{*}+X e->X e F^{*}+A r\right)$ as high as $4.5 \times 10^{-9} \mathrm{cc}$ molecule $e^{-1} \mathrm{sec}^{-1}$ has been reported (21).

In order to compare our rate constants with the literature values in the context of the pressure under which they are measured, we use a novel way to present the literature values and the measured values graphically. Figure 28 is a plot of $\log (k Q O A W A r])$ against $\log [A r]$. Figure 27 is a plot of $\log \left(k_{Q O N_{2}}\left[N_{2}\right]\right)$ against $\log \left[N_{2}\right]$. The $\left[\mathrm{N}_{2}\right]$ and [Ar] refer to the pressure under which the experiment is carried out. The straight line shown has its slope equal to $I$ and its intercept equal to logk ooAr or logkQON2 obtained by this experiment. Figures 29 and 30 show similar plots for the $k$ oo of water and oxygen. The reason for presenting the values in logarithmic scale is because the range of pressure covered by the values varies over two orders of magnitude. It would be difficult to show all the points clearly in linear scale over such a wide range of pressure. In addition to showing all the points, the plots also show that the three-body collision contribution is not significant at atmospheric pressure. Were the three-body contribution significant, the points would curve upward rather then lie in a straight line. Since the quantity measured is $k o_{0}^{[M]}$ and we wish to 


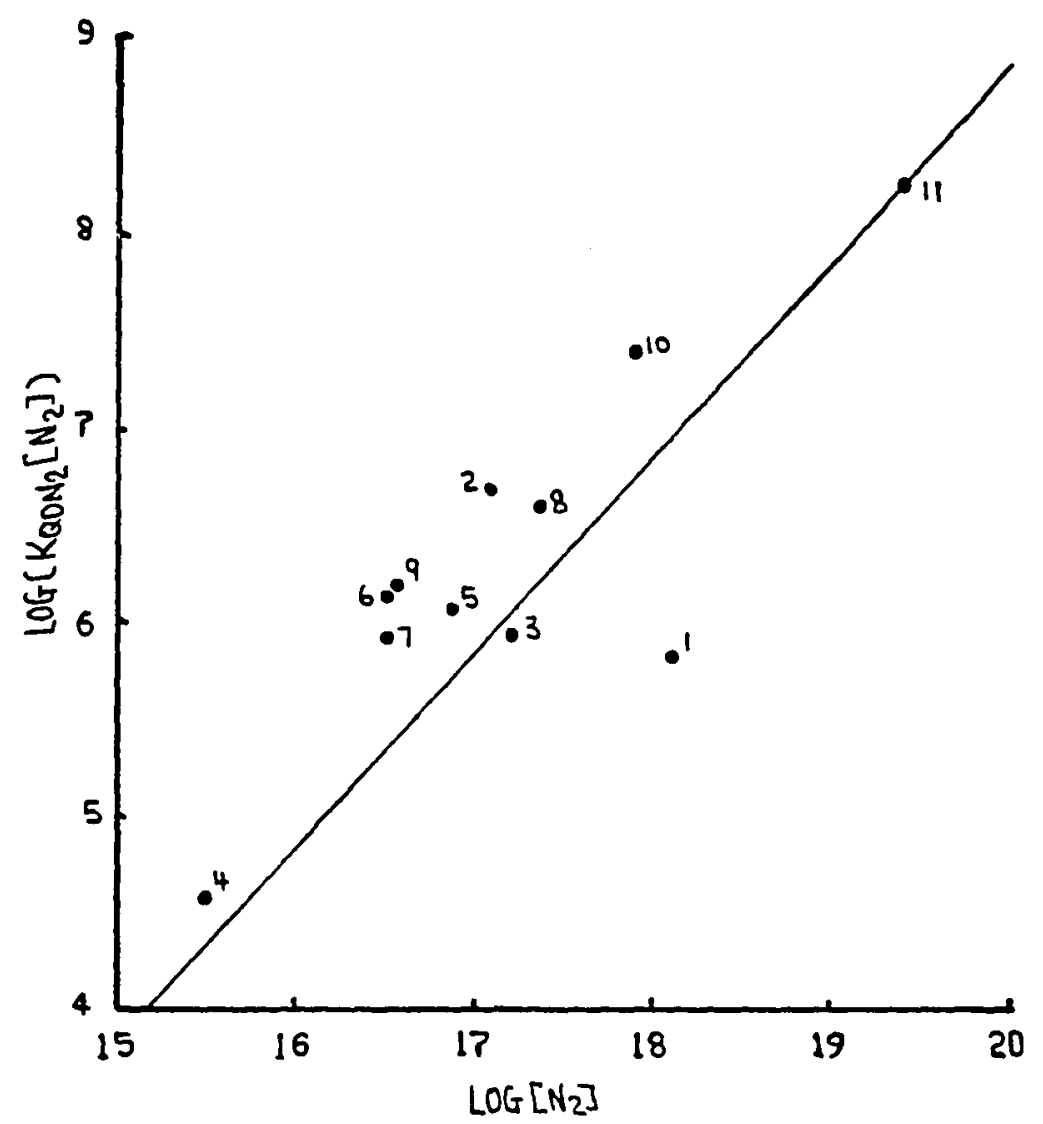

\begin{tabular}{rrrlll}
\multicolumn{3}{c}{ Ref. } & Ref. & Ref. \\
1 & cited in 24 & 2 & 42 & 3 & 40 \\
4 & 39 & 5 & 41 it in 24 & 6 & 44 \\
7 & 33 & 8 & 9 & 47 \\
10 & 23 & 11 cited this work & &
\end{tabular}

Figure 27 Plot of $\log \left(k_{\mathrm{QON}_{2}}\left[\mathrm{~N}_{2}\right]\right)$ against $\log \left[\mathrm{N}_{2}\right]$. The straight line has its slope equal to 1 and its intercept equal to $\log \left(\mathrm{k}_{\mathrm{QON}}\right)$ measured in the experiment. 


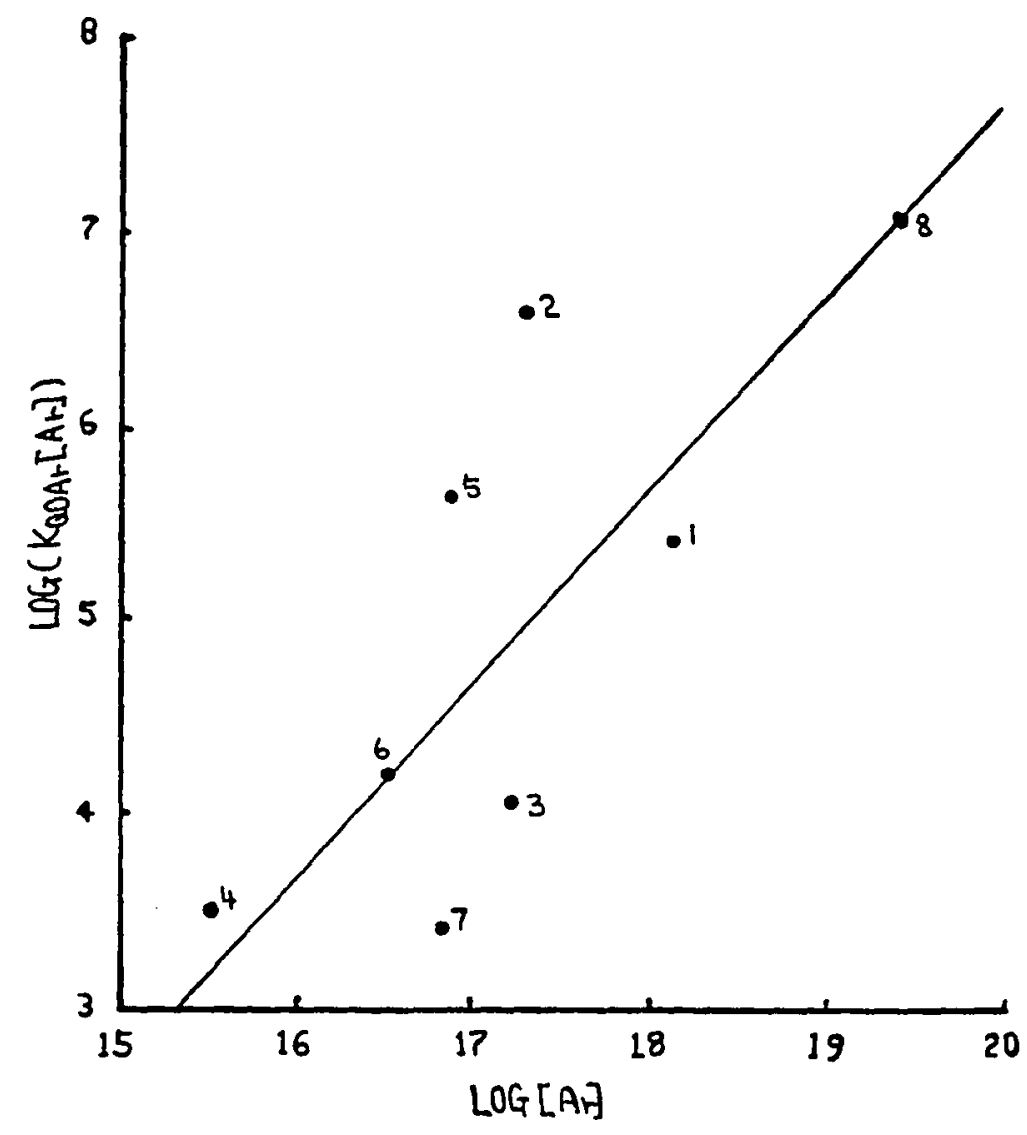

\begin{tabular}{lccccc}
\multicolumn{3}{c}{ Ref. } & Ref. & \multicolumn{2}{c}{ Ref. } \\
1 & cited in 24 & 2 & 3 & 3 & 40 \\
4 & 39 & 5 & 41 & 6 & cited in 24 \\
7 & cited in 24 & 8 & this work & &
\end{tabular}

Figure 28 Plot of $\log \left(\mathrm{kQOAr}_{\mathrm{Q}}[\mathrm{Ar}]\right)$ against $\log [\mathrm{Ar}]$. The straight line has slope of 1 and intercept of $\log \left(\mathrm{k}_{\mathrm{QOAr}}\right)$ measured in the experiment. 


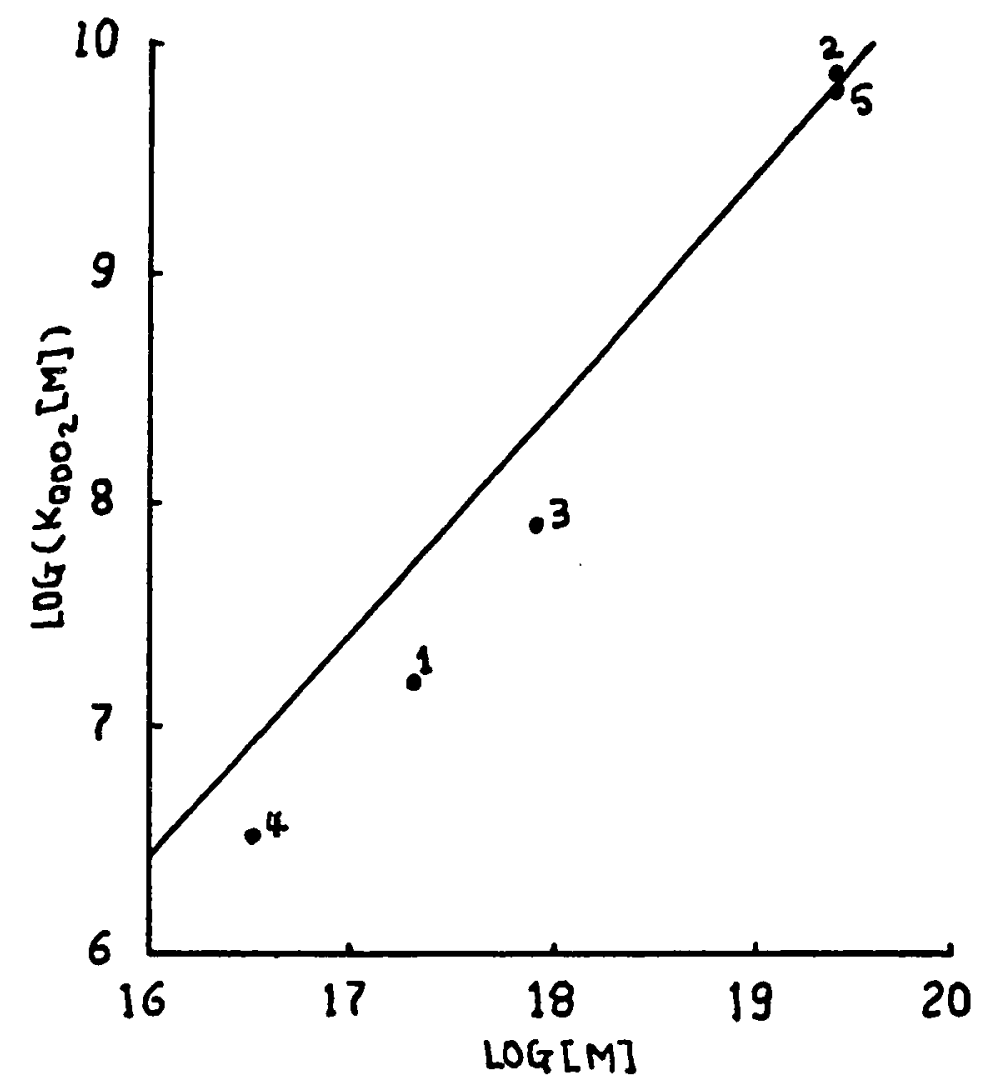

\begin{tabular}{cccccc} 
& Ref. & \multicolumn{2}{c}{ Ref. } & Ref. \\
1 & 3 & 2 & 6 & 3 & 23 \\
4 & 33 & 5 & This work & &
\end{tabular}

Figure 29 Plot of $\log \left(\mathrm{K}_{\mathrm{QOO}}[\mathrm{M]})\right.$ against $\log [\mathrm{M}]$. The straight line has slope of 1 and intercept of $\log \left(\mathrm{k}_{\mathrm{QOO}_{2}}\right)$ measured in the experiment. 


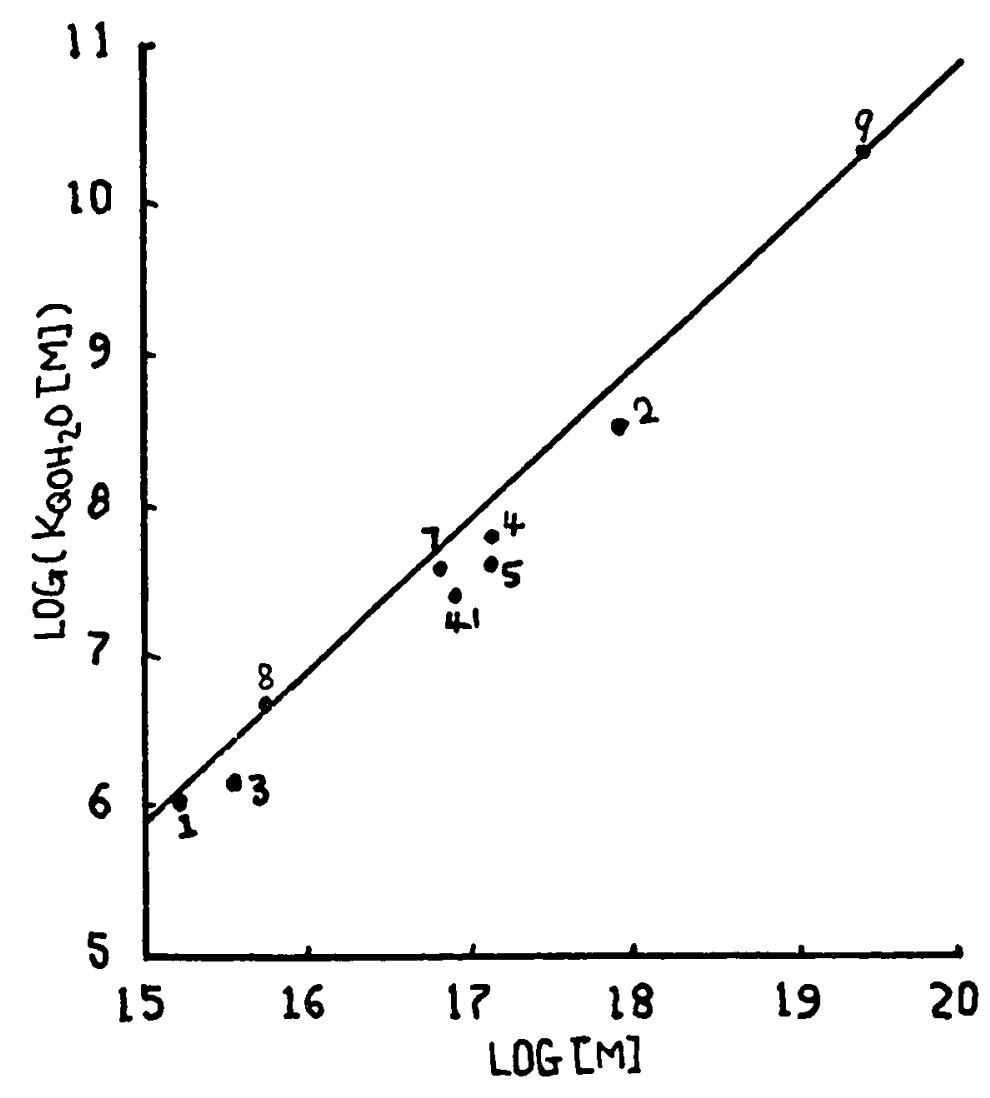

\begin{tabular}{cccccc} 
& Ref. & \multicolumn{2}{c}{ Ref. } & Ref. \\
1 & 5 & 2 & 23 & 3 & 39 \\
4 & 39 & 5 & 40 & 6 & 41 \\
7 & cited in 24 & 8 & cited in 24 & 9 & This work
\end{tabular}

\footnotetext{
Figure 30 Plot of $\log \left(\mathrm{k}_{\mathrm{QOH}} \mathrm{O}[\mathrm{M}]\right)$ against $\log [\mathrm{M}]$. The straight line has slope of 1 and intercept of $\log \left(\mathrm{k}_{\mathrm{QOH}_{2}} \mathrm{O}\right)$ measured in the experiment.
} 
obtain a reliable proportionality constant (e.g. rate constant), it is a common practice to make measurements under practical conditions which are as widely distributed as possible or at least over the range of conditions under which the rate constant is to be ultilized. The reason for this is that the errors associated with the dependent parameter are directly proportional to the distance of extrapolation. If we extrapolate the literature values out to atmospheric pressure, the deactivation rate will have large uncertainty. This is one argument for measuring the rate constant at atmospheric pressure. Figure 31 illustrates this point. The figure is a plot of the least squares fit to the literature values, $k_{Q O N_{2}}\left[N_{2}\right]$, in Table $\mathrm{XV}$ as a function of their corresponding experimental pressure. We can see that the least squares error due to extrapolation is large. The contribution of our measurement is both to provide a value and to narrow the error at atmospheric pressure.

Finally, let's consider the question of reproducibility of the experimental results. The experiment of argon plus water at dew point $-7.0 \mathrm{C}$ was done after the experiments of nitrogen and oxygen. That is about one month after the other argon plus water experiements were performed. The question that the low value of nitrogen is due to the change in the detection system can be ruled out, since the last argon plus water 


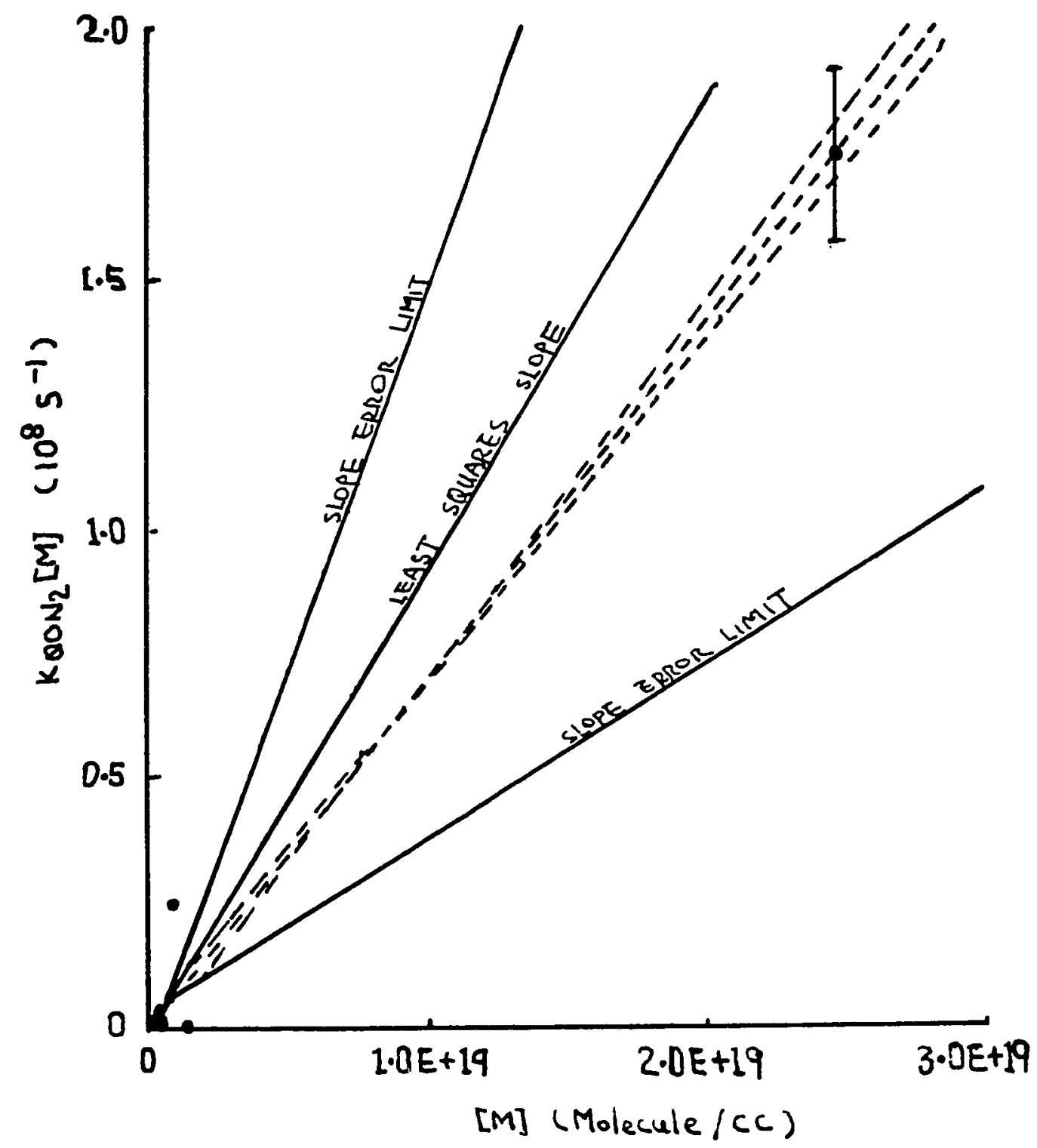

Figure 31 Linear least squares fit to the literature values, $\mathrm{kQON}_{2}[\mathrm{M}]$, in Table $\mathrm{XV}$ as a function of their corresponding experimental pressure. The solid lines do not include our own experimental value. The broken lines include our own experimental result. 
at dew point $-7.0 \mathrm{C}$ experiment agreed with the earlier results. In fact, repeated experiments with nitrogen showed no inconsistency with the earlier results. 


\section{CHAPTER V}

\section{ERROR ASSESSMENT}

This chapter assesses the uncertainty of our method and the limitation of our instruments. We will discuss the systematic errors due to the approximation by equation 26 and random errors due to the counting statistics. Finally, we will estimate the errors caused by the instability of our instruments.

Systematic and Bandom Errors

The discrete convolution (equation 26) is only an approximation. Its departure from the exact solution (equation 27 ) has to be reckoned with. Since the accuracy of the approximation depends on the step size (MCA resolution), we assessed the effects of the step size on the accuracy. The adopted strategy to check its accuracy was to simulate the input function by a Gamma function,

$$
f(t)=\alpha t^{2} \operatorname{Exp}(-0.6 t)
$$

The value of $\alpha$ was chosen so that the peak height was about 500, which is similar to real experimental results. Then the convolution was integrated in closed form with $A=2.0 \mathrm{~ns}^{-1}$ and $B=0.4 \mathrm{~ns}^{-1}$. Discrete values with various 
step sizes were then obtained for these $f(t)$ and $h(t)$. The simulated discrete data, $f(t)$ and $h(t)$, were evaluated for values of $A$ and $B$ with the simplex program. Table XVII shows the results. Evidently, larger step size introduces larger exrors. In actual experiments, the time range of the MCA was chosen for maximum resolution, while capturing the essential features of the decay curve. For values of $A$ and B comparable to Table XVII, 0.1 ns resolution was used. Thus we expect about 18 error as a result of the discrete convolution. This is small relative to the other errors. The idea is demonstrated by the time scales used in Figures 13 to 22 .

Effects of random noise on the accuracy of our approximation were also investigated. The method followed the procedure above, except random noise of various amplitudes was added to the discrete data, $f(t)$ and $h(t)$, before they were evaluated by the simplex program. Since counting statistics predicts that the noise is equal to the square root of the count, we varied the amplitude of the noise by changing the count of each channel and took the square root of the count as the noise. Thus we achieved varying noise amplitude while adhering to the square root relation. Results (Table XVIII) show that a minimum signal to noise ratio of 10 (peak count of 100 ) is required for a reliable evaluation of $A$ and $B$. In actual experiments, the peak counts are larger than 100. Thus, 
TABLE XVII

EFFECTS OF CHANNEL RESOLUTION

ON THE ACCURACY OF EQUATION 26

$\begin{array}{ccccc}\begin{array}{c}\text { Resolution } \\ \text { (ns) }\end{array} & \text { A } & \text { \% Error } & \text { B } & \text { \% Error } \\ & & & & \\ 0.25 & 2.08 & +4.0 & 0.398 & -0.4 \\ 0.20 & 2.05 & +2.3 & 0.399 & -0.2 \\ 0.15 & 2.02 & +1.0 & 0.3996 & -0.1 \\ 0.10 & 2.01 & +0.55 & 0.399 & -0.05 \\ \text { True value } & 2.00 & -- & 0.400 & --\end{array}$

TABLE XVIII

EFFECTS OF SIGNAL/NOISE RATIO ON

THE ACCURACY OF EQUATION 26

\begin{tabular}{|c|c|c|c|c|}
\hline channel & A & $\%$ Error & B & $\%$ Error \\
\hline $5 / 25$ & * & * & * & * \\
\hline $\begin{array}{l}10 / 100 \\
20 / 400 \\
30 / 900\end{array}$ & $\begin{array}{l}1.94 \\
1.99 \\
2.01\end{array}$ & $\begin{array}{l}-3.0 \\
-0.1 \\
+0.5\end{array}$ & $\begin{array}{l}0.403 \\
0.401 \\
0.399\end{array}$ & $\begin{array}{l}+0.75 \\
+0.25 \\
-0.25\end{array}$ \\
\hline True Value & 2.00 & -- & 0.400 & -- \\
\hline
\end{tabular}

* Simplex program does not converge. 
less than 38 error was introduced by limiting the length of the experiment.

\section{Convergence Test}

The idea behind the convergence test was to see how many counts had to be accumulated to give $A$ and $B$ with acceptable errors and what was the maximum count beyond which little was gained due to the errors of the other sources.

The strategy was to sample the fluorescence profile after every 1000 additional counts had been added. the experiment was carried out on the case of nitrogen plus 58 oxygen. The A's and B's were extracted from these 20 progressively growing fluorescence profiles and plotted as a function of increasing counts in Figure 32 .

The results show that initially the values do approach a certain value as the count increases. Beyond a surprisingly low 10,000 counts, the convergence is overwhelmed by the fluctuation due to other error sources. Notice that the values of $A$ and $B$ are comparatively large in this experiment.

Figure 32 also shows similar plots of $A^{\prime} s$ and $B^{\prime} s$ for argon with water concentration at dew point about -16.0C. From this figure, it appears that the values of $A$ don't converge. In the case where the $A$ and $B$ values are small, the fluorescence curve has a large area. For a large area, more counts are needed to reach the point 

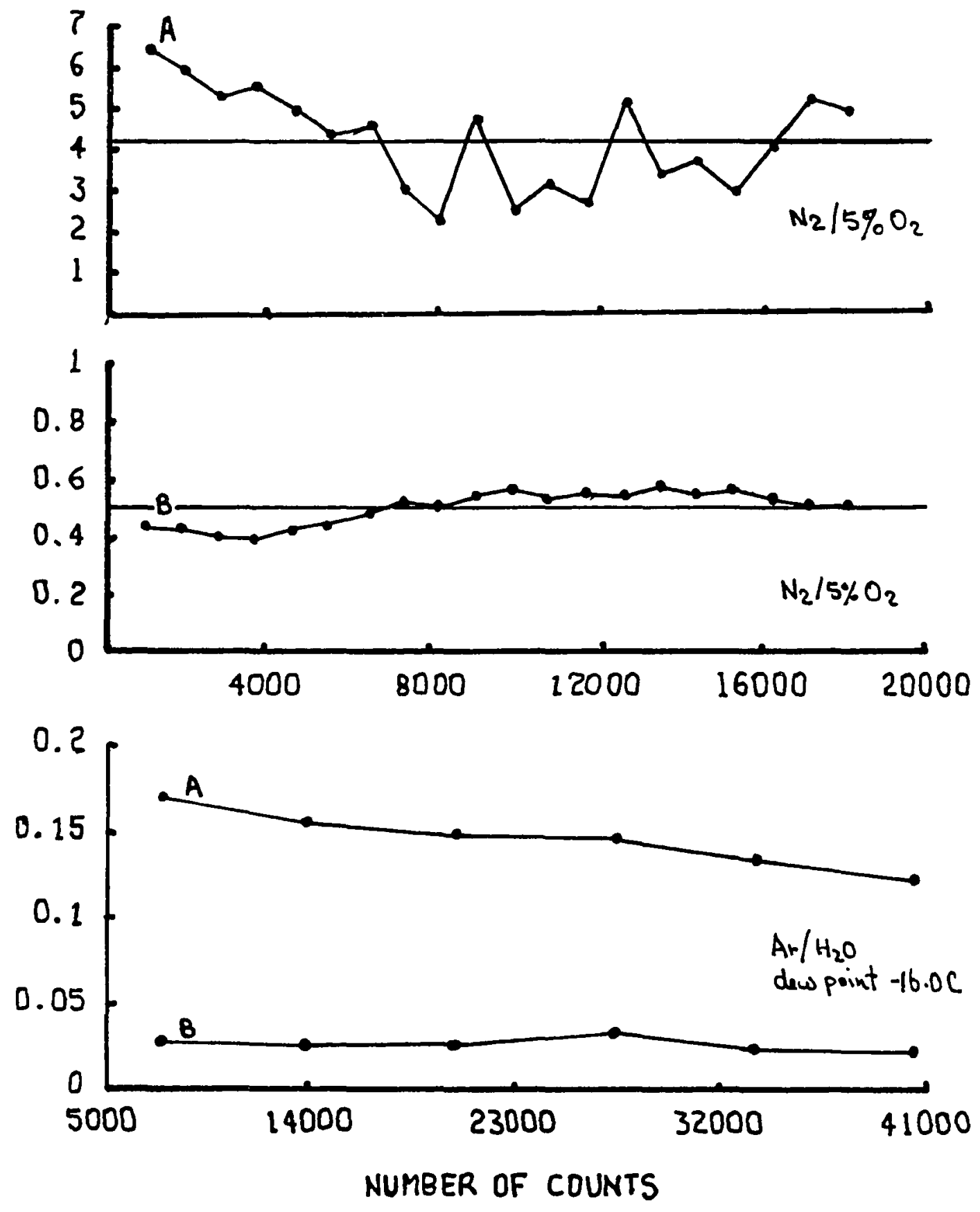

Figure 32 Values of $A^{\prime} s$ and $B^{\prime} s$ as a function of cumulative count in nitrogen $/ 5 \%$ oxygen and argon/water a dew point $-16.0 \mathrm{C}$. 
where the other fluctuations take over. Apparently this curve shows that the experiment has not passed the critical point yet.

Figure 33 is a plot of $\log$ (error) against $\log$ (count) of the results in Table XI. According to counting statistics, such a plot should result in a straight line with slope equal to -0.5 . Due to the way of defining the error $(\sigma)$, the error is equal to $1 / \sqrt{N}$, where $N$ is the count. A linear least squares fit produces a slope of -0.674 , which is somewhat greater than -0.5. No good explanation can be offered at the present time, but at least the error does decrease as the count increases.

\section{Timing Errors}

There are two sources of timing errors: the inherent timing uncertainty and the long term drift of the detection system. The inherent uncertainty refers to the uncertainty in the timing circuits of the MCA and the jitters in the start and stop pulses. The constant fraction discriminator is supposed to have minimized the jitters in the stop pulses. The largest errors are attributed to the high-speed photodiode that generated the start pulses.

To check the timing uncertainty of the MCA, a pulse was generated by a photodiode and fed into the start input of the MCA. The same pulse was delayed by a fixed length of cable (approximately 40 ns) which terminated at the 


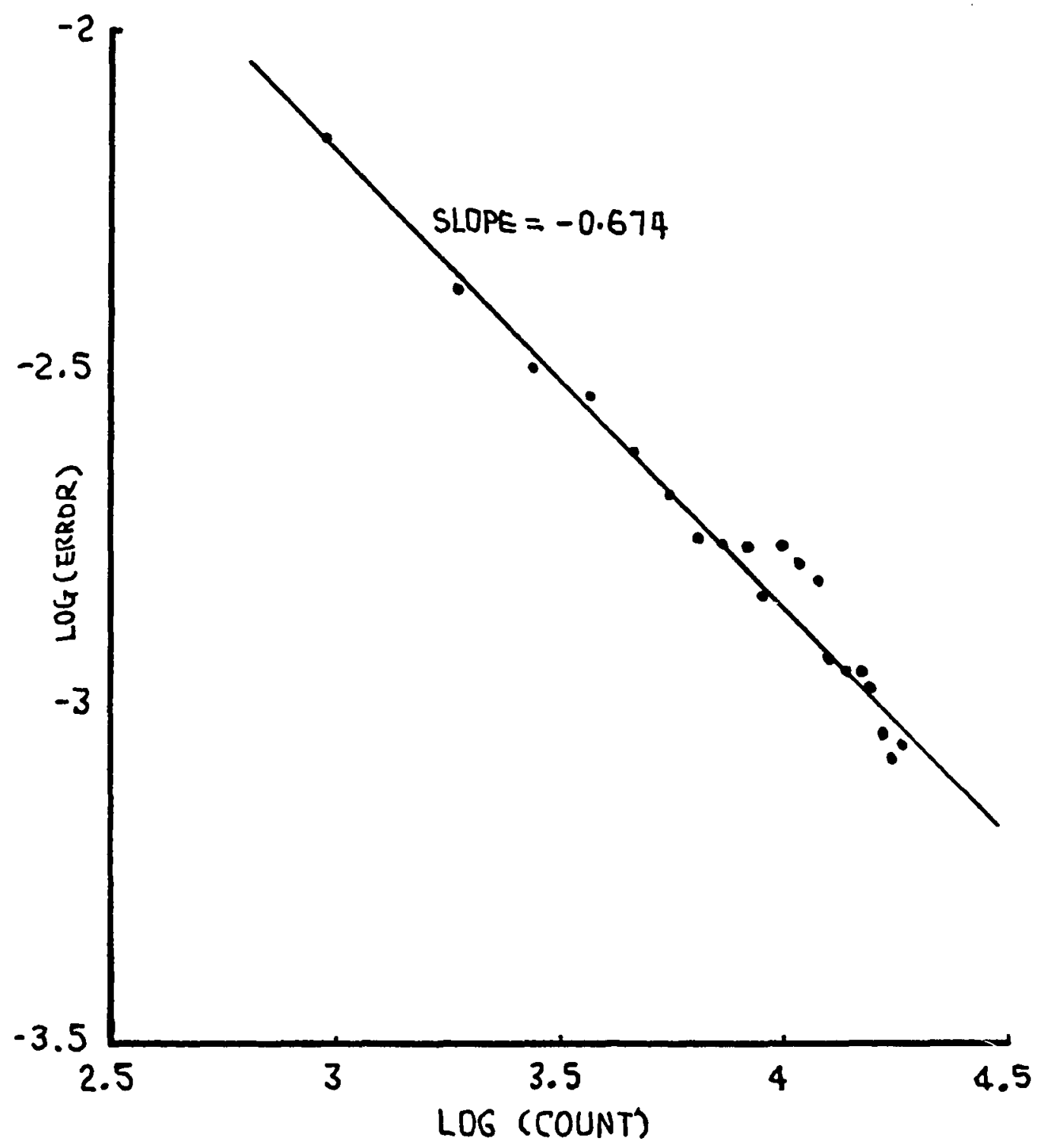

Figure 33 Plot of $\log$ (error) versus $\log$ (count) of the experiment on $\mathrm{OH}$ fluorescence in nitrogen. 
stop input. After 1,550 pulses, the spread of the delay times recorded by the MCA was analysed to have a standard deviation of about 0.08 ns. Figure 34 shows the result as it was displayed on an oscilloscope.

To check the uncertainty of the photodiode, two similar photodiodes looked at the same reflection of the laser. One photodiode generated a start and the other generated a stop pulse into the MCA. The stop pulse was routed through a longer cable to create a delay. After 18,000 laser pulses, the spread of the delay was analysed to have a standard deviation of about 0.2 ns (Figure 35). Since 0.2 ns is much larger the $0.08 \mathrm{~ns}$, the overall timing uncertainty of the detection system was estimated to be 0.2 ns.

Due to the low repetition rate of the laser system, usual experiments took several days while long experiments took over a week to complete. This long experimental time introduced errors due to the long-term detection system drift. The system drift essentially refers to the change in the timing circuits. For example, if we apply a fixed delay between the start and the stop pulse, the time circuits may measure the delay to be $3.3 \mathrm{~ns}$. A few days later, the same delay may be measured to be $3.0 \mathrm{~ns}$. This kind of drift will shift the whole laser, because the start pulse is always triggered by the laser itself. The response of the system to daily room temperature change 


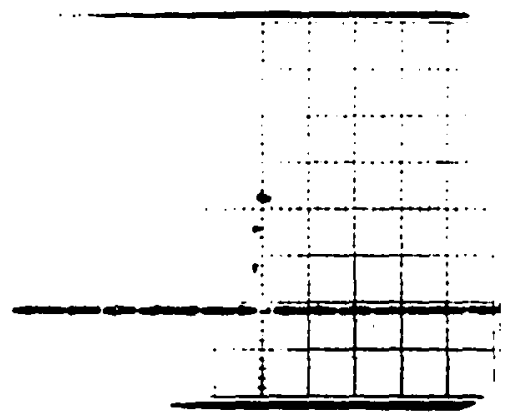

Figure 34 Uncertainty check of the MCA. Time scale is 0.1 ns per channel. 


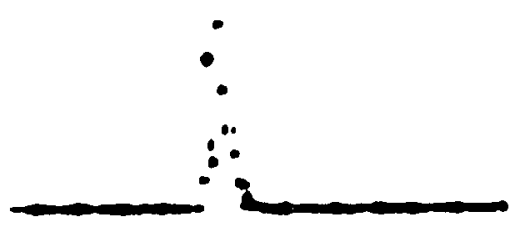

Figure 35 Uncertainty check of the high-speed photodiode. Time scale is $0.1 \mathrm{~ns}$ per channel. 
was one aspect of such kind of long-term drift.

The long term drift was tested by measuring the laser profile over a period of 12 days. Then the misalignment of the recorded laser profiles was attributed to the drifting of the whole detection system. Whether these errors were due to the constant fraction discriminator, the MCA or the photodiode were unknown, although it was most likely the photodiode. The misalignment is shown in Figures 36 to 38 .

After the detection system has warmed up for three days, the spread of the half-heights is about $0.7 \mathrm{~ns}$. The results indicate that the system, after the first three days of warming up, does not drift toward one direction but rather shifts back and forth. This led to the conclusion that the fluctuation is 0.3 ns and to the policy of leaving the detection system on continuously. It was most likely that the shifts were due to the effects of change in room temperature on the photodiode. In Figure 38, the variation of the laser half-width is also shown. The variation of the laser half-width is not as significant as the time shift.

The next logical step is to estimate the maximum effect of this 0.3 ns shift on the values of $A$ and $B$. As expected, the errors due to this shift depended on the sizes of $A$ and $B$. Thus the testing procedure used the practically observable extreme values of $A$ and $B$. 


$$
n
$$




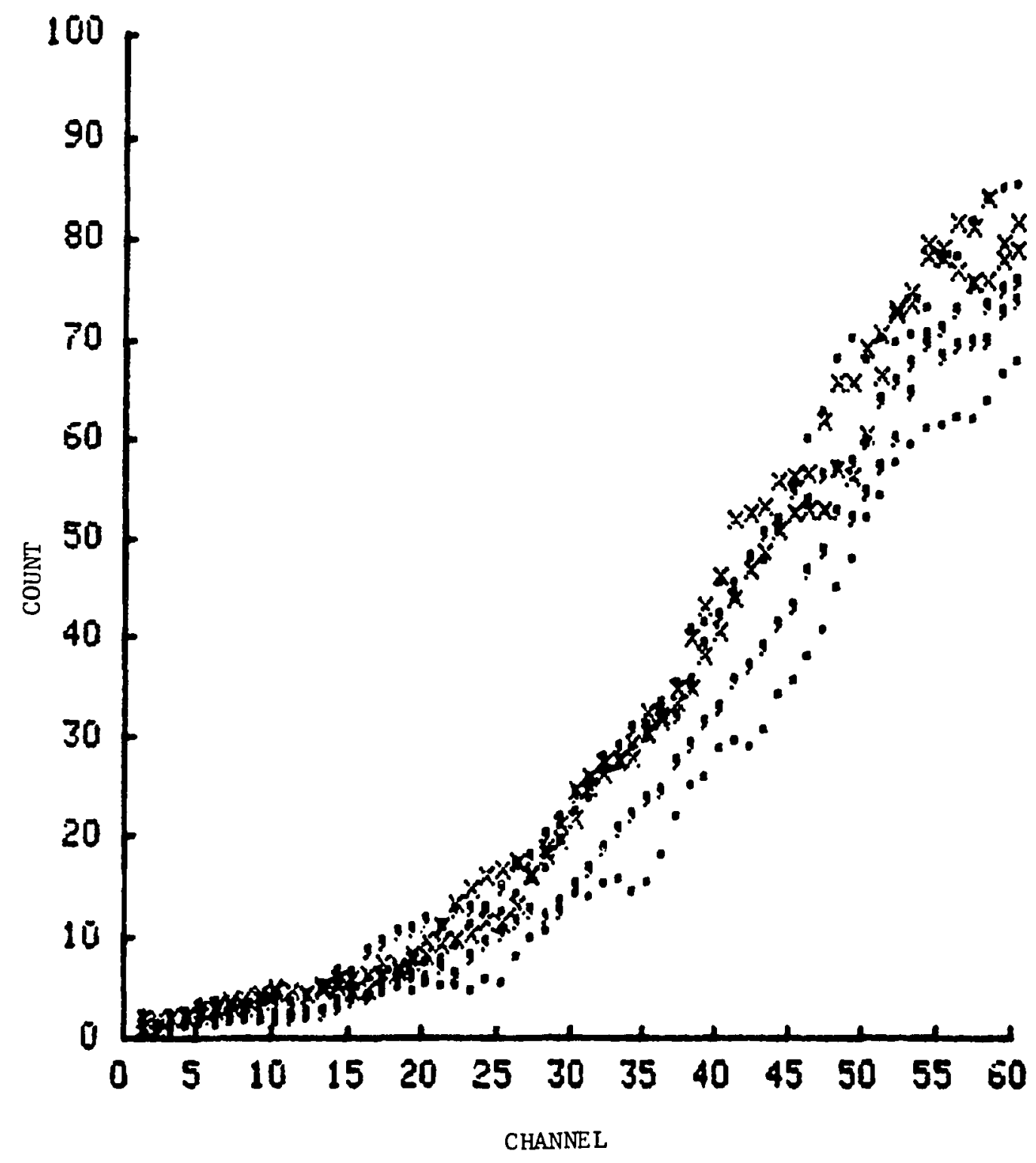

Figure 37 Misalignment of the laser profiles showing the rising portions of the profiles. 

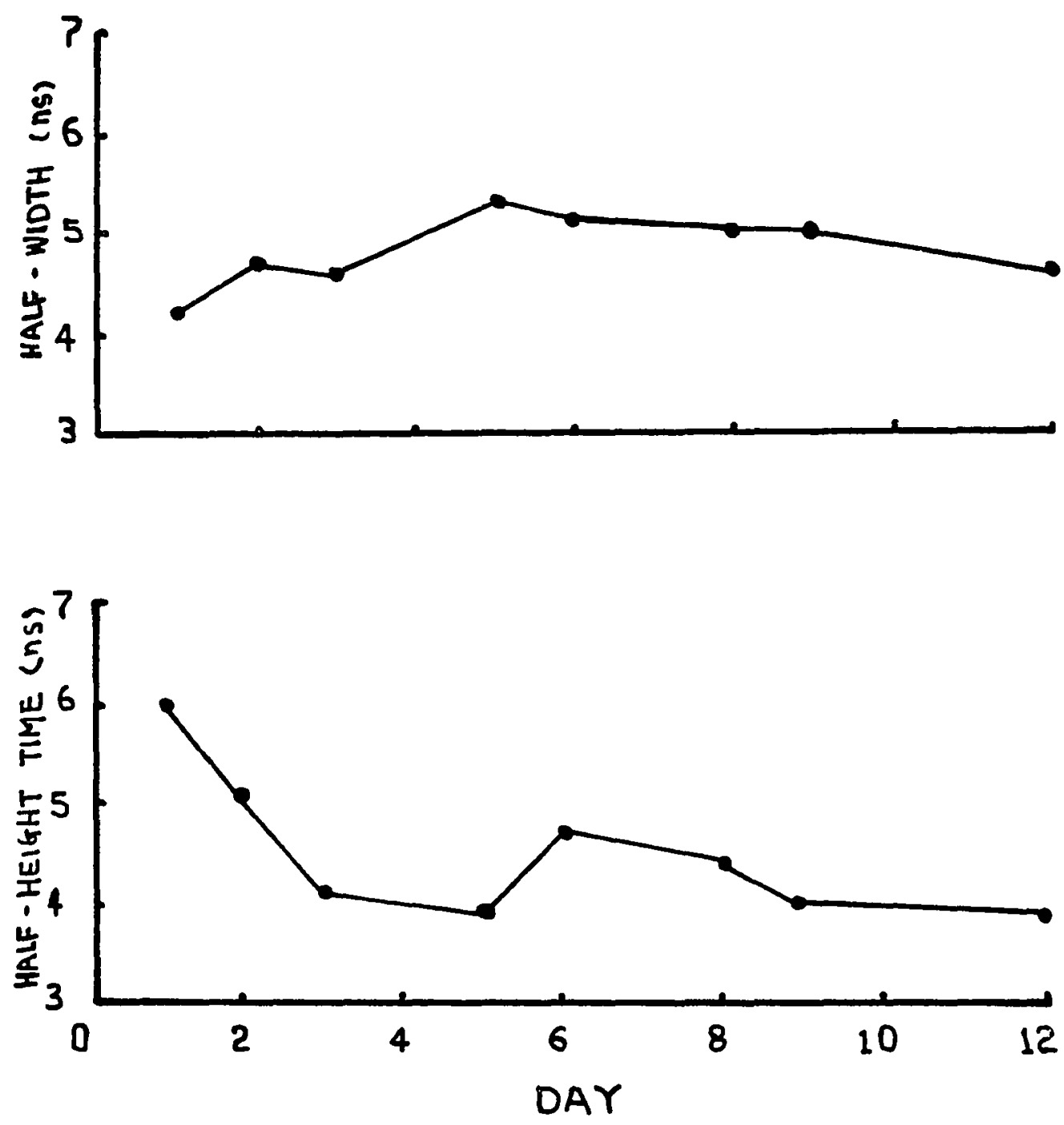

Figure 38 Plot of the half-widths and half-height times of the laser profiles as a function of days of operation. 
The testing started with a simulation of the laser profile of approximate shape and half-width. The function,

$$
f(t)=\alpha t^{2} \operatorname{Exp}(-0.6 t)
$$

was chosen. The convolution was generated by this simulated profile with various $A^{\prime} s$ and $B^{\prime} s$. After the fluorescence profile had been shifted $0.3 \mathrm{~ns}$ to the right, both the shifted fluorescence profile and the unshifted laser profile were fed into the simplex program for calculating A's and B's. The results of such trials of the selected extreme values of $A^{\prime} s$ and $B^{\prime} s$ are shown in Table XIX. The errors of this source can be as large as 308 when values of $A$ and $B$, similar to the case of nitrogen plus 58 oxygen, are large.

Large errors for large values of $A$ and $B$ are intuitively logical. Large values of $A$ and $B$ mean short decay times. Given an instrument, it is harder to measure a short decay than a long decay. If we take a simple view that the reciprocal of $A$ is the lifetime, when $A$ is $6 \times 10^{10} \mathrm{sec}^{-1}$, the lifetime is about $0.17 \mathrm{~ns}$, as compared to a laser half width of $7 \mathrm{~ns}$, and a potential timing uncertainty of 0.3 ns! 
TABLE XIX

ESTIMATION OF THE ERRORS DUE TO - 0.3

nS SHIFT OF THE LASER PROFILE SIMULATION

True Value

A

B

A

B
6.0

0.6

0.2

0.02
Simplex Value

7.81

0.723

0.208

0.0198
Percent Error

$+30.2 \%$

$+20.5 \%$

$+4.0 \%$

$+1.0 \%$ 
CHAPTER VI

DISCUSSION

\section{Limits en $A$ and $B$}

How large can the values of $A$ and $B$ be before our method ceases to provide answers with acceptable uncertainty? The limits on $A$ and $B$ are controlled by factors such as the resolution of the ilCA, the jitters of the start pulse and other uncertainty factors discussed in Chapter V. We will look at the effects of the laser half-width on the limits on $A$ and $B$.

The manifestation of reaching the limits of $A$ and $B$ is that beyond certain values of $A$ and $B$, a large change in the values of $A$ and $B$ does not produce $a$ significant change in the errors of the least squares fit. Thus, there is large uncertainty associated with the values of $A$ and $B$, because the simplex may result in a wide range of values.

In general, for narrower laser half-width, larger $A$ and $B$ can be resolved. This is because with a narrow laser half-width, comparatively large A and B can still produce an output function that aiffers significantly from the input function. This effect can be illustrated with our experimental results of $\mathrm{OH}$ in nitrogen.

In the early experiments, when the dye laser was 
tuned by a diffraction grating, the laser half-width was about 7 ns. With 7 ns half-width, we resolved the fluorescence of $\mathrm{OH}$ in nitrogen successfully. However, when the tuning mechanism was changed to a mirror to increase output power, the laser half-width was broadened to about 10 ns and the laser profile looked like two peaks overlapping each other with their peak maxima separated by about 5 ns (see Figure 39). Since then, we could not evaluate $A$ and $B$ from the fluorescence in nitrogen. The results are shown in Figure 39.

Actually, the experiments of $\mathrm{OH}$ fluorescence in $\mathrm{N}_{2} / 28 \mathrm{O}_{2}$ and $\mathrm{N}_{2} / 58 \quad \mathrm{O}_{2}$ had al ready been close to the limits of our instrument even with 7 ns laser half-width. This is evident from the error bars associated with each result shown in Figure 25. With a laser half-width of $10 \mathrm{~ns}$, such large values of $A$ and $B$ make the deconvolution impossible.

\section{Photelytic Interference}

Photolytic interference is caused by the generation of $\mathrm{OH}$ radicals by the laser. This, in effect, changes the $\mathrm{OH}$ concentration within the duration of the laser pulse and perturbs the linear system assumption.

To study the photolytic effects of ozone is a major project in its own right. We will touch upon the problem but will not provide a detailed solution to the problem. Essentially, we will show that the high values of the rate constants by oxygen are not due to ozone interference. 


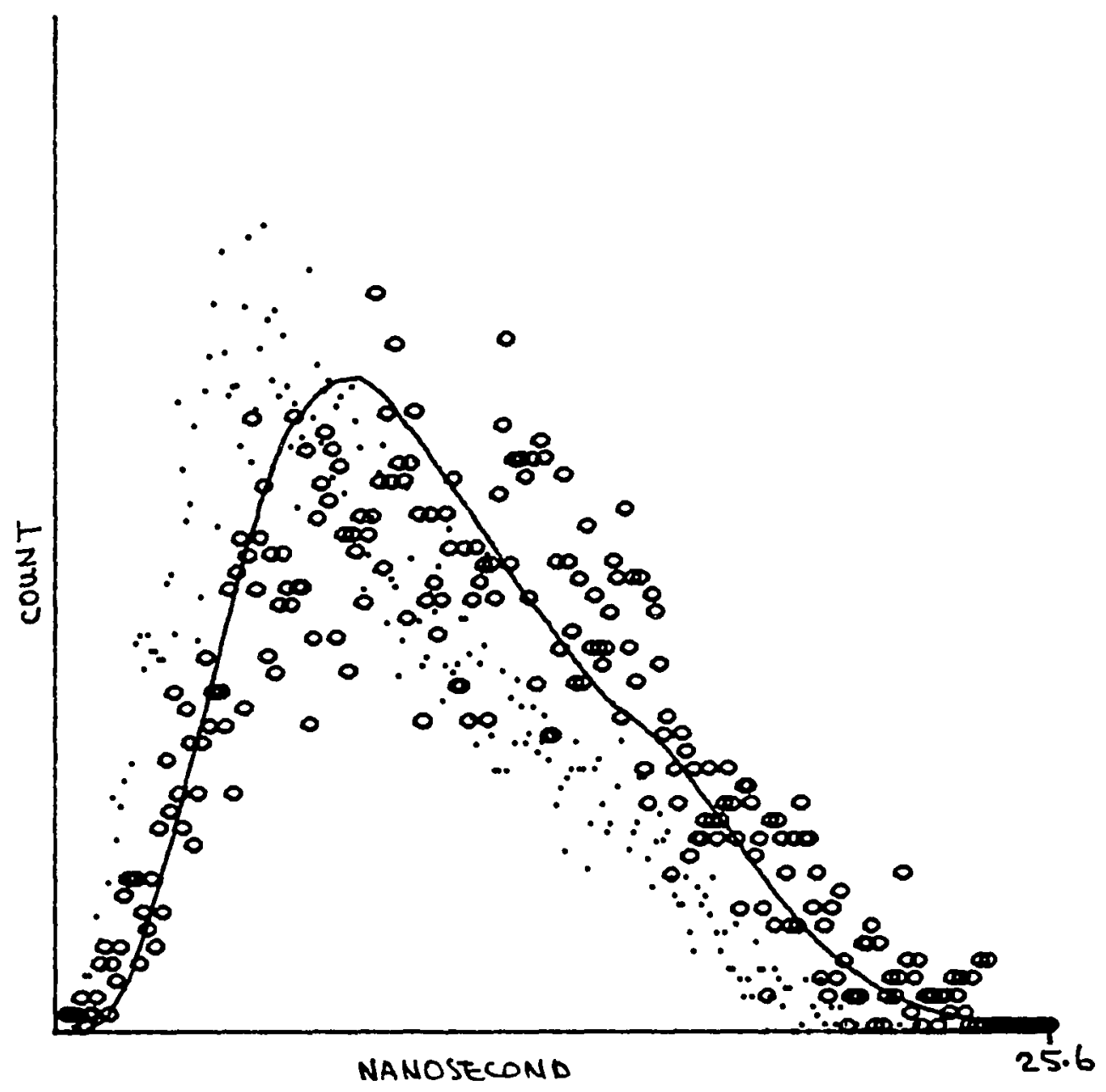

Figure 39 Fluorescence of $\mathrm{OH}$ in nitrogen due to the excitation by a 10 ns half-width laser. o - fluorescence, - laser, solid line - least squares fit. 
Photolytic interference by ozone is due to the photodecomposition of ozone into oxygen and $\mathrm{O}^{\prime} \mathrm{D}$. The $\mathrm{O}^{\mathrm{D}} \mathrm{D}$ subsequently reacts with water to produce rotationally excited $\mathrm{OH}(\mathrm{OH} t)$, which eventually cascades down to the ground state. In effect, this increases the $\mathrm{OH}$ concentration within the duration of the excitation laser pulse.

The processes can be represented by the following equations:

$$
\begin{aligned}
& \mathrm{O}_{3}+\mathrm{hJ}^{\mathrm{k}_{1}} \rightarrow \mathrm{O}^{\prime} \mathrm{D}+\mathrm{O}_{2} \quad 59 \\
& \mathrm{O}^{\prime} \mathrm{O}+\mathrm{H}_{2} \mathrm{O} \stackrel{\mathrm{K}_{2}}{\rightarrow} 2 \mathrm{OH}^{+} \quad 60 \\
& \mathrm{O}^{\prime} \mathrm{O}+\mathrm{N}_{2} \stackrel{\mathrm{K}_{3}}{\longrightarrow} \text { Loss } \\
& \mathrm{O}^{\prime} \mathrm{O}+\mathrm{O}_{2} \stackrel{\mathrm{KH}_{4}}{\longrightarrow} \text { Loss } 62 \\
& \mathrm{OH}^{+}+\mathrm{M} \stackrel{\mathrm{ks}}{\longrightarrow} \mathrm{OH} \quad 63
\end{aligned}
$$

We can write the rates of change of $\mathrm{O}^{\prime} \mathrm{D}$ and $\left[\mathrm{OH}^{+}\right]$as:

$$
\begin{aligned}
& \frac{d\left[O^{\prime} O\right]}{d t}=-\left[O^{\prime} D\right]\left(K_{2}\left[H_{2} D\right]+K_{3}\left[N_{2}\right]+K_{4}\left[O_{2}\right]\right) \\
& \frac{d[O H t]}{d t}=2\left[O^{\prime} D\right]\left[H_{2} O\right] K_{2}-K_{5}\left[O^{t}\right][M]
\end{aligned}
$$

In equation 64 we assume that there is an initial concentration of $O^{\prime} D\left(\left[O^{\prime} D\right]_{0}\right)$ just as we assume that there is an initial concentration $\left[\mathrm{OH}^{*}\right]_{0}$ in Chapter II. Later, we can replace the $\left[O^{\prime} \mathrm{D}\right]_{0}$ with a time dependent input function related to the laser profile. If we solve 
equations 64 and 65 , we will obtain an double exponential decay as in the case of $\left[\mathrm{OH}^{*}\right]$ cascading into [OH**]. The relaxation of $\mathrm{OH}^{+}$into $\mathrm{OH}$ is one more step that modifies the double exponential decay a bit. Then we can use the laser as an input function and the modified response function to find out how the concentration of the spurious $\mathrm{OH}$ changes as a function time. One complication is that we have to know the absolute concentration of the ozone, the laser intensity and the quantum yield of old at $282 \mathrm{~nm}$ in order to assess the final effect on the fluorescence decay curve. In general, this spurious $\mathrm{OH}$ will distort the true fluorescence curve. Figure 40 shows an approximate spurious fluorescence curve as compared to the true fluorescence.

Another photolytic source is two-photon photolysis of $\mathrm{H}_{2} \mathrm{O}(22)$. The two-photon dissociation process was minimized by keeping the laser energy low and the beam diameter large (about $0.3 \mathrm{~cm}$ ). Still another source of spurious $\mathrm{OH}$ is by photolysis of $\mathrm{H}_{2} \mathrm{O}_{2}$ generated by the reaction of $\mathrm{OH}+\mathrm{OH}$. Since its absorption has not quite tailed out near $280 \mathrm{~nm}, \mathrm{H}_{2} \mathrm{O}_{2}$ still can be photolysed by the laser. But notice that the detection zone is always illuminated by the mercury lamps. Any $\mathrm{H}_{2} \mathrm{O}_{2}$ will be quickly photolysed by the lamps. Under experimental conditions, production of $\mathrm{H}_{2} \mathrm{O}_{2}$ is not favored. Hence, photolysis of $\mathrm{H}_{2} \mathrm{O}_{2}$ by the laser to $\mathrm{OH}$ is minimized. 


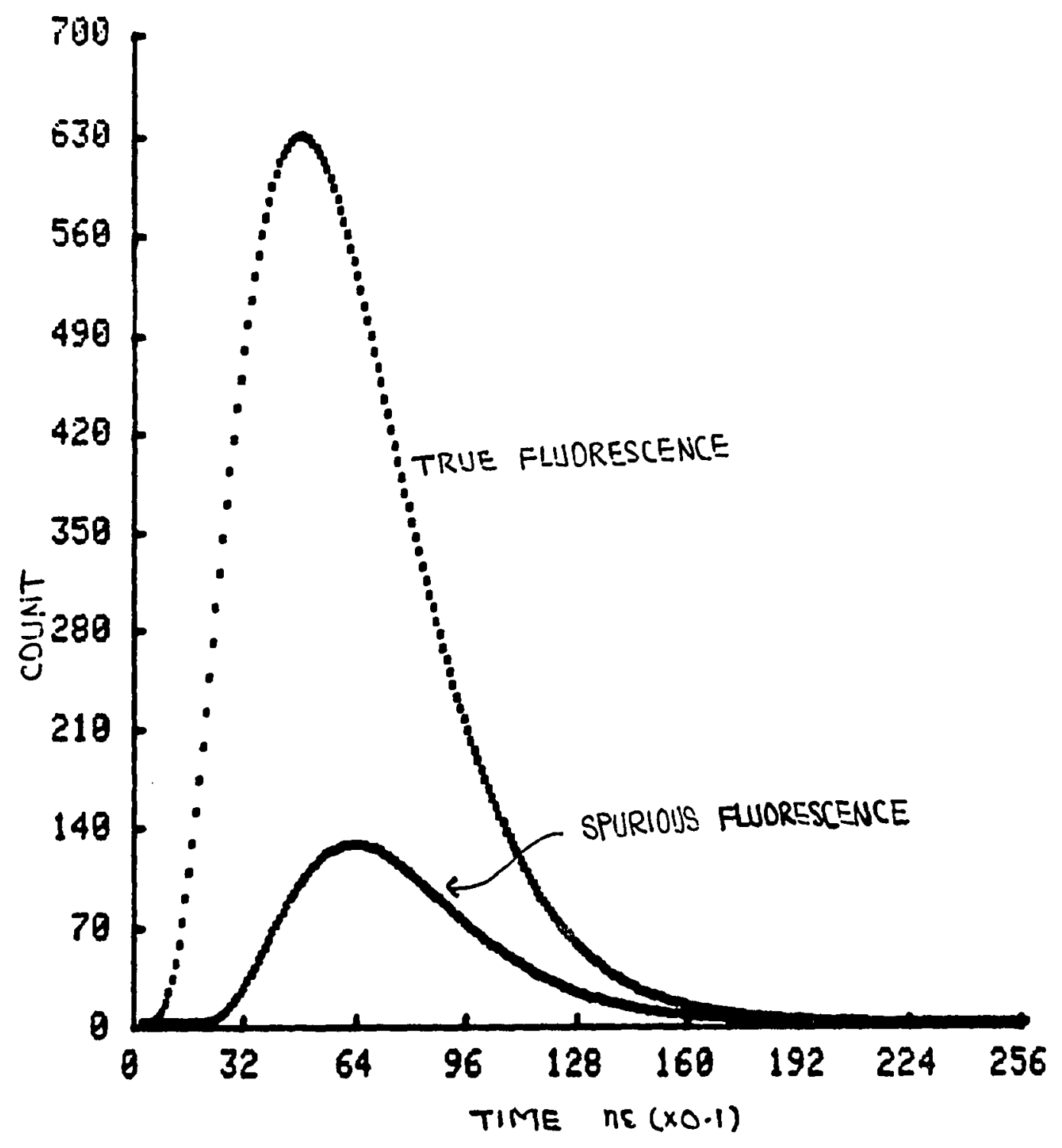

$\begin{aligned} & \text { Figure } 40 \text { Time dependency of spurious OH fluorescence } \\ & \text { signal as compared to the true fluorescence signal. }\end{aligned}$ 
The effects of spurious fluorescence on the true fluorescence were checked with simulations. Spurious fluorescence of various amplitudes was added to the simulated fluorescence curves and these corrupted Eluorescence curves were analyzed for $A$ and $B$ by the simplex program. The results are shown in Table $x x$. The results show that the spurious fluorescence can only reduce the values of $A$ and $B$ and therefore cannot explain the high results.

\section{Improvement}

The biggest problem is the long term drift of the detection system described in Chapter V. An immediate improvement is to use a laser with higher repetition rate. High repetition rate shortens the experimental time which minimizes the arift due to the change in room temperature or the drift of the instruments. A high repetition rate also makes a larger count feasible. This again decreases the errors. One suitable candidate is the XeBr laser.

The other timing errors can be reduced by a fast and less temperature sensitive photodiode. Enclosing the photodiode in a constant temperature oven is another approach to the temperature problem. A shorter rise time definitely reduces the time jitter. A Laser with narrower pulse width will also allow larger values of $A$ and $B$ to be measured.

Another improvement that can be made is to use two 
TABLE XX

EFFECTS OF OZONE INTERFERENCE ON THE VALUES OF A AND B

$\begin{array}{ccc}\text { Amplitude* } & \text { A } & \text { B } \\ 0 & & \\ 0.1 & 2.0 & 0.40 \\ 0.2 & 1.59 & 0.384 \\ 0.3 & 1.27 & 0.380 \\ 0.4 & 1.01 & 0.389 \\ 0.5 & 0.82 & 0.41 \\ & 0.89 & 0.37\end{array}$

* Amplitude refers to the ratio of the peak height of the spurious signal to the true fluorescence signal. 
detection systems. One detector monitors the laser scattering while the other measures the fluorescence. This will minimize the effects due to the change of the laser profile.

\section{Effects of The New Rate constants}

What are the effects of the new rate constants on the reported ambient $\mathrm{OH}$ concentration? According to equation 52, the integrated fluorescence intensity at 309 $\mathrm{nm}$ is inversely proportional to the product of $\mathrm{A}$ and $\mathrm{B}$ and directly proportional to $k^{\prime} 10$. We will consider the correction by the rate constant of water alone and by all measured rate constants. For comparison, the rate constants recommended by scholfield will be used. We will assume $\mathrm{K}_{10} \mathrm{H}_{2} \mathrm{O}$ to be $1 \times 10^{-9} \mathrm{~cm}$ molecule $\mathrm{sec}^{-1}$, since it is quoted as "fast".

For the case of the rate constant of water alone, it results in an 32.58 increase in the reported values. For the case of all the rate constants, it results in and $31.2 \%$ increase. In essence, our experimental results agree with the reported $\mathrm{OH}$ measurements within the instrumental uncertainty. 


\section{REFERENCES}

1 R.K. Lengel and D.R. Crosley, J. Chem. Phys. 64, 3900 (1976).

2 J.A. Coxon, Can. J. Phys. 58, 933 (1980).

3 T. Carrington, J. Chem. Phys, 41, 2021 (1964).

4 V.N. Kondrat'ev, Chem. Kinetics of Gas Reaction (Pergamon Press Inc., N.Y. 1964).

5 B.G. Bunnett and F.W. Dalby, J. Chem. Phys. 40, 1414 (1964).

6 H.P. Hooymayers and C.Th.J. Alkemabe, J. Qunt. Spectry. Radiative Transfer 7, 495 (1967).

7 C.C. Wang, L.I. Davis Jr., C.H. Wu, S. Japar N. Niki and B. Weinstock, Science 189, 797 (1975).

8 D.D. Davis, W. Heaps and T. McGee, Geophys. Res. Lett. $3,331(1976)$.

9 P.J. Crutzen and J. Fishman, Geophys. Res. Lett 4, 321 (1977).

10 H. Levy, Science 173, 141 (1971).

11 S.C. Wofsy, J.C. McConnel and M.B. McElroy, J. Geophys. Res. 77, 4477 (1972).

12 W.L. Chameides and J.C.G. Walker, J. Geophys. Res. 78,8751 (1973). 
13 J.A. Logan, M.J. Prather, S.C. Wofsy and M.B. McElroy, J. Geophys. Res. 86, 7210 (1981).

14 J.G. Anderson, Geophys. Res. Lett. 3, 165 (1976).

15 C.R. Burnett, Geophys. Res. Lett. 3, 319 (1976).

16 D. Perner, D.H. Ehhalt, H.W. Patz, U.Platt, E.P. Roth and A. Voiz, Geophys. Res. Lett. 3, 466 (1976).

17 M.J. Campbell, J.C. Sheppard and A.F. Au, Geophys. Res. Lett. 3, 175 (1979).

18 E.L. Baardsen and R.W. Terhune, Appl. Phys. Lett. 21,209 (1972).

19 C.C. Wang, L.I. Davis Jr., P.M. Selzer and R. Munoz, J. Geophys. Res. 86, 1181 (1981).

20 D.D. Davis, W.S. Heaps, D. Philen, M. Rodgers, T. McGee, A. Nelson and A.J. Moriarty, Rev. Sci. Instrum. 50,1505 (1979).

21 M. Rokni, J.H. Jacob, J.A. Mangano and R. Brochu, Appl. Phys. Lett. 31, 79 (1977).

22 C.C. Wang and L.I. Davis Jr., J. Chem. Phys. 62, 53 (1975).

23 P.M. Selzer and C.C. Wang, J. Chem. Phys. 71, 3786 (1979).

24 K. Schofield, J. Phys. Chem. Ref. Data 8, 763 (1979).

25 J. Yguerabide, Methods of Enzymology XXVI, 498 (1972).

26 V.J. Koester and R.M. Dowden, Rev. Sci. Instrum. 49,1186 (1978). 
27 C.C. Davis and T.A. King, Rev. Sci. Instrum. 4l, 407 (1970).

28 C.C. Davis and T.A. King, J. Phys. A3, 101 (1970).

29 D.E. Donohue and R.C. Stern, Rev. Sci. Instrum. 43, 791 (1972).

30 P.B. Coates, J. Phys. E1, 878 (1968).

31 D.A. Gedcke and W.J. McDonald, Nucl. Instrum. Methods $58,253(1968)$.

32 ORTEC Model 270 Constant Fraction Timing Photomultiplier Base Operating Manuel.

33 K.R. German, J. Chem. Phys. 64, 4065 (1976).

34 2. Bay, Phys, Rev. 77, 419 (1950).

35 z. Bay, V.P. Heuri and H. Kanner, Phys. Rev. 100, 1197 (1955).

36 W.P. Helman, Inst. J. Radiat. Phys. Chem. 3, 283 (1971).

37 I. Isenberg and R.D. Dyson, Biophys. J. 9, 1337 (1969).

$38 \mathrm{R}$. Schuyler and I. Isenberg, Rev. Sci. Instrum. 42, 813 (1971).

39 K.H. Becker, D. Haaks, Z. Naturfosch 28a, 249 (1973).

40 D. Kley and K.H. Welge, J. Chem. Phys. 49, 2870 (1968).

41 M.A.A. Clyne and S. Down, JCS Faraday Trans. II 70, 253 (1974). 
42 M.Kaneko, Y. Mori and I. Taneka, J. Chem. Phys. 48, 4468 (1968).

43 P. Hogan and D.D. Davis, J. Chem. Phys. 64, 3901 (1976).

44 R.K. Lengel and D.R. Crosley, Chem. Phys. Lett. 32, $261(1975)$.

45 J.A. Nelder and R. Mead, The Computer J. 5, 308 (1965).

46 L.C.W. Dixon, Nonlinear Optimisation (Crane, Russak and Co. Inc., N.Y. 1972).

47 R.K. Lengel and D.R. Crosley, J. Chem. Phys. $68,5309(1978)$. 
APPENDICES 


\section{APPENDIX A}

\section{SIMPLEX SEARCH}

The current accepted Simplex optimization technique is that due to Nelder and Mead(45). The following is mostly based on Dixon(46).

A simplex consists of a pattern of at least $n+l$ points enclosing a non-zero volume in $\mathrm{n}$ dimensional space. The simplex search is now commonly used for minimizing a mathematical function of several variables. In our case, this function will be the variance or the standard deviation.

Let $n+1$ points of the simplex be denoted by $x^{i}$, $i=1, \ldots, n+1$. The initial simplex is normally formed by making an estimate $x^{\prime}$ and then taking a step along each axis $e^{i}, i=1, \ldots, n$ so that

$$
x^{1+i}=k x^{i}
$$

for some selected values of $k$. In this program, $k$ is 0.5 . The function values (standard deviations), $f i, i=1, \ldots n$, of each point $x^{i}$ are calculated. The values $f i$ are sorted into

$$
f\left(x^{h}\right)=\text { maximum } f_{i} \text {, }
$$




$$
\begin{aligned}
& f\left(x^{g}\right)=\text { second maximum } f_{i}, \\
& f\left(x^{l}\right)=\text { minimum } f i .
\end{aligned}
$$

of the points of the simplex, $x^{h}$ now has the worst function value. It is therefore the point to be replaced.

To determine the new point, the centroid $x^{c}$ of the remaining points is calculated:

$$
x^{c}=\left(\left(\sum_{i=1}^{n+1} x^{i}\right)-x^{h}\right) / n \text {. }
$$

AS

Then the reflection point of $x^{2}$ about the controid,

$$
x^{h}=2 x^{c}-x^{h}
$$

A6

and its function value $f\left(x^{r}\right)$ are calculated. Then this function value is checked for improvement. If we have

$$
f\left(x^{h}\right) \geq f\left(x^{h}\right)
$$

too large a step has been taken, and a contraction, $x n$, is made according to the definition:

$$
x^{n}=0.3 x^{h}+0.7 x^{c}
$$

A8

If the $\mathrm{x}^{r}$ is an improvement based on the criterion:

$$
4 f\left(x^{r}\right)-f\left(x^{h}\right)<f\left(x^{l}\right),
$$


then there is a possibility that a larger step in the same direction may be beneficial, i.e.

$$
x^{e}=4 x^{r}-3 x^{2} \text {. }
$$

A10

If the extension is successful, i.e.

$$
f\left(x^{e}\right) \leqslant f\left(x^{r}\right),
$$

then we replace the $x h$ by $x e$. If $x e$ is not succesful, then we replace $x^{h}$ by $x^{r}$.

If the contraction results in

$$
f\left(x^{n}\right) \geq f\left(x^{h}\right)
$$

Al2

then a massive contraction is made on the simplex by

$$
x^{i}=\left(2 x^{i}+x^{l}\right) / 3
$$

Al3

The process is terminated as soon as

$$
\sum_{i=1}^{n+1}\left(f\left(x^{i}\right)-f\left(x^{l}\right)\right)^{2}<\varepsilon
$$

A14

where $\varepsilon$ is some preset small number called the convergence factor.

The above description is intended to introduce the terminology used in the flow chart (Figure 41). For the details on the interation procedure, please consult the 
flow chart in Figure 41. A FORTRAN program of the flow chart can be found in Table XXI. Any ventures into the forbidden values by the program e.g. negative $A$ and $B$ are discouraged by returning an artificially large function value.

The biggest defect of the simplex mehtod is that sometimes it does not converge on the true minimum but terminates itself in local minimum. 


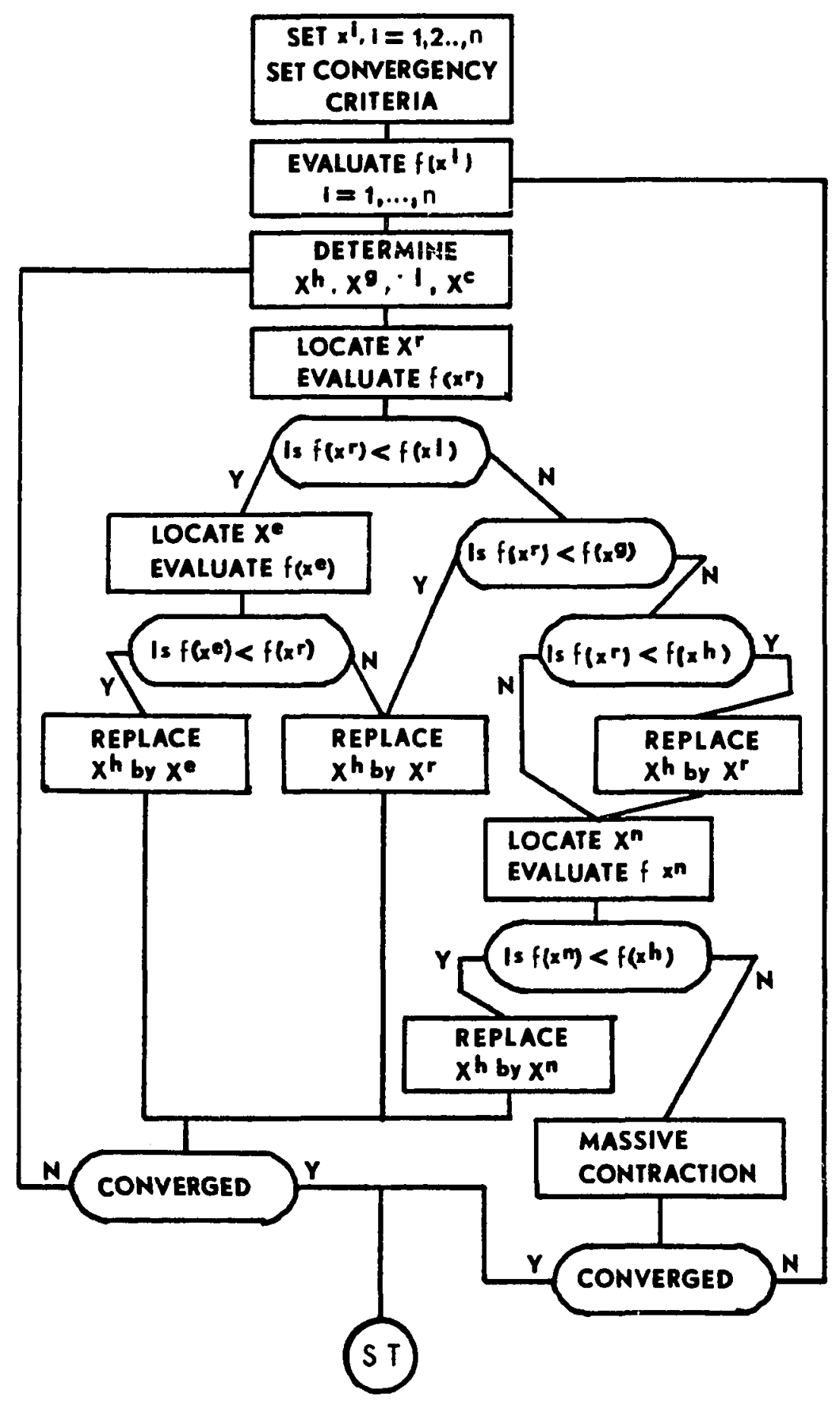

Figure 41 Flow chart of the simplex iteration procedure. 
TABLE XXI

SIMPLEX PROGRAM WITH THE CONVOLUTION SUBROUTINE

C $N$ IS THE NUMBER OF VARIABLES TO BE SOUGHT.

C N+3 IN THIS CASE. Y 8 IS THE RETURNED

C FUNCTION VALUE TO BE MINIMIZED

10 IMPLICIT REAL (A-Z)

20 INTEGER I, J,K,KL,K2,K3,JI,LI,N

$25 \mathrm{~N}=3$

30 DIMENSION $V(N), H(256), L(256), D(256), D \perp(256)$

35 DIMENSION $B(N, N+2), C(N), R(N), Y 9(N+2)$

C TRIAL COUNT

$40 \mathrm{LI}=0$

C READ DATA FORM PERMANENT FILES TO MATRICES D AND D 1

$50 \mathrm{~K}=0$

60 DO $35 I=1,64$

$70 \mathrm{KI}=\mathrm{K}+1$

$80 \mathrm{~K} 2=K 1+1$

$90 \times 3-K 2+1$

$100 \mathrm{~K}=\mathrm{K} 3+1$

110 READ $(22,33) D(K 1), D(K 2), D(K 3), D(R)$

120 READ $(23,33) D I(K), D 1(K 2), D I(K 3), D 1(K)$

13035 CONTINUE

14033 FORMAT (F 8.3,10X,F 8.3,10X,F8.3,10X,F 8.3)

C CONVERGENCE FACTOR

$150 \mathrm{CE}=1 . \mathrm{OE}-5$

C STARTING VARIABLES GUESSES, CHANGE ACCORDING TO $\mathrm{N}$

$160 \mathrm{~B}(1,1)=40$

$170 \mathrm{~B}(2,1)=.18$

$180 \mathrm{~B}(3,1)=1.3$

C CALCULATE THE OTHER VERTICES, 0.5 OF ORIGINAL VALUES

190 DO I I $=2, \mathrm{~N}+1$

200 DO $2 \mathrm{~J}=1, \mathrm{~N}$

210 IE (I-1.EQ.J) Goro 100

$220 B(J, I)=B(J, 1)$

230 GOTO 2

$240100 B(J, I)=0.5 \star B(J, 1)$

2502 CONTINUE

2601 CONTINUE

27050 DO $3 \quad I=1, N+1$

280 DO $4 \mathrm{~J}=1, \mathrm{~N}$

$290 \& V(J)=B(J, I)$

300 CALL CALC $(Y B, V, D, L, H, D), L I)$

310 Y 9 (I) $=\operatorname{SQRT}(Y 8)$

3203 CONTINUE

C SORTING, $B(X, 1)$ IS THE SET $(X)$ WITH LARGEST VARIANCE

33060 DO $5 \quad I=1, N$

340 DO $6 \quad J=I+1, N+1$

350 IF ( $Y 9(I)-Y 9(J)$. GT. O) GOTO 6

$360 \times 9(N+2)=Y 9(\mathrm{~J})$

370 Y $9(J)=Y 9(I)$

$380 Y 9(I)=Y 9(N+2)$

390 DO $7 \mathrm{~K}=1, \mathrm{~N}$

$400 B(K, N+2)=B(K, J)$

$410 \mathrm{~B}(\mathrm{R}, \mathrm{J})=\mathrm{B}(\mathrm{K}, \mathrm{I})$

$4207 \mathrm{~B}(\mathrm{~K}, I)=\mathrm{B}(\mathrm{K}, \mathrm{N}+2)$

4306 CONTINUE

4405 CONTINUE

C CALCULATE THE CENTROID

450 DO $8 I=1, N$

$460 \mathrm{C}(I)=0$

470 DO $9 \mathrm{~J}=1, \mathrm{~N}+1$

$4809 C(I)=C(I)+B(I, J)$

$490 C(I)=(C(I)-B(I, I)) / N$

5008 CONTINUE

C calculate the REFLECTion potnT

510 DO $10 I=1, N$

$52010 R(I)=2 * C(I)-B(I, 1)$

C CALCULATE THE VARIANCE OF THE REFLECTION POINT

530 DO $11 I=1, \mathrm{~N}$

$54011 V(I)=R(I)$

550 CALL CALC (Y $8, V, D, L, H, D 1, L 1)$

560 PRINT, 'NUMBER OF TRIALS:',

570 PRINT, 'LEAST VARIANCE '

580 PRINT, 'VARIABLE 1' 'VARIABLE 2', 'VARIABLE $3{ }^{\prime}$

5 9ी PRINT, B $(1,4), B(2,4), B(3,4)$

60) PRINT, 'CONVERGENT FACTOR',

610 PRINT, $* \hbar *$

$620 \mathrm{Rl}=\mathrm{SORT}(\mathrm{Y} 8)$ 
TABLE XXI CONTINUED

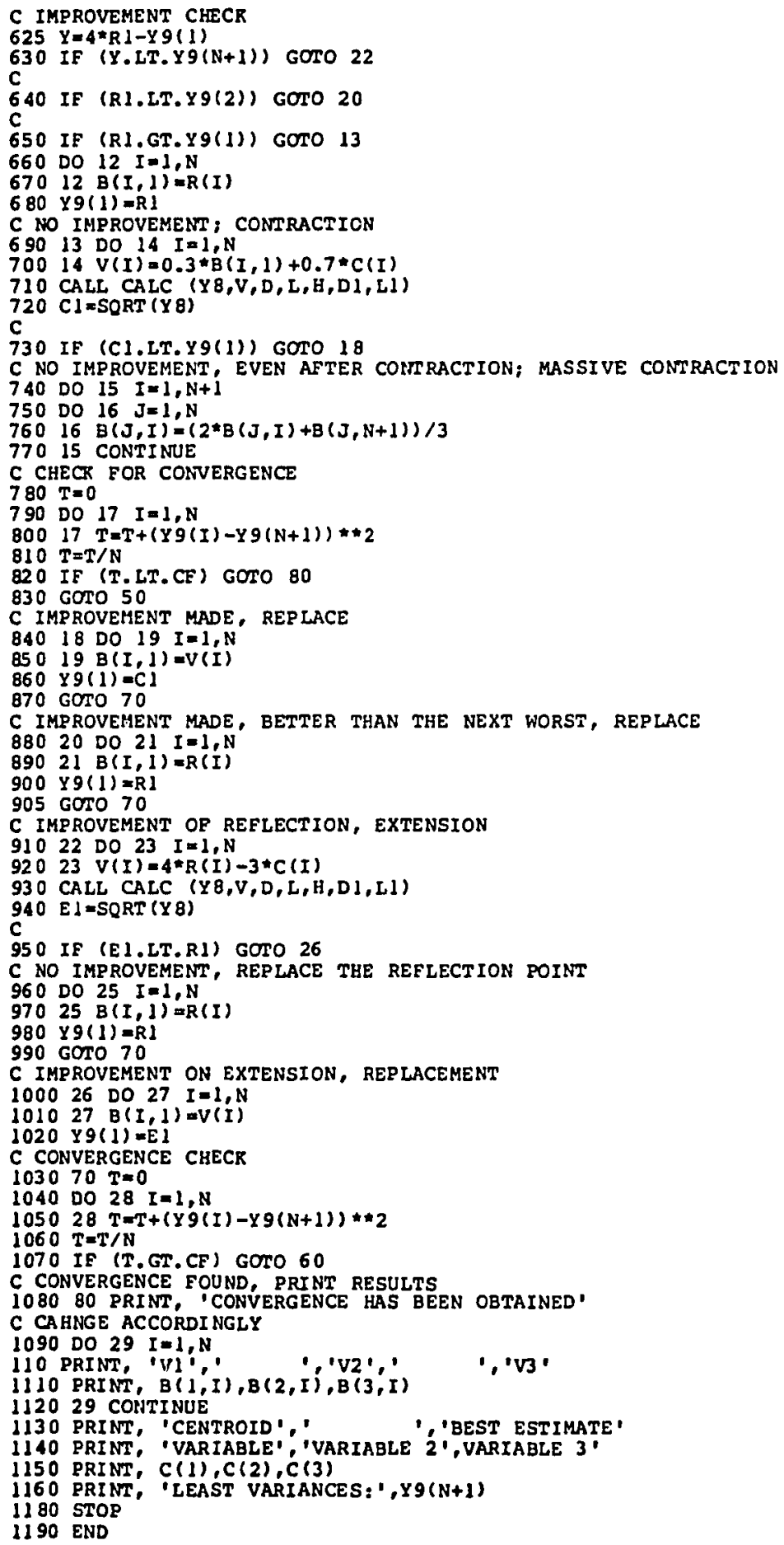


TABLE XXI CONTINUED

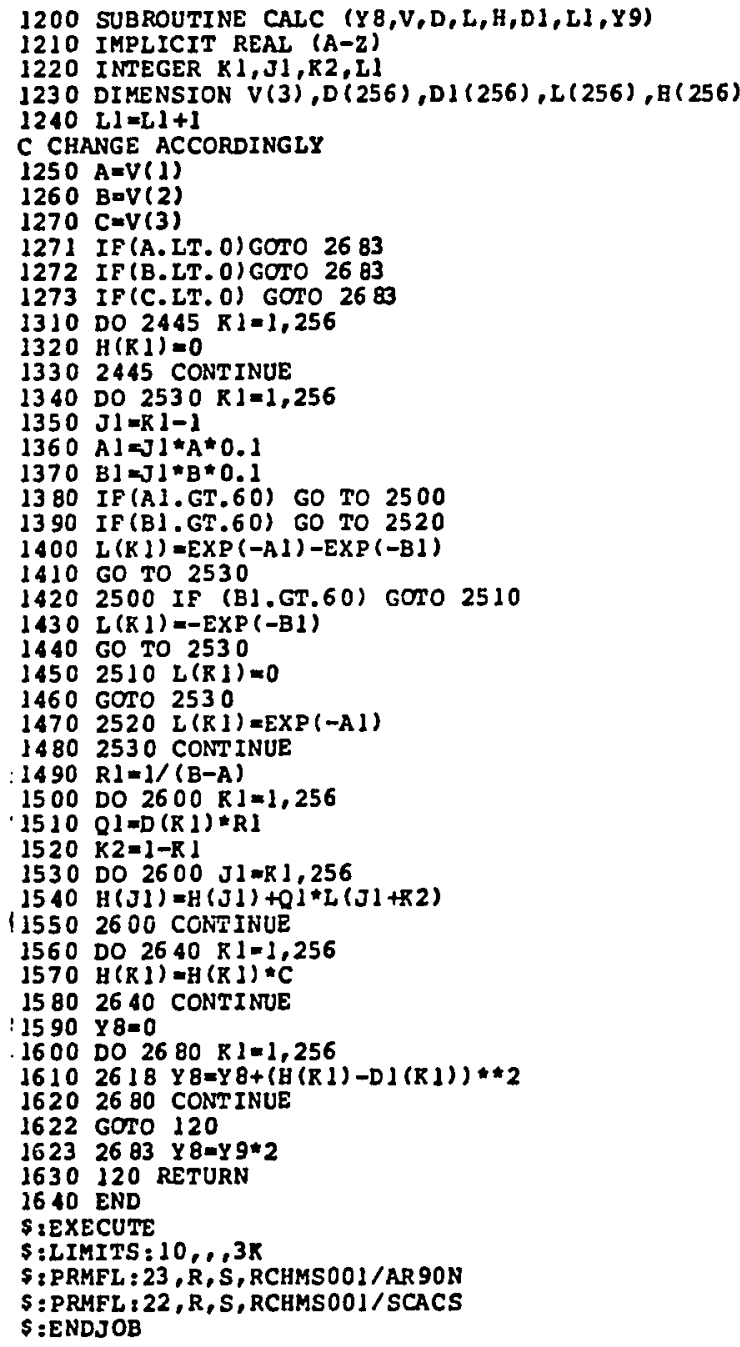




\section{APPENDIX B}

\section{AIM-65 TO LeCrOY 300IQVT MCA INTERFACE}

The interface adaptor allows the AIM-65 microcomputer to communicate with the LeCroy 3001 QVT MCA. It enables the memory contents of the MCA to be read by the AIM-65. The microcomputer can also alter the memory of the MCA. It also provides controls such as start, stop and clear.

Figure 42 gives the schematics of the interface adaptor. The adaptor essentially provides a 16 bit bidirectional buffer for data transfers between the MCA and the microcomputer. It also has a 10 bit address counter and various one-shots to provide different addresses of the MCA memory and controls.

The adaptor communicates with the microcomputer through two VIA's(6522). The 16 bit data are transmitted through the $16 \mathrm{I} / 0$ pins (PAO to $\mathrm{PA} 7$ and $\mathrm{PBO}$ to PB7). Table XXII summarizes the logic sequences to execute the desired commands. This logic is implemented by the assembly codes shown in Table XXIII. The commands are structured so that each command becomes a BASIC multi-statement. Table XXIV lists the BASIC statements that execute the desired operations. Finally, Table XXV shows the locations of the microcomputer memory containing the contents of the MCA. 


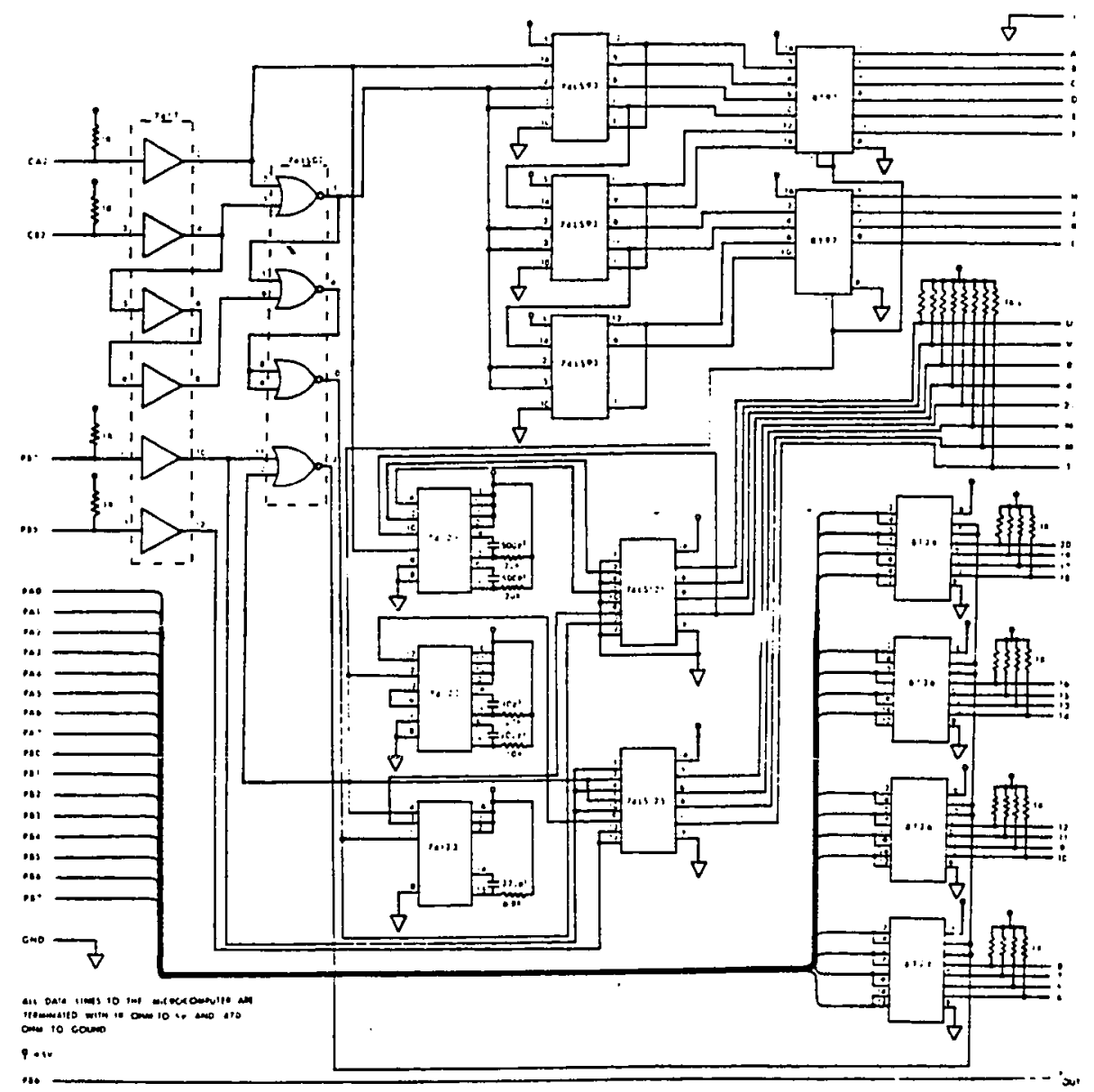

Figure 42 Schematics of the MCA to AIM-65 interface adaptor. Labels on the left side of the figure refer to the VIA on the AIM-65. Labels on the right refer to the rear connector of the MCA. 
TABLE XXII

LOGIC SEQUENCES FOR EXECUTING COMMANDS TO

CONTROL THE MCA THROUGH THE INTERFACE

ADAPTOR BY THE AIM-65

To Clear the MVA - Clear 1: write zeros.

Clear 2: bring PB5 low for $100 \mathrm{~ms}$.

To clear address counter - Bring CA2 and CB2 low.

To advance address - Bring CB2 high and toggle CA2 (4 low's for quadrant mode).

To read - Set $\mathrm{PB} 7 \mathrm{high}$ and toggle $\mathrm{CB} 2$ once to read one channel. Read I/O ports when CB2 is low.

To write - Set PB7 low and toggle CB2 one to write one channel. Always return $P B 7$ high after writing. Set up output data before bringing CB2 low.

To count pulse - Set T2 to count pulse from PB6 (BUSY from the MCA).

To stop MCA - Advance one address when CA2 is low.

To start MCA - Set PB7 high and bring CB2 low once. 
TABLE XXIII

ASSEMBLY CODES FOR CONTROLLING THE MCA

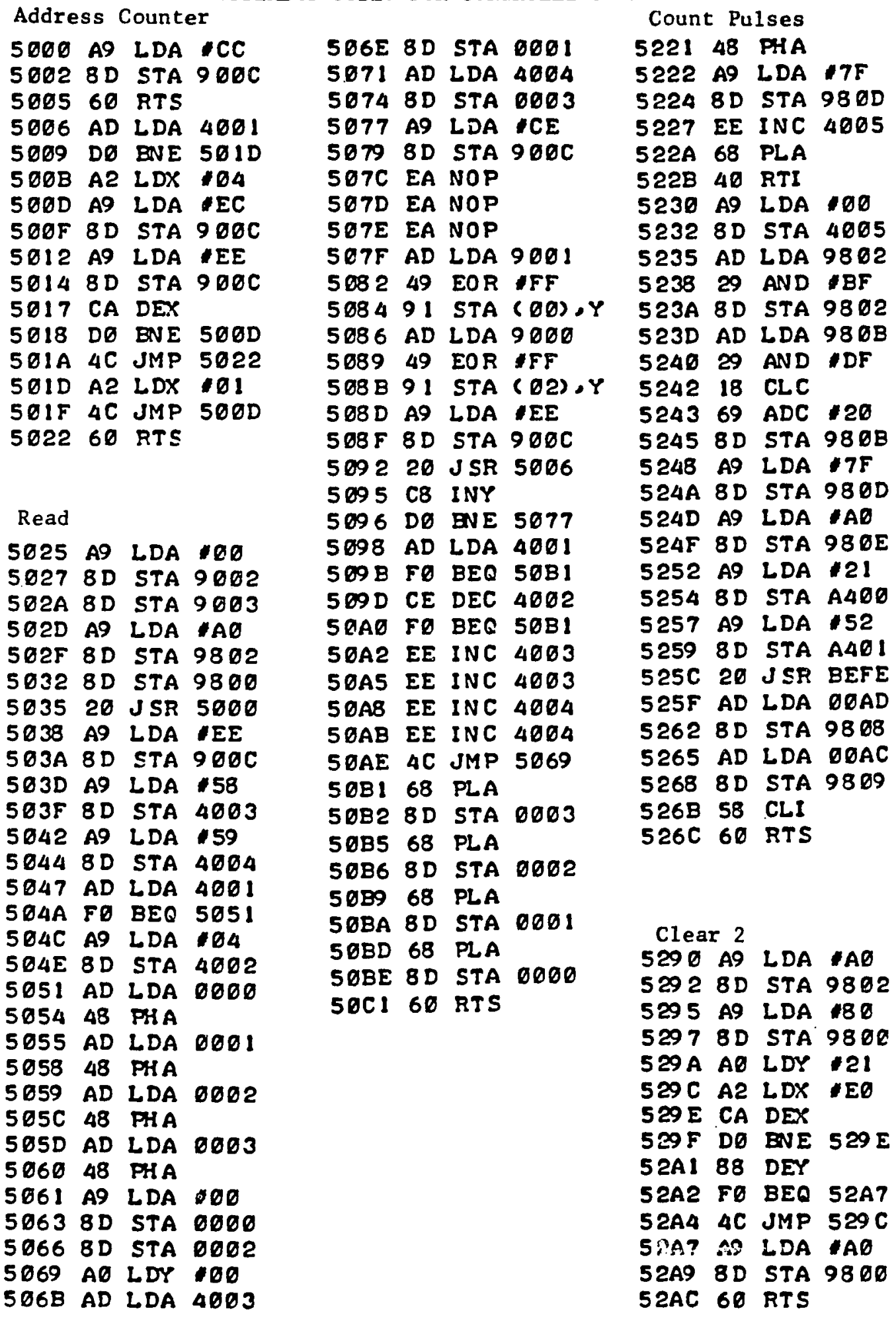


TABLE XXIII CONTINUED

\begin{tabular}{|c|c|c|c|}
\hline \multicolumn{4}{|c|}{ Write } \\
\hline $50 C D$ & 20 & J SR & 50D0 \\
\hline 5000 & A9 & LDA & $F F$ \\
\hline $50 D 2$ & 80 & STA & 9002 \\
\hline 5 OD5 & 80 & STA & 9003 \\
\hline $50 D 8$ & 8D & STA & 9000 \\
\hline $50 \mathrm{DB}$ & $8 D$ & STA & 9001 \\
\hline 50DE & A9 & LDA & $A Q$ \\
\hline $50 E Q$ & $8 D$ & STA & 9800 \\
\hline $50 E 3$ & $8 D$ & STA & 9802 \\
\hline $50 E 6$ & 20 & $\mathbf{J} \leq \mathbb{R}$ & 5000 \\
\hline $50 E 9$ & A9 & LDA & EE \\
\hline 50EB & 8D & STA & $900 \mathrm{C}$ \\
\hline 50EE & A9 & LDA & 58 \\
\hline $50 F$ & $8 D$ & STA & 4803 \\
\hline $50 \mathrm{~F} 3$ & A9 & LDA & 59 \\
\hline $50 F 5$ & 8D & STA & 4604 \\
\hline 5078 & $A D$ & LDA & $\triangle 8 E I$ \\
\hline $50 F B$ & $F 0$ & $B E Q$ & 5102 \\
\hline 50FD & A9 & LDA & 104 \\
\hline $50 F F$ & 8D & STA & 4002 \\
\hline 5102 & $A D$ & LDA & 0000 \\
\hline 5105 & 48 & PHA & \\
\hline 5106 & AD & LDA & 2001 \\
\hline 5169 & 48 & PHA & \\
\hline $510 \mathrm{~A}$ & $A D$ & LDA & 0002 \\
\hline 5100 & 48 & PH A & \\
\hline $510 E$ & $A D$ & LDA & 0003 \\
\hline 5111 & 48 & PHA & \\
\hline 5112 & A9 & LDA & 180 \\
\hline 5114 & 8D & STA & 0000 \\
\hline 5117 & 8D & STA & 0002 \\
\hline $5: 1 A$ & $A \theta$ & LDY & 100 \\
\hline $511 \mathrm{C}$ & $A D$ & LDA & 4003 \\
\hline $511 F$ & 8D & STA & 0021 \\
\hline 5122 & $A D$ & LDA & 4004 \\
\hline 5125 & $8 D$ & STA & 0003 \\
\hline 5128 & BI & LDA & $(\theta \theta), Y$ \\
\hline $512 A$ & 49 & EOR & IFF \\
\hline $512 \mathrm{C}$ & 80 & STA & 9001 \\
\hline $512 F$ & B! & LDA & $(02), Y$ \\
\hline 5131 & 49 & EO R & $F F$ \\
\hline 5133 & 8D & STA & 9000 \\
\hline 5136 & A9 & LDA & 20 \\
\hline 5138 & 8D & STA & 9800 \\
\hline $513 B$ & A9 & LDA & ICE \\
\hline 5130 & $8 D$ & STA & $900 \mathrm{C}$ \\
\hline
\end{tabular}

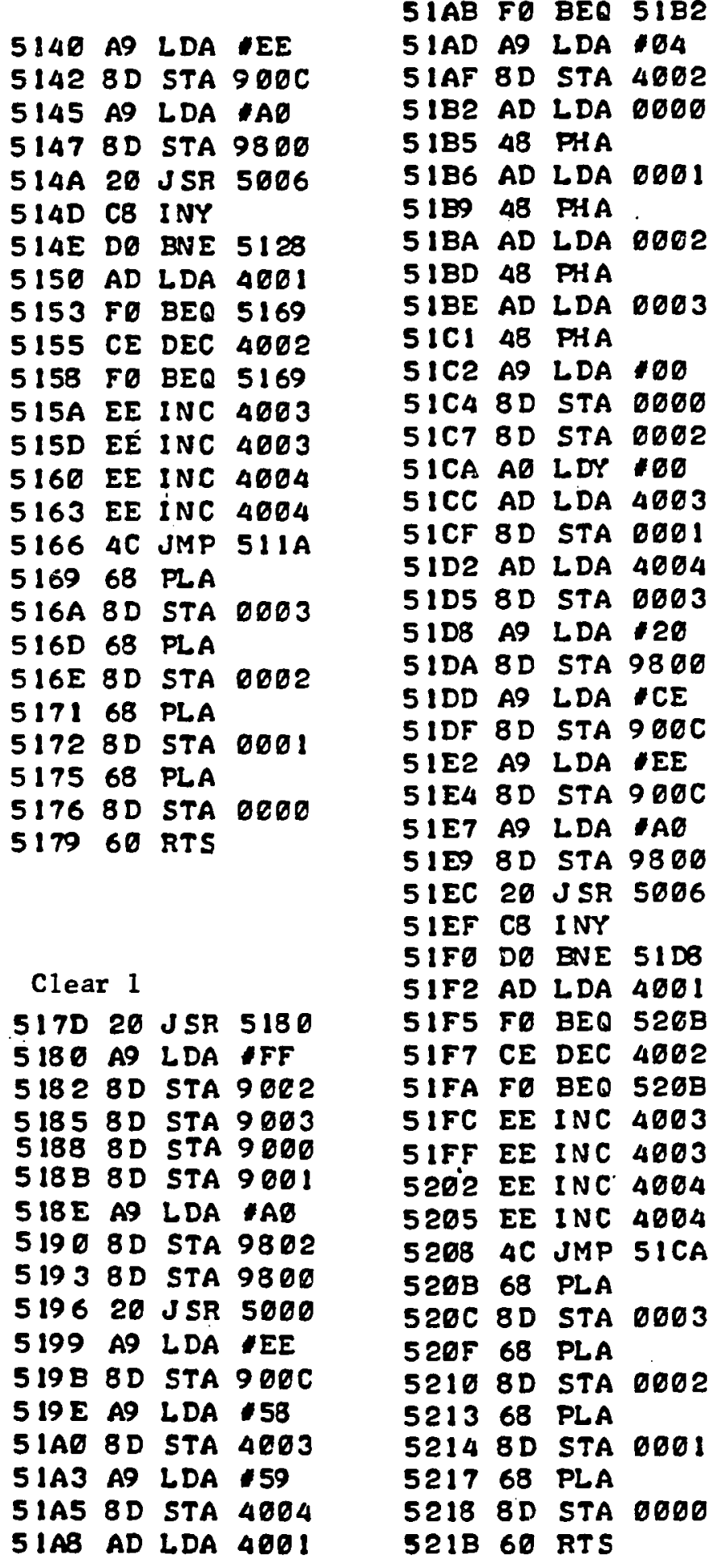

$51 A B$ FO BEO $51 B 2$

5 IAF BD STA 4002

$51 B 2$ AD LDA $O D O D$

5 IB5 48 PHA

5186 AD LDA DOOI

$51 B 9 \quad 48$ PHA

5 IBA AD LDA 0002

5 IBE AD LDA BOO3

$51 C 148$ PHA

$51 C 2$ A9 LDA 100

51C4 8D STA DOED

$51 C 7$ BD STA 0002

$51 C C$ AD LDA 4003

5 ICF $8 D$ STA DOOI

5105 8D STA BOO3

$51 D B$ A9 LDA 20

5 IDA 8 D STA 9800

5 IDD A9 LDA CE

$51 E 2$ A9 LDA EEE

$51 E 4$ 8D STA $900 \mathrm{C}$

51E9 8D STA 9800

$5 I E C 20$ JSR 5006

5 IEF CB INY

$51 F 2$ AD LDA 4001

$51 F 5$ FO BEQ 526B

$51 F 7$ CE DEC 4002

5IFA FO BEQ 520B

5 IFC EE INC 4003

5 IFF EE INC 4003

5202 EE INC 4004

5205 EE INC $\triangle 004$

529868 PLA

520C 8D STA 0003

$520 F 68$ PLA

5210 8D STA OOO2

521368 PLA

5214 8D STA DOOI

5218 8D STA OODO

S21B 60 RTS 
TABLE XXIII CONTINUED

$\begin{array}{lllll}5270 & A 9 & \text { LDA } & \text { IEC } & \text { Stop } \\ 5272 & 8 D & \text { STA } 900 C & \\ 5275 & 4 C & \text { JMP } & 527 D & \\ 5278 & \text { A9 } & \text { LDA } & \text { CE } & \text { Start } \\ 527 A & 8 D & \text { STA } 900 C & \\ 527 D & \text { A9 } & \text { LDA } & \text { EE } & \\ 527 F & 8 D & \text { STA } 900 C & \\ 5282 & 60 & \text { RTS } & & \end{array}$


TABLE XXIV

COMMANDS FOR CONTROLLING THE MCA

IN BASIC STATEMENTS

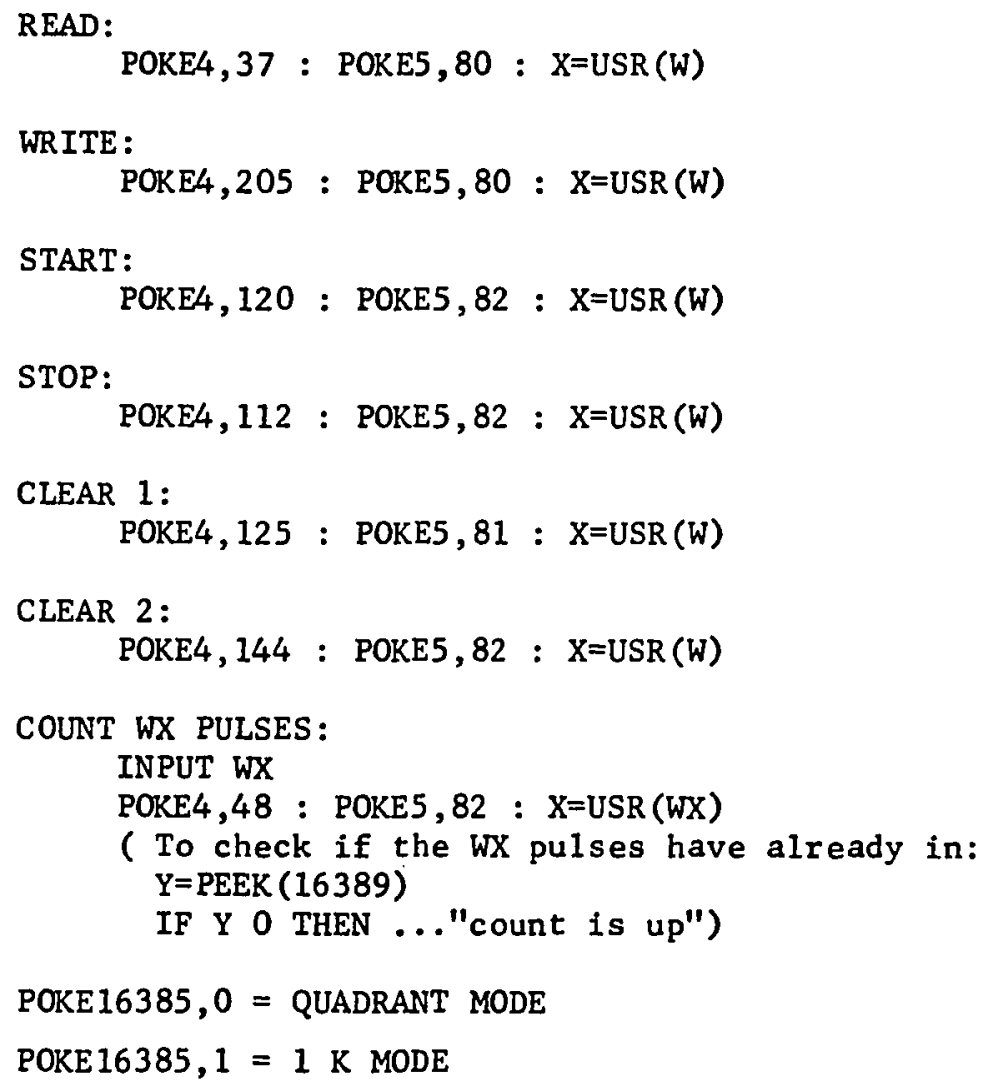


TABLE XXV

MEMORY MAP OF THE COPIED MCA CONTENTS

QUADRANT MODE

MCA

Channel 1

Channel 2

-

Channel 256

I K MODE

MCA

Channel 1

Channel 2

-

Channe1 256

Channe1 257

-

Channel 512

Channel 513

Channel 1024
Addresses in AIM-65

22784 (H. 8 bits);22528(L. 8 bits) 22785 (H. 8 bits);22529(L. 8 bits)

23039 (H. 8 bits) $; 27783$ (L. 8 bits)

Addresses in AIM-65

22784 (H. 8 bits);22528(L. 8 bits) 22785 (H.8 bits);22529(L.8 bits)

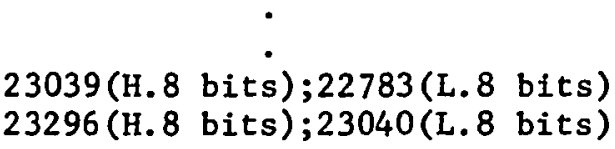

23296 (H. 8 bits);23040(L. 8 bits)

23551 (H. 8 bits);23295(L. 8 bits) 23808 (H. 8 bits);23552(L.8 bits)

24875 (H. 8 bits);24139(L. 8 bits) 


\section{APPENDIX C}

\section{LASER POWER MONITOR}

The laser power monitor provides a means of monitoring the energy of each individual laser pulse. It is composed of two main parts: a vacuum photodiode and a peak detector. Figure 43 illustrates the organization of the monitor. Figure 44 is a schematic of the peak detector.

A portion of the UV laser pulse illuminates the vacuum potodiode and produces a electrical pulse. The peak detector captures the peak voltage from the vacuum photodiode and the analog to digital converter (A/D) digitizes the captured peak voltage. The digitized voltage can be acquired by the AIM-65 microcomputer. The same analog peak voltage form the peak detector is sent to a LED bar graph (NSM 3914) for visual display. The LED display provides visual feedback for tunning the laser for optimum energy output.

The peak detector automatically updates its digital output whenever a new laser pulse is detected. Its EOC ouput goes high to indicate that a new convertion has been completed. Its input TRI-STATE has to be held high before the valid data are presented at the data pins. Clock rate of the A/D is one MHz. Convertion time is about 100 


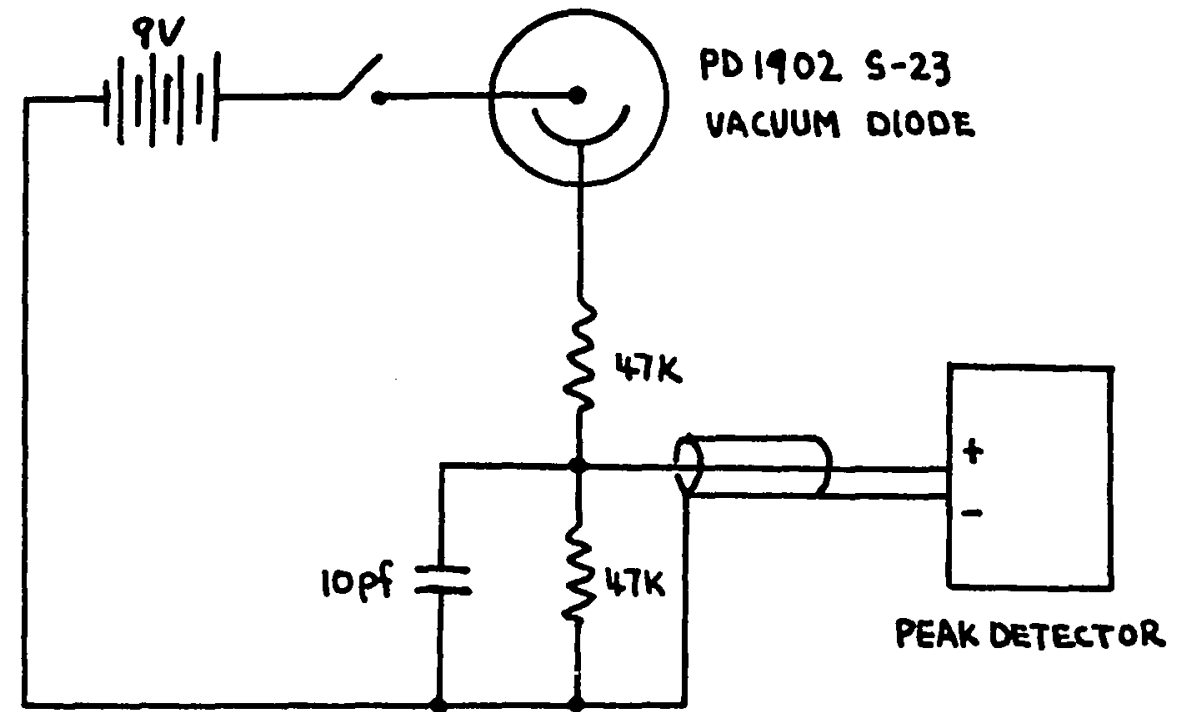

Figure 43 Laser power monitor. Details of the peak detector is shown in Figure 37. 


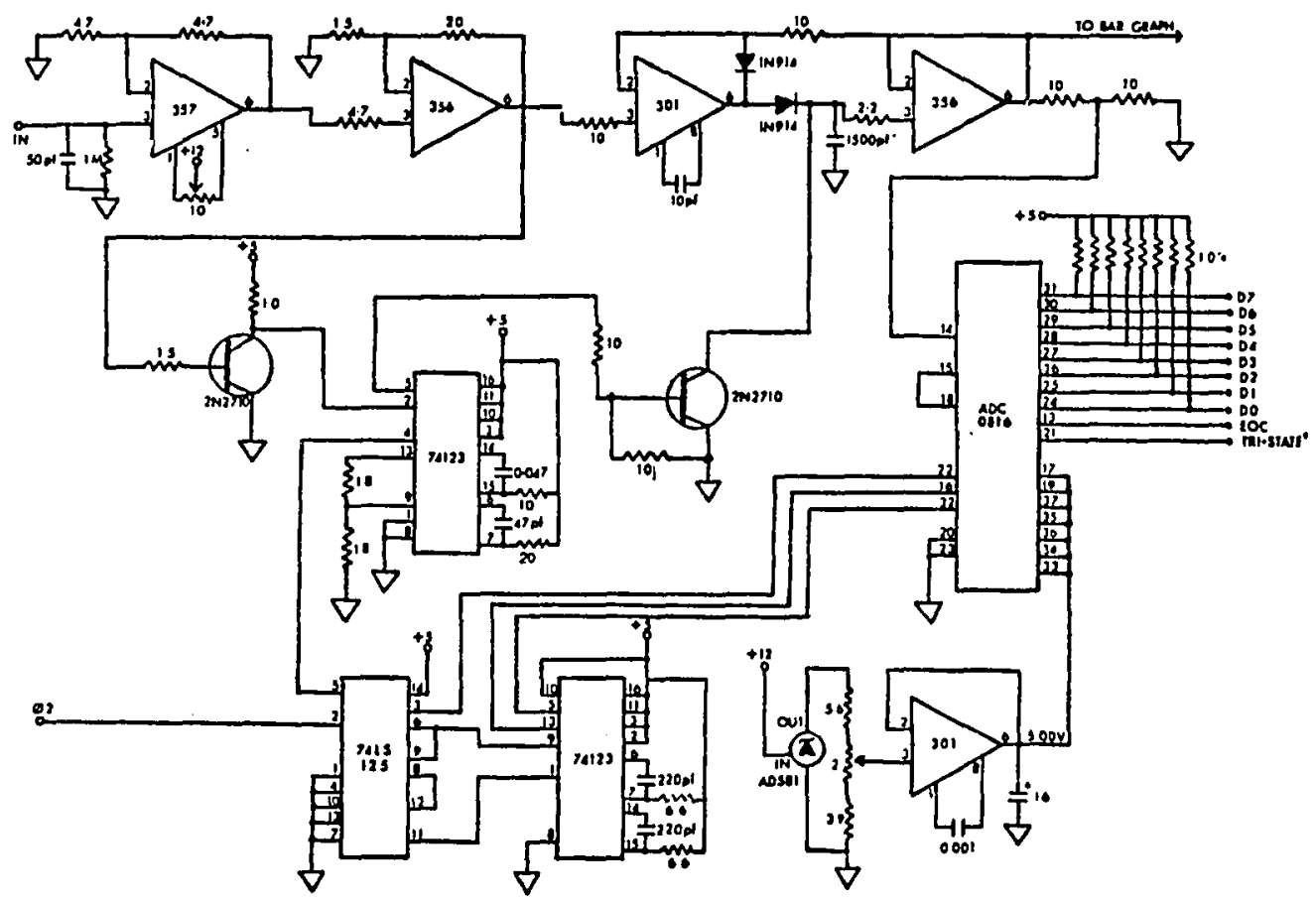

F1gure 44 Schematica of the peak detector. 12 refers to the master clock of the AIM-65. All resistors are in K-ohm except as Indicated. All capacftors are in microfarad except as Indicated (*-Bilver mICa). $V_{C C}$ and $V_{E E}$ of all operational amplifiers are connected to $+12 \mathrm{~V}$ and $-12 \mathrm{~V}$. 
microseconds. The AIM-65 communicates with the peak detector through the EOC which is connected to the CAI and the TRI-STATE which is connected to the CA2. The 8 bit A/D output takes up a portion of the unused I/O pins of the two VIA's on the DRAM expansion board. The peak detector can be used concurrently with the MCA interface adaptor.

The program listed in Table XXVI allows the integrated photomultiplier current (Q-mode) obtained by the MCA to be normalized against the laser power. The program duplicates the contents of the MCA onto the (HEX) 5800 and (HEX) 5900 blocks of memory. 5800 (L.B.) and 5900 (H.B.) correspond to the first channel of the MCA. When a laser pulse is detected, the BUSY output from the MCA decrements a count of the T2 of the VIA through the PB6 pin and at the same time interrupts the microcomputer through the CBI pin. The interrupt service program compares the duplicate and the new contents of the MCA channel by channel until a mismatch is located. A count is then added to the mismatched channel to update the duplicate. The mismatched channel number is then stored together with the laser power from the peak detector. The channel numbers and the peak detector outputs are stored in memory locations from (HEX) 6400 upward. For example, location 6400 contains the peak detector output and 6401 contains the corresponding channel number. The purpose of this program is that when the MCA is used in Q-mode, the 
TABLE XXVI

ASSEMBLY CODES FOR THE LASER POWER MONITOR AND THE MCA

\begin{tabular}{|c|c|c|c|c|c|c|c|}
\hline $\begin{array}{l}2 F 5 \\
3 e !\end{array}$ & $\begin{array}{l}A 2 \\
B D\end{array}$ & $\begin{array}{l}\text { LDX } \\
\text { LDA }\end{array}$ & $\begin{array}{l}10 \\
0000, x\end{array}$ & $\begin{array}{l}5378 \\
5373\end{array}$ & $\begin{array}{l}8 D \\
A D\end{array}$ & $\begin{array}{l}\text { STA } \\
\text { LDA }\end{array}$ & $\begin{array}{l}9803 \\
O O A C\end{array}$ \\
\hline 394 & 48 & FHA & & 5376 & BD & STA & 9809 \\
\hline $\begin{array}{l}305 \\
207\end{array}$ & $\begin{array}{l}A 3 \\
7 D\end{array}$ & $\begin{array}{l}\text { LDA } \\
\text { STA }\end{array}$ & $\begin{array}{l}\text { eq } \\
\rho \in Q Q, Y\end{array}$ & $\begin{array}{l}5379 \\
5378\end{array}$ & $\begin{array}{l}A 9 \\
8 D\end{array}$ & $\begin{array}{l}\text { LDA } \\
\text { STA }\end{array}$ & $\begin{array}{l}800 \\
9300\end{array}$ \\
\hline $30 \mathrm{~A}$ & EB & Ins $x$ & & $537 E$ & $A \theta$ & LDY & 120 \\
\hline $3 E \mathrm{E}$ & $E Q$ & CPX & $\because 1 A$ & $33 ?$ & A2 & LDX & $\| E 0$ \\
\hline $3 \mathrm{CD}$ & $D C$ & BNE & 5301 & 382 & CA & DEX & \\
\hline $30 \mathrm{~F}$ & AP & LDA & 100 & 383 & $D \theta$ & BNE & 5382 \\
\hline 311 & SD & STA & 9002 & 5385 & 83 & DEY & \\
\hline 314 & $8 D$ & STA & 9 Re 3 & 5386 & $\mathrm{Fe}$ & BEC & $538 \mathrm{~B}$ \\
\hline 317 & $8 D$ & STA & 9803 & 5338 & $4 C$ & JMP & 5332 \\
\hline $\begin{array}{l}31 \mathrm{~A} \\
310\end{array}$ & 8D & STA & 4006 & $\begin{array}{l}5398 \\
5330\end{array}$ & $\begin{array}{l}A 9 \\
B D\end{array}$ & $\begin{array}{l}\text { LDA } \\
\text { STA }\end{array}$ & $A O$ \\
\hline$? 15$ & $B D$ & STA & 9802 & 539 & A? & LDA & DCE \\
\hline $3 \varepsilon 2$ & $8 \mathrm{D}$ & STA & 9800 & 5392 & 8D & STA & $9 R O C$ \\
\hline 325 & A9 & $\angle D A$ & VEE & 5395 & A9 & LDA & "EE \\
\hline 327 & $8 D$ & STA & $900 \mathrm{C}$ & 5397 & $8 D$ & STA & $900 \mathrm{C}$ \\
\hline $\begin{array}{l}32 A \\
32 C\end{array}$ & $\begin{array}{l}A 9 \\
B D\end{array}$ & $\begin{array}{l}\text { LDA } \\
\text { STA }\end{array}$ & $\begin{array}{l}\text { I58 } \\
\text { EE 11 }\end{array}$ & $\begin{array}{l}539 \mathrm{~A} \\
539 \mathrm{C}\end{array}$ & $\begin{array}{l}A 9 \\
8 D\end{array}$ & $\begin{array}{l}\text { LDA } \\
\text { STA }\end{array}$ & $\begin{array}{l}\# O C \\
33 Q C\end{array}$ \\
\hline 325 & $A 9$ & LDA & 153 & $533 \mathrm{~F}$ & $A B$ & LDY & nea \\
\hline 331 & $8 D$ & STA & 2.13 & $53 \mathrm{Al}$ & 98 & $T Y A$ & \\
\hline 334 & $A 9$ & LDA & 162 & $53 A 2$ & 91 & STA & $(10), Y$ \\
\hline 336 & $3 D$ & STA & 2815 & $53 A 4$ & 91 & STA & $(12), Y$ \\
\hline 339 & A? & LDA & 163 & $53 A 6$ & C8 & I.JY & \\
\hline 338 & 8D & STA & 2017 & $53 A 7$ & $D Q$ & BNE & $53 A 2$ \\
\hline $33 E$ & A9 & LDA & 164 & $53 A 3$ & 58 & CLI & \\
\hline 348 & $8 D$ & STA & eQ19 & $53 \mathrm{AA}$ & $A D$ & LDA & 4000 \\
\hline 343 & $A 3$ & $\angle D A$ & 78 & $53 A D$ & $F$ & BEQ & 53AA \\
\hline $\begin{array}{l}345 \\
348\end{array}$ & $\begin{array}{l}8 D \\
8 D\end{array}$ & $\begin{array}{l}\text { STA } \\
\text { STA }\end{array}$ & $\begin{array}{l}980 E \\
980 D\end{array}$ & 53AF & A9 & LDA & $17 F$ \\
\hline 348 & $A 9$ & LDA & $\begin{array}{l}9811 \mathrm{D} \\
\angle \mathrm{BE}\end{array}$ & 381 & & STA & $986 E$ \\
\hline $34 D$ & $8 D$ & STA & $98 \mathrm{EE}$ & $53 E 4$ & $A D$ & LDA & 0019 \\
\hline 350 & $A 3$ & LDA & 100 & 5387 & $A C$ & LDY & 4026 \\
\hline 352 & $8 D$ & STA & $\triangle Q B Q$ & $\begin{array}{l}53 B A \\
53 B D\end{array}$ & $\begin{array}{l}20 \\
A ?\end{array}$ & $\begin{array}{l}\text { J SR } \\
\text { LDX }\end{array}$ & $\begin{array}{l}C O D I \\
119\end{array}$ \\
\hline 355 & $A D$ & LDA & $980 \mathrm{~B}$ & $538 F$ & 68 & PLA & \\
\hline 350 & 29 & AND & $D F$ & $53 \mathrm{CQ}$ & $9 D$ & STA & $000, x$ \\
\hline $35 B$ & 69 & $\begin{array}{l}C L C \\
A D C\end{array}$ & 129 & $53 \mathrm{C} 3$ & $C A$ & DEX & \\
\hline & $8 D$ & STA & $780 \mathrm{~B}$ & $53 C_{4}$ & EQ & CFX & 10 \\
\hline & AP & LDA & $\angle D O$ & $53 C_{6}$ & DE & ENE & $53 B F$ \\
\hline & $8 D$ & STA & ALER & $53 \mathrm{CB}$ & 68 & PLA & \\
\hline 365 & A9 & LDA & 153 & $53 \mathrm{Cg}$ & 8D & STA & 0210 \\
\hline 367 & BD & STA & A48 1 & $53 \mathrm{CC}$ & & PTS & \\
\hline & 20 & 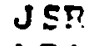 & BEFE & & & & \\
\hline & & & & & & & \\
\hline
\end{tabular}


TABLE XXVI CONTINUED

\begin{tabular}{|c|c|c|c|}
\hline 53D? & 43 & PHA & \\
\hline 5301 & SA & $T X A$ & \\
\hline 5322 & 48 & PHA & \\
\hline 5303 & 98 & TYA & \\
\hline 5304 & 49 & MIA & \\
\hline 53D5 & A9 & $L D A$ & EC \\
\hline 5307 & 30 & STA & $3 \& 8 \mathrm{C}$ \\
\hline $53 \Omega A$ & $A D$ & $L D A$ & $33 \cong D$ \\
\hline 53DD & 27 & AND & $12 e$ \\
\hline $53 D F$ & Fe & EEG & 53EC \\
\hline $53 E 1$ & $A 9$ & $\angle D A$ & $\because 20$ \\
\hline $53 E ?$ & $B \Gamma$ & STA & 9800 \\
\hline $52 E 6$ & $E \Sigma$ & I:JC & $\angle C Q E$ \\
\hline 53 도 & $4 C$ & JMF & $54 \mathrm{Al}$ \\
\hline $53 E C$ & $n 3$ & LDA & $\mathrm{CC}$ \\
\hline 53EE & $B D$ & STA & secc \\
\hline 5351 & $A C$ & LDY & 114 \\
\hline $53 F 3$ & $A 3$ & LDA & $E E$ \\
\hline $53 F 5$ & 30 & STA & $9 R 0 C$ \\
\hline 5353 & $A 2$ & LDX & $\because 50$ \\
\hline 5?FA & A3 & $\angle D A$ & \#CC \\
\hline $535 C$ & $8 D$ & STA & $9 \in \mathbb{C}$ \\
\hline & $\begin{array}{l}A 9 \\
3 D\end{array}$ & $\begin{array}{l}\text { LDA } \\
\subseteq T A\end{array}$ & $\begin{array}{l}\text { HEE } \\
\text { 9日QC }\end{array}$ \\
\hline $\begin{array}{l}5484 \\
5465\end{array}$ & $\begin{array}{l}C A \\
D Q\end{array}$ & $\begin{array}{l}\text { DEX } \\
\text { BNE }\end{array}$ & $53 F A$ \\
\hline $\begin{array}{l}5407 \\
5403\end{array}$ & $\begin{array}{l}A 9 \\
3 D\end{array}$ & $\begin{array}{l}L D A \\
\text { STA }\end{array}$ & $\begin{array}{l}1 \mathrm{CE} \\
980 \mathrm{C}\end{array}$ \\
\hline $540 \mathrm{C}$ & $A D$ & $\angle D A$ & $9 \mathbb{C e}$ \\
\hline $54 Q F$ & 42 & EOR & $\angle F$ \\
\hline 5411 & D 1 & $\mathrm{Cl} 1 \mathrm{P}$ & $(12) \cdot Y$ \\
\hline 5413 & $D a$ & BNE & 5460 \\
\hline 5415 & $A D$ & $L D A$ & 9001 \\
\hline 5418 & 49 & EO? & $A F$ \\
\hline $541 \mathrm{~A}$ & DI & CMP & $(1 E), Y$ \\
\hline $541 \mathrm{C}$ & $D Q$ & $B M E$ & 5460 \\
\hline & $A 7$ & $L D A$ & $E E$ \\
\hline
\end{tabular}

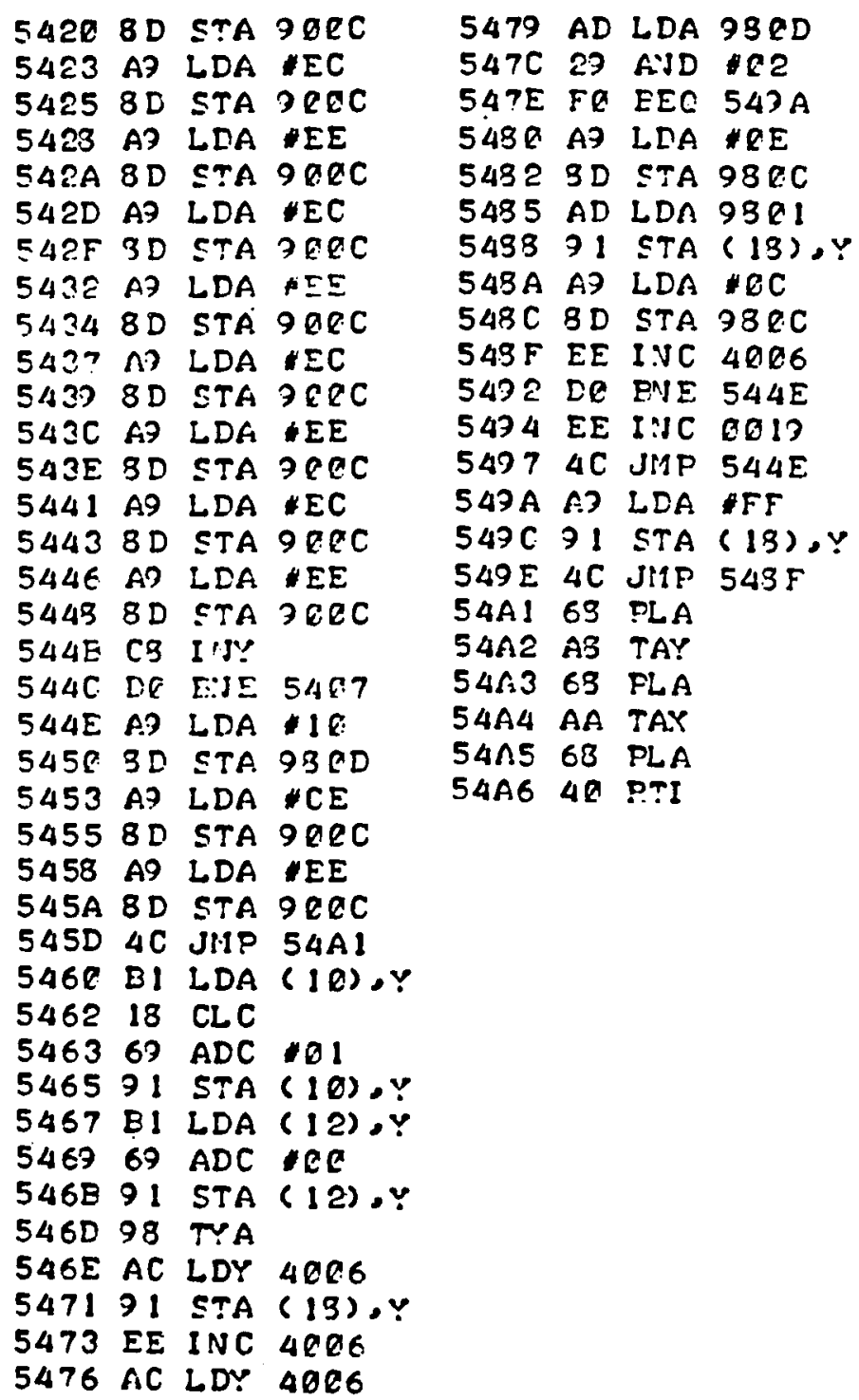


channel number is proportional to the integrated photomultiplier current. Thus the program keeps a record of the integrated current and its corresponding laser power. This record can be used to normalize the detected fluorescence intensity.

The program only works when the MCA is in quadrant mode. Whenever a laser pulse is fired, but its power is not high enough to trigger the peak detector, (HEX)FF will be stored as the laser power next to the channel number. In most cases, the channel corresponding to zero photomultiplier current is not the first channel of the MCA. This zero channel have to be set at the program location (53F3). For the listed program, content of memory location $53 F 3$ is (HEX) 14 which indicates that channel 20 is the zero channel. The memory location at $53 \mathrm{~F} 9$ has also be changed to 4 times that of $53 F 3$ i.e. (HEX) 50 in this case.

The program operates on base of a predetermined number of laser pulses. The program can be called up by the BASIC multi-statement:

POKE $4,255:$ POKE5 , $82: X=U S R(W)$

The variable $W$ is the number of laser pulses to be recorded. Variable $\mathrm{x}$ is the address (in decimal) of the top of the recorded channel-laser power pairs. Once the machine program is invoked, program execution will continue in the machine program until the count is up. Any 
disruptions of the mechine program will cause the zero page registers of the BASIC interpreter to be destroyed. The consequence is disastrous! 